Andrews University

Digital Commons @ Andrews University

2016

\title{
Teachers' Cultural Competence and Students' Perception of the Social Classroom Climate in Culturally Different Middle School Classrooms
}

Olivia L. R. Spence

Andrews University, spenceo@andrews.edu

Follow this and additional works at: https://digitalcommons.andrews.edu/dissertations

Part of the Bilingual, Multilingual, and Multicultural Education Commons

\section{Recommended Citation}

Spence, Olivia L. R., "Teachers' Cultural Competence and Students' Perception of the Social Classroom Climate in Culturally Different Middle School Classrooms" (2016). Dissertations. 1604.

https://digitalcommons.andrews.edu/dissertations/1604

https://dx.doi.org/10.32597/dissertations/1604

This Dissertation is brought to you for free and open access by the Graduate Research at Digital Commons @ Andrews University. It has been accepted for inclusion in Dissertations by an authorized administrator of Digital Commons@ Andrews University. For more information, please contact repository@andrews.edu. 


\begin{abstract}
TEACHERS' CULTURAL COMPETENCE AND STUDENTS' PERCEPTION OF THE SOCIAL CLASSROOM CLIMATE IN CULTURALLY DIFFERENT MIDDLE SCHOOL CLASSROOMS
\end{abstract}

by

Olivia L. R. Spence

Chair: Elvin Gabriel 


\title{
ABSTRACT OF GRADUATE STUDENT RESEARCH
}

\author{
Dissertation
}

Andrews University

School of Education

Title: TEACHERS' CULTURAL COMPETENCE AND STUDENTS' PERCEPTION OF THE SOCIAL CLASSROOM CLIMATE IN CULTURALLY DIFFERENT MIDDLE SCHOOL CLASSROOMS

Name of researcher: Olivia L. R. Spence

Name and degree of faculty chair: Elvin Gabriel, Ed.D.

Date completed: April 2016

\section{Problem}

Teachers and students often come from different cultural backgrounds, so classrooms are increasingly becoming the venue where interactions, if not appropriately managed, will produce a social climate not conducive to learning. The present study seeks to determine to what extent teacher cultural competence impacts student perception of the classroom social environment.

\section{Method}

The Teacher Multicultural Attitudes Survey was used to quantify teachers' cultural competence and a Social Classroom Climate Measure was used to gather scores on the 
four key factors of the social climate. Hierarchical Linear Modelling was used to assess the influence of teacher cultural competence and several demographic variables on student perception of the classroom social environment.

\section{Results}

Several demographic variables were shown to impact students' perception of the classroom social climate. The teacher's reported level of cultural competence, however, was not shown to be a predictor of students' perception of classroom social climate.

\section{Conclusions}

The results of this study highlight the possibility of two major issues. First, students' perceptions of the classroom social climate are affected by particular student characteristics, in this case, grade-level and ethnicity. This outcome lends support to the push to place students at the center of learning and pedagogical decisions. Second, it is difficult to differentiate between the effects of cultural competence and good teaching. Hence, it is important for teachers to rigorously engage in high-quality pedagogical strategies in an effort to produce instruction that addresses the ways in which all students learn best. This concept is at the heart of cultural competency, which requires teachers to have the knowledge and skills to successfully teach all students. 


\author{
Andrews University \\ School Of Education
}

\title{
TEACHERS' CULTURAL COMPETENCE AND STUDENTS' PERCEPTION OF THE SOCIAL CLASSROOM CLIMATE IN CULTURALLY DIFFERENT MIDDLE SCHOOL CLASSROOMS
}

\author{
A Dissertation \\ Presented in Partial Fulfillment \\ of the Requirements for the Degree \\ Doctor of Philosophy
}

by

Olivia L. R. Spence

April 2016 
(C) Copyright by Olivia L. R. Spence 2016 All Rights Reserved 


\title{
TEACHERS' CULTURAL COMPETENCE AND STUDENTS' PERCEPTION OF THE SOCIAL CLASSROOM CLIMATE IN CULTURALLY DIFFERENT MIDDLE SCHOOL CLASSROOMS
}

\author{
A dissertation \\ presented in partial fulfillment \\ of the requirements for the degree \\ Doctor of Philosophy
}

by

Olivia L. R. Spence

APPROVAL BY THE COMMITTEE:

Chair: Elvin Gabriel

Member: Tevni Grajales

Member: Larry Burton

External: Lionel Matthews
Dean, School of Education

Robson Marinho

Date approved 
To the Almighty God, He led me all the way 


\section{TABLE OF CONTENTS}

LIST OF TABLES ............................................................. vii

LIST OF ABBREVIATIONS.................................................. viii

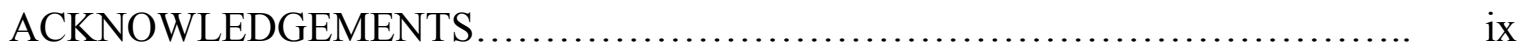

Chapter

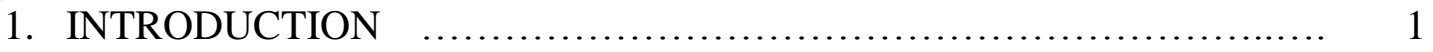

Statement of the Problem............................................... 7

Purpose of the Study ................................................ 8

Research Questions........................................... 8

Significance of the Study........................................ 10

Conceptual Framework......................................... 11

Assumptions of the Study ....................................... 14

Delimitations...................................................... 15

Definition of Terms.......................................... 15

2. LITERATURE REVIEW ................................................. 18

Purpose of Literature Review...................................... 18

Sources for Material Included in this Literature Review............... 19

Attributes of Cultural Competence.................................... 20

Cultural Competence and Multicultural Education................... 22

Cultural Competence in the Classroom........................ 24

Criticisms and Challenges in Cultural Competence................ 26

Culturally Relevant Pedagogy................................. 28

Historical/Philosophical Overview of the Social Classroom Climate................................................... 32

Components of the Social Classroom Climate........................ 35

Teacher Support........................................... 36

Mutual Respect............................................. 37

Task Related Interaction................................... 38

Effects of the Social Classroom Climate on Education ................ 39

Influence of Demographic Variables .............................. 41 
Social Classroom Climate Within the Context of Adolescent

Development-Ecological Developmental Theory

and Cultural Ecological Theory ................................. 42

Need for Further Study ...................................... 47

3. METHODOLOGY................................................. 49

Research Design............................................... 49

Population \& Sample......................................... 51

Null Hypotheses.............................................. 52

Definition of Variables ........................................ 53

Instrumentation.................................................. 55

Teacher Multicultural Attitude Survey........................... 56

Quick Discrimination Index................................ 56

Social Classroom Climate Measure............................. 57

Data Collection................................................. 58

Data Analysis ............................................... 62

Hierarchical Linear Modeling................................... 63

Advantages of HLM ...................................... 63

Treatment of Missing Data...................................... 64

Descriptive Analysis.......................................... 64

Correlation Analysis.......................................... 64

HLM Analysis............................................. 65

Recoding Predictor Variables for HLM Analyses................. 65

Models of the Study............................................ 66

Level-1 Models................................................. 67

Level-2 Models............................................... 69

Summary.............................................................. 70

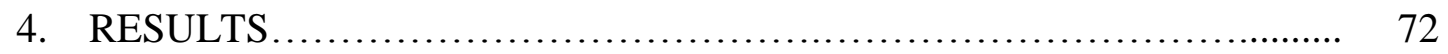

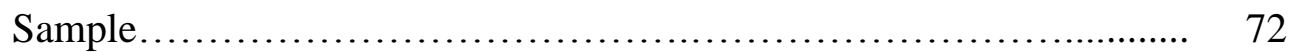

Descriptive Analysis.......................................... 72

Bivariate Analysis............................................. 75

Evaluation of HLM Assumptions............................... 77

Hypothesis Testing........................................... 78

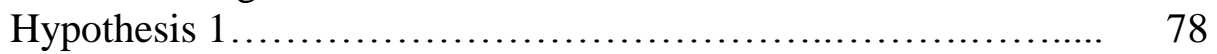

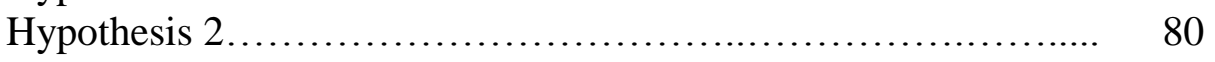

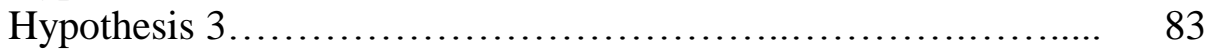

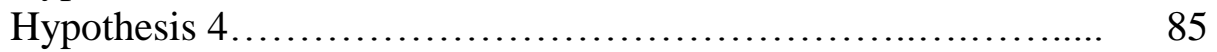

5. DISCUSSION, CONCLUSION AND RECOMMENDATIONS.......... 92

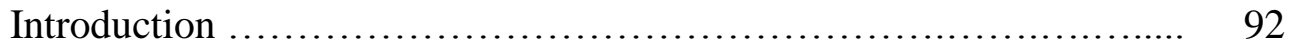

Purpose of the Study.......................................... 93

Summary of the Problem.......................................... 94 
Summary of the Literature Review............................. 94

Methodology................................................. 95

Population and Sample....................................... 96

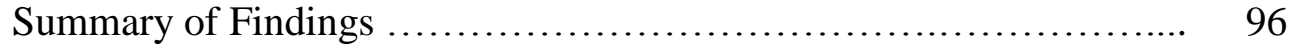

Conclusions and Discussion...................................... 100

Recommendations for Practice.................................. 105

Recommendations for Future Research........................... 106

Limitations of the Study..................................... 107

Appendix

A TABLE OF VARIABLES........................................... 110

B SURVEYS ...................................................... 120

C IRB LETTER OF APPROVAL ......................................... 131

D INSTITUTIONAL CONSENT....................................... 134

E INFORMED CONSENTS ...................................... 136

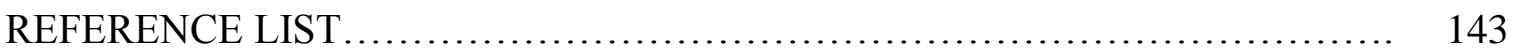

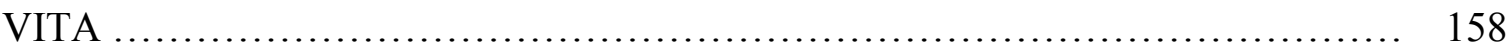




\section{LIST OF TABLES}

1. Demographic Characteristic of Participating Students ....................................73

2. Descriptive Characteristic of Outcome Variable ............................................ 74

3. Demographic Characteristic of Participating Teachers ................................... 75

4. Descriptive Characteristic of Level 2 Variables ….......................................75

5. Correlations Between Key Level 1 Variables ................................................. 76

6. Correlations Between Key Level 2 Variables .................................................. 77

7. Parameter Estimates for Unconditional Model 1a ......................................... 79

8. Results of Regression of TES Criterion on Level 1 Predictor Variables ...............80

9. Parameter Estimates for Unconditional Model 1b ........................................ 81

10. Results of Regression of TAS Criterion on Level 1 Predictor Variables ............. 82

11. Parameter Estimates for Unconditional Model 1c ........................................ 83

12. Results of Regression of MR Criterion on Level 1 Predictor Variables ............... 84

13. Parameter Estimates for Unconditional Model 1d ............................................ 86

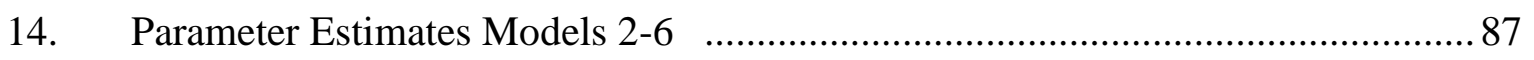

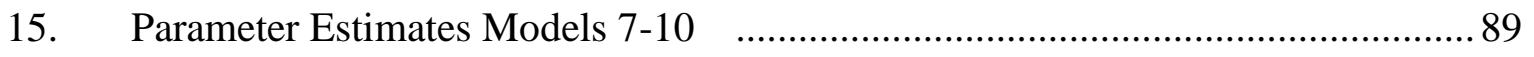




\section{LIST OF ABBREVIATIONS}

$\begin{array}{ll}\text { CRT } & \text { Culturally Relevant Teaching } \\ \text { FRL } & \text { Free or Reduced Lunch } \\ \text { HLM } & \text { Hierarchical Linear Modeling } \\ \text { NCATE } & \text { National Council for Accreditation of Teacher Education } \\ \text { MI } & \text { Michigan } \\ \text { MR } & \text { Mutual Respect } \\ \text { MLR } & \text { Multiple Linear Regression } \\ \text { RESA } & \text { Regional Education Service Agency } \\ \text { SAS } & \text { Social Attitude Survey } \\ \text { SPSS } & \text { Statistical Program for the Social Sciences } \\ \text { TAS } & \text { Teacher Academic Support } \\ \text { TES } & \text { Teacher Emotional Support } \\ \text { TMAS } & \text { Teacher Multicultural Attitude Survey } \\ \text { TRI } & \text { Task-Related Interaction } \\ \text { SCCM } & \text { Social Classroom Climate Survey } \\ \text { QDI } & \text { Quick Discrimination Index }\end{array}$




\section{ACKNOWLEDGMENTS}

Give thanks to the LORD, call upon His name; make known among the nations what He has done. - 1 Chronicles 16:8

At times, our own light goes out and is rekindled by a spark from another person. Each of us has cause to think with deep gratitude of those who have lighted the flame within us. Albert Schweitzer

As I journeyed along the road to the completion of my dissertation, many mentors, colleagues and friends traveled with me. Without the support and encouragement of these individuals, I would not have made it this far. I want to take this opportunity to thank these individuals for their invaluable contributions.

First, I must recognize the hand of Almighty God in my journey. This milestone was undoubtedly divinely ordained. Indeed, the Lord looked upon me with mercy and grace and declared "I know the plans I have for you."

My committee members also played a vital role in my dissertation experience. I stand completed because I stood on their shoulders. I would like to express my deepest gratitude to my committee chair, Dr. Elvin Gabriel, my methodologist, Dr. Tevni Grajales, and my content expert Dr. Larry Burton. It was the wealth and depth of their collective intellect, counsel, and patience that guided me on this journey. I would also like to thank Dr. Lionel Matthews, my external examiner for his advice and words of encouragement.

I would like to thank my mother, Ann Marie, my siblings, and my family members whose support, reassurance, and prayers helped me to stay the course. My love, Marlon Gregory, you have been my biggest supporter and encourager. When times were tough, 
I could always find inspiration in your words and presence. I am grateful to God that $\mathrm{He}$ brought you into my life. To my spiritual mothers Edythe and Yvonne, and my spiritual sisters Stacey, Margeaux, Petra, and Denise, your words and support have been life to me. To my church family and friends, your prayers have always worked powerfully in my life. Additionally, I would like to thank the staff and faculty of the Teaching, Learning and Curriculum Department at Andrews University. Under their wise tutelage, I came to understand, appreciate and embrace the role of an educator. In particular, I would like to thank Dr. Faith-Ann McGarrell whose guidance was so instrumental in this effort. I would also like to thank Mordekai Ongo and Anna Piskozub for their assistance, which was above and beyond the call of duty and Mr. Ryan Pesce for his consent to and advocacy of this project.

Finally, I would like to thank the Government of the Republic of Trinidad and Tobago, who financed this journey. I am deeply grateful for the opportunity to achieve my goals and expand my horizons. 


\section{CHAPTER 1}

\section{INTRODUCTION}

Recent statistics in the United States indicate a disparity between the racial compositions of the student population and teaching workforce (National Center for Education Statistics, 2013). This disparity stems from the dramatic growth of diversity in the United States population. According to projections, fewer than half of all school children will be white, non-Hispanic by 2019 (Federal Interagency Forum on Child and Family Statistics, 2013). On the other hand, the teaching workforce, which has long been predominantly white, non-Hispanic will still constitute over $80 \%$ of the overall teaching workforce (National Center for Education Information, 2012). Along with these changing demographic characteristics, the teaching and student populations are characterized by distinct linguistic and socioeconomic differences. For example, one in ten students speaks limited English and two in ten come from low-income families and neighborhoods, while the majority of teachers come from Caucasian, middle-class backgrounds (Black, 2006; Gay, 2010).

These disparities in cultural and economic demographics undoubtedly carry implications for student-teacher interactions, the creation of a positive classroom climate, and the classroom social climate. Many teachers may expect ethnically diverse students to learn and behave according to historic mainstream norms and cultural standards; these expectations, however, may discriminate against students who come from racial and 
ethnic minority backgrounds, whose behavioral patterns do not conform to the mainstream (Black, 2006; Gay, 2010; Weinstein, Curran, \& Tomlinson-Clarke, 2003). Such discrimination can occur because teachers may not recognize culturally influenced behaviors and may devalue, censure, or even punish rather than manage such behaviors (Weinstein et al., 2003). This culturally dissonant situation can engender uncomfortable social interactions within the classroom and eventually lead to decreased learning (Colombo, 2005).

Nieto (1999) recognizes a connection between the classroom's social environment and learning. She states "learning cannot be separated from the context within which it takes place because minds do not exist in a vacuum" (Nieto, 1999, p. 11). She also notes that several factors, including social identities, can influence the extent to which learners are ultimately successful or, alternatively unsuccessful in their educational progress.

Ryan and Patrick (2001) substantiate this position and argue that the social environment in a classroom is crucial to both motivation and engagement. Patrick, Kaplan and Ryan (2011) and Fraser, Aldridge, and Adolphe (2010) further identify the social dimensions of a teacher's emotional support, academic support, promotion of mutual respect, and promotion of task-related interaction as significant correlates in the creation of an environment where students are interested, motivated, and well engaged when it comes to learning. Additionally, factors such as the social classroom system, social attitudes, and the fit between learner and classroom can either hinder or enhance classroom behavior and learning. Indeed, these factors will impact and even determine 
the nature of the social classroom climate (The Center for Mental Health in Schools at UCLA, n.d.).

This concept can be advanced using the person-environment fit theory. This theory suggests, "behavior, motivation, and mental health are influenced by the fit between the characteristics individuals bring to their social environments and the characteristics of these social environments" (Eccles et al., 1993, p. 254). In essence, the theory suggests that when a mismatch between a student and his or her classroom's social environment occurs, the result can be a demotivated, disengaged learner who underperforms.

The research also indicates that while motivation and engagement are necessary for students of all ages, they are particularly important for adolescent students (Carnegie Council on Adolescent Development, 1995; Eccles et al., 1993). Wang and Holcombe (2010) identify adolescence as a period where the social dynamics of school are particularly significant. During this phase of development, relationships with nonparental adults take on an increased meaning. They further conclude that the fulfillment of social needs may be positively associated with increased levels of school participation during adolescence.

Likewise, Eccles et al. (1993) highlight the importance of having a positive educational environment during adolescence. They suggest that students are more motivated as a consequence of synchrony between the developmental trajectory of early adolescent growth and environmental change across the school years. In other words, students will experience continued positive growth when their school environment responds to changing adolescent needs. 
Several studies note that the creation of a positive social classroom climate rests primarily with the teacher. According to Smith, Neisworth, and Greer (1978), "of all the factors that have contributed to the social environment in which students are educated..., the teacher has been the most decisive" (as cited in Bennett, 2001, p.23). Moos (1979) also suggests that teachers are of greater significance than students' characteristics when forming a classroom climate. Noddings (as cited in Wentzel, 1997) posits "the academic objectives of schools cannot be met unless teachers provide students with a caring and supportive classroom environment”( p. 411). Irvine and York (as cited in Gay, 2000) further explain that "teaching is an act of social interaction, and the resultant classroom climate is related directly to the interpersonal relationship between student and teacher" (p. 148). Ryan and Patrick (2001) also affirm that teachers play a critical role in constructing social environments through the creation of norms, rules for social behavior, and instruction on student interactions.

Undoubtedly, the teacher's role is paramount in creating a positive social climate in any classroom; however, that role drastically increases in a culturally different class. Colombo (2005) maintains that working in such classrooms requires teachers with cultural knowledge of the various means of knowing, communicating, and doing that exist within the homes of minorities. Bennett (2001) also states that in culturally different classrooms, "personal biases and emotions have often overshadowed the subtle variables that affect interaction... and a child's inappropriate behavior at least partially, is a consequence of the actions of the teacher" (p. 23).

As such, those who take on the challenge of teaching in a culturally different environment must possess dispositions that adequately enables and equips them to 
recognize and manage cultural differences that will create a positive social environment. This is certainly important because teachers who understand and appreciate various funds of cultural knowledge are more likely to provide an enriching and responsive learning environments. These environments not only celebrate, but also capitalize on children's cultural differences (Colombo, 2005). In essence, social classroom experiences and interactions should, to the greatest extent possible, be modified to accommodate the home culture of students (Gay, 2000). This practice as key in the culturally different class because it honors the student's identity and aids development of their full potential, which can result in improved learning experiences for all students.

An inherent component of culturally responsive teaching is the disposition of cross-cultural competence. Although cross-cultural competence or cultural competence has several conceptual and operational definitions, it is characterized by core universal tenets (Haynes, 2008). Such characteristics include individuals and systems with the knowledge, skills, and capacity to interact with culturally different individuals. In turn, these culturally responsive and relevant interactions, produce better outcomes for all stakeholders (Betancourt, 2003; Cross, Bazron, Dennis, \& Isaacs, 1989; Davis, 1997; Erickson, 1987; Ladson-Billings, 1990). In relation to the teaching profession, Grant and Ladson-Billings (1997) define teachers who do possess a disposition of cross-cultural competence as teachers who: are comfortable with their students' cultural style, are aware of the diversity within racial and cultural groups, they know that cultures are in perpetual change, and they are aware of the dangers of stereotyping. At the same time they know if they ignore their students' cultural attributes, they are likely to be guided by their 
own cultural lenses, unaware of how their culturally conditioned expectations might cause learning difficulties for some children. (p.54)

Essentially, cross-cultural competence can serve as a linchpin to foster greater understanding and appreciation of values, views, and behaviors that are different from one's own. This appreciation, in turn, promotes a positive social classroom climate, which is necessary for strong motivation and successful learning (Calloway-Thomas, 2010; Meyer \& Tuner, 2006). Undoubtedly, possessing cultural competence is imperative for teachers; it gives them the tools to understand their students' cultural forms, behaviors, and experience,s which ultimately allows them to appropriately contextualize teacher-student interactions. This facilitates the creation of a classroom social climate wherein all students have the opportunity to develop to their highest potential through successful learning experiences (Gay, 2010).

It must be noted, however, that a teacher's cultural competence, and a student's perception of it, does not exist in a vacuum and can be influenced by extraneous variables. Cohen and Manion (1994) believe that a fuller understanding of human behavior can be achieved by identifying the relationships between factors and elements that are deemed to have some bearing on the phenomena under investigation. Straffon (2001) and Sims (2011) identify several demographic factors that can potentially have an impact on the variables in question in this study. These variables include gender, ethnicity, nationality, age, highest level of education completed, and years of teaching experience. This study will examine and include student demographic variables - gender, grade-level, ethnicity, and SES - and teacher demographic variables - ethnicity, years of 
teaching experience, and level of education attained in order to gain the most precise and in-depth understanding of the relationships between variables.

\section{Statement of the Problem}

Interaction, regardless of its form- "direct or indirect, intellectual or emotional, physical or social didactic or communal, literal or symbolic verbal or nonverbal"'establishes a classroom's social climate, which is the site where learning experiences do or do not occur (Gay, 2010, p.175).

As teachers and students increasingly come from different cultural backgrounds, the classroom is fast becoming a place where social interactions between teachers and students can erupt into cultural clashes. These differences, if not appropriately managed, can produce a social classroom climate not conducive to learning (Black, 2006). Robinson (2012) however, posits that cultural competence is the antecedent to implementing effective practices when working in a culturally different environment because it equips professionals not only with knowledge, but the capability to apply that knowledge appropriately. He further notes that because both the teachers' and students' cultural lens affect learning, it is imperative that educators learn, understand, possess, and employ strong cultural competence skills to ensure that the needs of all students in the classroom environment are fully met.

In essence, teachers need to be cognizant of their own level of cross-cultural competency in their effort to identify inconsistencies and inadequacies in their personal interactions with the students from various cultural backgrounds. Any shortcomings can then be addressed by engaging in culturally relevant and responsive pedagogical practices the result of which can lead to the creation of a more supportive and efficient social 
classroom climate. This process is crucial, as the classroom social climate is a fundamental factor to address when fostering favorable and enhanced learning experiences for all students. This study examines these culturally different classrooms through the lens of teachers' level of cross-cultural competence and the impact of that competence on their students' perceptions of their classroom social climate.

\section{Purpose of the study}

The purpose of this exploratory study is to investigate teachers' levels of cultural competency, their ethnicity, years of teaching experience and level of education and the student demographic characteristics of socio-economic status (SES), ethnicity and gradelevel and the relationship between these factors and students' perceptions of the classroom social climate in a culturally different middle school. The study will explore this relationship using Hierarchical Linear Modeling (HLM) analysis. The Teacher Multicultural Attitude Survey (TMAS) and the Quick Discrimination Index (QDI) will be utilized to quantify teachers' perceptions of their own cultural competency. The Social Classroom Climate Measure (SCCM) will be used to gauge students' perception of their classroom social climate. In doing so, this study seeks to identify the role of teacher cross-cultural competency in the creation of a positive social classroom environment.

\section{Research Questions}

1. Are the teacher characteristics of level of cultural competency, ethnicity, educational level, and years of teaching experience and student demographic characteristics of grade-level, gender, SES, and ethnicity significant predictors of the students' perception of the "teacher emotional support" factor of the social 
classroom climate in culturally different middle school classrooms in a Midwest Public Schools system?

2. Are the teacher characteristics of level of cultural competency, ethnicity, educational level, and years of teaching experience and student demographic characteristics of grade-level, gender, SES, and ethnicity significant predictors of the students' perception of the "teacher academic support" factor of the social classroom climate in culturally different middle school classrooms in a Midwest Public Schools system?

3. Are the teacher characteristics of level of cultural competency, ethnicity, educational level, and years of teaching experience and student demographic characteristics grade-level, gender, SES, and ethnicity significant predictors of the students' perception of the "promotion of mutual respect" factor of the social classroom climate in culturally different middle school classrooms in a Midwest Public Schools system?

4. Are the teacher characteristics of level of cultural competency, ethnicity, educational level, and years of teaching experience and student demographic characteristics grade-level, gender, SES, and ethnicity significant predictors of the students' perception of the "promotion of task-related interaction" factor of the social classroom climate in culturally different middle school classrooms in a Midwest Public Schools system? 


\section{Significance of the Study}

Meyer and Turner (2006) suggest that the social classroom experience undergirds the creation of teacher-student relationships and interactions, which are necessary for learning motivation. Moos (1979) reiterates that teachers create a positive learning environment by demonstrating their dedication and commitment to enhancing the learning experiences of all children.

The creation of a positive social climate in a culturally different classroom environment requires teachers to understand the role and importance of being culturally competent. Cultural competence entails more than merely knowing about a particular culture and its overt behavioral manifestations and communication patterns. It involves the teacher unpacking and reflecting upon their culture in an effort to understand how their cultural lenses, as well as those of the students, interweave and connect within the classroom context. More importantly, it embodies the notion of honoring and respecting cultural differences within the classroom by working toward the creation of positive interactions and learning experiences (Moule, 2012).

Gay (2010) ascribes a similar degree of importance to cultural competence and asserts that it is the teacher's moral responsibility to teach cross-culturally. She notes that failing to adopt such practices permits hegemonic structures, which maintain personal denigration and allow educational inequality, to continually exist. It is imperative that teachers move beyond surface-level knowledge and skills when teaching in the culturally different classroom, to acquire new pedagogical practices that are culturally responsive and relevant (Gay, 2010). 
While considerable research has been conducted regarding the impact of the classroom learning climate, few studies have differentiated and explored the specific factors that create a positive classroom social environment. Additionally, the disposition of cross-cultural competence has been studied in several fields, but it has only recently gathered momentum in education. As such, only a few current studies have directly explored the role of teachers' levels of cross-cultural competence in e culturally different middle school classrooms. This study will add to the limited body of literature in this particular area.

\section{Conceptual Framework}

Three development theories are the foundational tenets on which this study is built: (1) the ecological human development theory by Bronfenbrenner (1974); (2) the person-environment fit theory by French, Rodgers, and Cobb (1974); and (3) the theory of cultural competence initially articulated by Cross, Bazron, Dennis, and Isaacs (1989). These theories suggest that classroom dynamics are multifaceted and multilayered in nature, and student academic performance is rooted in more than traditional instructional practice (Gould, 2007; Loukas, 2004).

Bronfenbrenner (1979) suggests that student development occurs in complex, overlapping systems that include also human and relational elements (as cited in Gould, 2007). This theory provides a deeper understanding of the sometimes unspoken issues that face adolescents in schools as well as an avenue to address such issues and establish caring relationships, which in turn support students' motivation to learn (Gould, 2007). This theory further espouses the notion that individual characteristics such as race and personality influence the manner in which students interact and assign meaning to their 
various environments. It is a notion that has strong implications for school environments (LaSalle, 2013).

Bear, Gaskins, Blank, and Chen (2011) and Brand, Felner, Shim, Seitsinger, and Dumas (2003) further illustrate the connections between individual characteristics like culture and environment, and particularly, the educational environment. They note that when students perceive respect for diversity and their teacher implements fair and equitable rules for all students, both academic achievement, and psychological well-being are enhanced. Obgu (2003) also highlights the importance of race and ethnicity in the classroom environment. He suggests its inclusion in the educational climate framework because the concept of race is socially constructed and does indeed impact a student's identity and experiences.

The person-environment fit theory further adds to the concept of environmental effects and influences. It espouses the notion that stress or conflict arises not from an individual or the environment, but rather from the congruence between a person and their environment, i.e., whether the environment satisfactorily meets the individual's needs (Eccles et al., 1993). This theory suggests that a good fit between a person and their environment engenders satisfaction and motivation. The implication for education revolves around the notion that students will be optimally motivated to learn in a classroom that can meet their needs (Eccles et al., 1993).

Several studies articulate this concept and identify a cultural match or mismatch as the potential explanation for group differences in both academic achievement and activity choices (Eccles \& Roeser, 2009; Edwards, 2010). Valencia (1991) concludes “a mismatch of both the values of the school and the materials being taught contributed to 
the poor performance and high dropout rates among Latino youth in the high school they studied" (as cited in Eccles \& Roeser, 2009, p. 132).

Similarly, Deyhle and LeCompte (1999) argue that in the context of traditional middle schools, Native American youths tend to perform poorly. The authors ascribe this poor performance to "the misfit between the needs of young adolescents and the nature of junior high school environments" (as cited in Eccles \& Roeser, 200, p.132). This situation is an example of the person-fit dynamic impact.

The concept of cultural competence considers the cultural differences and needs of students and acknowledges that such needs can conflict with dominant societal values and thought patterns. All preferences, however, should be viewed as equally valid and appropriately met through culturally responsive pedagogical practices (Gallegos, Tindall, \& Gallegos, 2008). This process requires individuals to have or develop skills in the areas of (1) self-awareness, (2) awareness and acceptance of differences, (3) managing the dynamics of difference, (4) knowledge of a client's culture, and (5) adaptation of skills (Cross et al., 1989). These skills are necessary to create environments where positive person-fit dynamics exist, i.e., environments where cultural clashes are minimized or managed appropriately. Gay (2000), Ladson-Billings (2001), and Nieto (2004) propose that teachers facilitate this process by learning about their students' cultures and engaging students in culturally responsive instruction. Irvine (2009) also acknowledged the need for culturally relevant pedagogy because learning should relate to students' cultural experiences. She maintains that if new knowledge is not relevant to an individual's cultural and cognitive framework, it will never be remembered (Irvine, 2009). The unfortunate result is low academic achievement. Therefore, teachers need to master 
awareness of and sensitivity to other cultures because this enables them to successfully teach students who come from cultures other than their own. In essence, they need to possess cultural competence (Moule, 2012).

The ecological theory, person-environment fit theory and theory of cultural competence combine to create a framework to explore and understand the social dynamics with the culturally different middle school classroom. These theories recognize the developmental, personal, and cultural needs of students. Moreover, they highlight the interrelatedness of these needs, i.e., specific developmental needs of each student are influenced by their personal and cultural needs, and vice versa. This research study adds to the limited body of literature that examines the impact of teacher cultural competence in the creation of a classroom environment containing culturally different students. This study intends to determine the extent to which teacher cultural competence affects students' perceptions of the classroom social environment, i.e., it explores whether teacher cultural competence impacts the person-fit dynamic in culturally different middle schools.

\section{Assumptions of the Study}

This researcher made three main assumptions. Firstly, it was assumed that in classrooms where teachers employed cross-cultural teaching practices, their students would have a positive perception of the classroom climate. A second assumption was that the surveyed teachers and students were candid and truthful about their attitudes and perceptions. Finally, the researcher assumed that despite typical problems with survey instrument, those utilized in the study measure the variables under observation. 


\section{Delimitations}

This study involved two self-report scales; a cultural awareness scale for teachers to assess their level of cross-cultural competence and a social classroom climate scale for students to convey their perception of the social environment. Self-report scales require the individuals completing them to know themselves, their emotions, as well as have the ability to accurately communicate those opinions on a survey instrument. There is often a concern that individuals completing the survey will not take it seriously, therefore, causing the data to be less valid.

This research is also delimited by site selection. The study was conducted in a Midwest Public Schools district. This district was chosen because of its predominance of culturally different classrooms.

\section{Definition of Terms}

Cultural awareness: Being cognizant, observant, and conscious of similarities and differences among cultural groups (National Center for Cultural Competence, 2013) Cultural competency (in education): "Cultural competency is the ability to teach successfully students who come from cultures other than your own. It entails mastering complex awareness and sensitivity, various bodies of knowledge, and a set of skills that, taken together, underlie effective cross-cultural teaching” (Moule, 2012, p.19).

Culturally different: "Culturally different is used synonymously with cross-cultural or ethnic and implies that the student comes from a different culture than the teacher. It includes no value judgment about the superiority of one culture over the other only that people have been socialized in very different ways and may find communication problematic" (Moule, 2012, p.12). 
Culturally relevant pedagogy: "an approach to teaching and learning that empowers students intellectually, socially, emotionally, and politically by using cultural referents to impart knowledge, skills, and attitudes"(Ladson-Billings, 1994, p. 18).

Culturally responsive pedagogy: "using the cultural knowledge, prior experiences, and performance styles of diverse students to make learning more appropriate and efficient for them; it teaches to and through the strengths of these students (Gay, 2010, p. 29). Cultural sensitivity: Understanding the needs and emotions of your culture and the culture of others (National Center for Cultural Competence, 2013, p. 2).

Culture: It is the lens through which individuals explain, value and give their world meaning. It shapes beliefs and influences what behaviors are deemed appropriate (Diller $\&$ Moule, 2005).

Disposition: The National Council for Accreditation of Teacher Education (NCATE) (2002) defines the term dispositions as "the values, commitments, and professional ethics that influence behaviors toward students, families, colleagues, and communities and affect student learning, motivation and development as well as the educator's own professional growth" (p. 20). Dispositions are guided by beliefs and attitudes related to values such as caring, fairness, honesty, responsibility, and social justice.

Social classroom climate: the atmosphere of the class as a social group which is defined by the factors of teacher and student support, promotion of mutual respect, promotion of task-related interaction (Patrick, Ryan \& Kaplan, 2007).

Teacher emotional support: "students' perceptions that their teacher cares about and will help them... emotional or personal support, involving perceptions that 
the teacher likes and cares about the student as an individual" (Patrick et al., 2007, p.84).

Teacher academic support: "the student belief that the teacher cares about students' learning, wants to help them learn, and wants them to do their best" (Patrick et al., 2007, p.84).

Mutual respect: "a perception that the teacher expects all students to value one another and their contributions, requires students to be considerate of others' feelings and prohibits students making fun of each other" (Patrick et al., 2007, p.85).

Task-related interaction: "the extent to which they encourage students to interact and exchange ideas with each other during lessons" (Patrick et al., 2007, p. 85). 


\section{CHAPTER 2}

\section{LITERATURE REVIEW}

\section{Purpose of Literature Review}

The purpose of this literature review is to establish a theoretical framework that highlights how a teacher's level of cultural competency, can impact students' perceptions of the classroom social climate in a culturally different middle school. This review emphasizes those studies that highlight the importance of these variables; establishing a connection between these variables will be a primary focus.

The research has shown that when teachers who work in ethnically diverse classrooms exhibit cultural competence, students are more likely to demonstrate dispositions (such as high motivation and engagement), which results in a positive view of the social climate, which in turn leads to their improved school performance. (Gay, 2010; Moule, 2012; Patrick et al., 2007).

Teacher cultural competence will also be viewed here as a medium to facilitate a positive social environment for culturally different students by embedding it a within culturally relevant teaching (CRT) perspective. This view highlights the importance of developing a social environment that considers and challenges structural and cultural inequities that may exist in classrooms. The discussion will be augmented by research into the interactions between teacher's cultural competence, and how that competence may influence the ways students perceive their classroom climate. 
Thereafter, will be an analysis of the relationship between the developmental needs of adolescents and the school climates in which they function. This analysis will be guided by Bronfenbrenner's ecological theory, which explores the importance of the connection between individuals and the various environments in which they exist. This theory further buttresses the argument that the nature of the social climate where students exist impacts their perceptions of that climate, and consequently, their performances.

This literature review is necessary because only a few current studies have directly explored the role of teachers' levels of cross-cultural competence in culturally different middle school classrooms as well as how this competence relates to the creation of a positive social climate. The literature review concludes with an in-depth analysis of the importance of cultural competency in an effort to develop a positive social climate in culturally different middle schools.

\section{Sources for Material Included in this Literature Review}

The articles used in this literature review were found through online databases namely EBSCO Host, Academic Search Complete and ProQuest. Additional articles were retrieved from the James White Library Journals and Periodicals Collection. These articles were published in journals such as American School Board Journal, American Psychologist, Anthropology \& Educational Quarterly, Educational Psychology Review, Journal of Educational Psychology, Journal of Teacher Education, Theory into Practice. Articles were also sourced from several national and state agencies (MI School Data, National Center for Cultural Competence, National Center for Education Information, National Center for Education Statistics, National Middle School Association). The main 
criteria used were cultural competence, culturally different middle schools, and classroom social climate.

\section{Attributes of Cultural Competence}

Pinderhughes (1989) first coined the term cultural competence. She utilized the term to conceptualize the changes required in the helping professions — such as health, mental health, social services, and education - in the face of an increasingly pluralistic society (as cited in Lum, 2011). In her study, professionals were urged to engage in reflective practices, which allowed them to understand how differences in cultural backgrounds impacted the delivery of services (Lum, 2011). Another seminal study related to the development of cultural competence was that of Cross et al. (1989). The authors' objective was to provide professionals with the tools needed to respond to cultural differences. To achieve this task, six anchor points along the continuum toward cultural competence and five skill areas necessary for the development of cultural competence were outlined. These skill areas include (1) self-awareness, (2) awareness and acceptance of differences, (3) managing the dynamics of difference, (4) knowledge of a client's culture, and (5) adaptation of skills to circumstance.

While the concept of cultural competence has permeated the health and social work field since the 1970s, in the educational domain, cultural competency emerged following the teaching for tolerance and antiracism movements of the 1980s (Lindsey, Nuri-Robins, \& Terrell, 2003). Accordingly, the scholarship in this area, although limited, has moved in multiple directions. For instance, in its inchoate stages, cultural competence was understood only in terms of a body of cultural knowledge to be acquired while its emotional aspect was overlooked. Recently, descriptors relating to the concept 
provided a holistic perspective, which brought forth an awareness of cultural competence as a personal process, practice framework, and professional standard (Sue, Zane, Nagayama-Hall, \& Berger, 2009). This approach to cultural competence is reflected in the works of Diller and Moule (2005) and also Moule (2012), who describe the development of cultural competency as the continual acquisition of knowledge, the development of new and more advanced skills, and an ongoing reflective self-evaluation of one's progress. They further posited that such competency is a lifelong journey and dynamic process that requires the courage to challenge personally held assumptions and learn culturally responsive skills.

Cultural competence also acknowledges the predominant role of culture in shaping behaviors and values, such as education, and the capability of dominant culture values to reinforce students' minority status in educational institutions. Subsequently, the development of students can be hindered, leading to self-esteem, identity formation, and isolation issues in addition to flawed assumptions regarding the central role of schooling (Robinson, 2012).

Further, cultural competence extends beyond the boundaries of the classroom into the natural support systems of students, such as family units and communities. It enables educators to serve culturally different students better by adapting their personal and professional practices to cultural differences that relate to thought patterns, preferences, values, and behaviors. The adoption of these strategies is an important aspect of cultural competence because it offers an awareness of the impact of marginalization and discriminatory practices in the daily lives of students (Robinson, 2012). 
Ladson-Billings $(1995,2003)$ supports this concept and recommends that natal culture should be used as a guide to select educational elements, which helps to avoid undesired behaviors and produce desirable ones. In essence, while focusing on its application in schools, cultural competence has a parallel focus on the fair allocation of human and capital resources, the function of power and oppression in the educational system, and the attainment of academic success for all students through delivery of highquality instruction (Lum, 2011; Robinson, 2012).

For this study, however, cultural competence is defined as "the ability to successfully teach students who come from cultures other than your own. It entails mastering... complex awareness and sensitivities, learning specific bodies of cultural knowledge and mastering a set of skills that, taken together, underlie effective crosscultural teaching" (Moule, 2012, p. 2). Furthermore, it is an approach to teaching and learning that "empowers students intellectually, socially, emotionally, and politically by using cultural referents to impart knowledge, skills, and attitudes" (Ladson-Billings, 1994, p.18).

\section{Cultural Competence and Multicultural Education}

Current demographical patterns and anticipated trends of the student population have prompted educators to recognize the need for cultural diversification within the education system. Multicultural curriculum theorists have advocated for defining multicultural education from a critical perspective. According to Gay (2010), there is a need for exploring the dialectical relationship between theory and practice, valuing and committing to human emancipation and exposing contradictions in culture. She notes that this process involves explaining how traditional and current curriculum and instruction 
perpetuate socioeconomic exploitation and subjugation as well as articulating innovative methods to create equality in schools.

Several curriculum theorists have advanced this same notion of multicultural education as a tool for critically engaging and changing current curriculum practices. Ornstein and Hunkins (1998), for instance, envision multicultural education as an expression of the belief that "challenges us to analyze why we think a curriculum should be developed in a certain way for particular students" (p. 173). Furthermore, they articulate that its purpose is to give credence and recognition to ethnic and cultural diversity and highlight its role in shaping social experiences, personal identities, and educational opportunities in a manner that ensures equitable treatment for diverse individuals and groups (as cited in Gay, 2003).

Bennett (1999) describes multicultural education as a system encompassing curricula and processes for understanding the culture, history, and contribution of various ethnic groups as well as developing attitudes, values, behaviors, and strategies for combating inequitable treatment of such groups. Gay (2003) proposes culturally sensitive pedagogical practices as the precondition for achieving maximal academic outcomes for culturally diverse students. Nieto (2004) further broadens the context of multicultural education and argues it should not only permeate curriculum and instructional strategies, but also be extended into the conceptualization of the nature of teaching and learning and actual interactions between teachers, students, and parents.

These definitions of multicultural education have a common linchpin. They require an understanding of the needs of culturally diverse students, cognizance of limitations in such knowledge and abilities, and an awareness of personal bias that may 
purposely or inadvertently perpetuate educational inequalities. In essence, the disposition of cultural competence is at the heart of multicultural education.

\section{Cultural Competence in the Classroom}

A number of studies have investigated cultural competence within an educational setting. For example, Marks's (2011) qualitative study, which explores teachers' knowledge and their perceptions of cultural competence, found that prior training is a prerequisite for the utilization of culturally relevant practices. Additionally, school support and personal experience impact the degree to which cultural competence is perceived as important. Finally, teachers with informal cultural competence training depend on personal experience and gut instinct to guide their classroom practices. Gies (2010) further noted that professional developing training can positively affect teachers' perspectives of cultural competence; however, heavily mandated and ineffective programs can create adverse conceptions and views of the role of cultural competence.

In terms of academic success, Wells-Rivers (2011) found that students from marginalized cultures exhibit academic growth when teachers acquire enhanced skills related to the delivery of culturally relevant instruction. This growth, however, extends to students from both dominant and non-dominant cultures. In addition, a decline in discipline referrals was seen as teachers developed culturally relevant practices.

Robinson (2012) investigated the role of cultural competence and its impact on student engagement from an international school perspective. The researcher found that self-reported cultural competency did not have a significant correlation to students' perceptions of their teacher's cultural competency. However, it does bear a strong positive relationship with student engagement. 
Templeton (2011) conducted an experimental study that utilized culturally competent teaching practices. These practices included the implementation of culture acclimation and high expectations in a study group of 100\% African American students. The study revealed that there were measurable differences between the study group and the control group — where the practices were absent — regarding academic performance. These findings lend support to the theory that the implementation of cultural competency aids achievement. In essence, teachers who are culturally competent can engender greater positive outcomes from their students.

Coggins and Campbell (2008) suggest that the integration of cultural competence into teaching approaches is a key component for closing the achievement gap between minority and non-minority students. They note that the existence of an achievement gap between ethnic minorities and dominant culture students should serve as a warning to educators that the examination of pedagogical practices through the lens of cultural competence is no longer optional.

Lewis, Hancock, and Hill-Jackson (2008) argue that the deficit of cultural competence and educational responsiveness in schools and among teachers are two principal reasons for the academic achievement difficulties of many minorities, particularly African Americans. They further identify social-structural inequality paradigms and racist policies and practices as the leading causes of culturally unresponsive pedagogy perpetuation.

According to Talbert-Johnson (2004), a lack of cultural knowledge and competence among teachers is a primary factor in low academic performances of minority students. This lack of cultural knowledge often constitutes preconceived notions 
on the teachers' part. It often includes the belief that minority students have lower abilities and potential. Such beliefs can have debilitating effects on students because it positions students to develop behaviors that hinder academic performance and success, such as a lack of motivation and low self-expectations.

Diamond, Randolph, and Spillane (2004) corroborates this assertion and explain that a teacher's expectations are often influenced by racial and social class perception and stereotypes. This results in teachers deeming minority students as being less capable than their Caucasian counterparts. To counteract such beliefs, it is suggested that teachers be respectful of diverse cultures and engage in reflections to identify and challenge their racial and social biases; these are practices in which cultural competent teachers should engage (Diamond et al., 2004).

\section{Criticisms and Challenges of Cultural Competence}

Cultural competence is not without its criticisms and challenges. The most common challenge revolves around the clarity of its definition, its role as a framework for actual practice, genuineness as a strategy for equity in the classroom, and whether teachers are adequately prepared to exhibit true cultural competence.

Lum (2011) posits that the greatest challenge for cultural competence is achieving a common consensus on a concrete definition. This lack of consensus leads to a clouding of the theory, which then translates into unclear methodologies. In addition, cultural competence can simply be perceived as only a vehicle for ideological thrust and agendas. To avoid such superficial definitions, Lum (2011) argues that remaining centered on its core meaning, assumptions, and principles can engender a cohesive operational definition. 
A second criticism is its lack of ability — as a framework for educational practice - to lend itself to the actual outlining of specific and concrete learning objectives (Furness, 2005; Williams, 2006). This claim, however, is supported by unsubstantiated empirical evidence and studies. In fact, Bronstein, Berman-Rossi, and Winfield (2002) argue that this challenge is often supported by evidence that relates to the amount of content matter taught and learned, rather than the delineation of actual objectives that students are failing to achieve. Moreover, NCATE (2008) has offered clarity in its standards and includes the notion of cultural competence in three of its standards that relate to the dispositions that teachers must possess.

Another challenge that cultural competence faces is the tendency of some to reduce it to a list of characteristics to be developed and exhibited, rather than being seen as a continuous and dynamic process containing complex interactions (Gray \& Thomas, 2006). This oversimplification of cultural competence can imperil the very existence of cultural competence. That is, the confusion may inadvertently produce and reinforce opposing negative racial perspectives, such as color-blindness and dominant group hegemony rather than allowing racial discourse that honors and respect differences in cultural identity (Abrams \& Moio, 2009; Jay, 2006).

Finally, it has been argued by some that many educators are ill-prepared to implement culturally relevant practices in the classroom. This issue, it is posited, occurs to the extent that many instructors utilize didactic, traditional instructional methods, even in the delivery of diversity education courses. Additionally, many educators lack the ability to cope with and effectively address the intense reactions that typically accompany any discussion related to racism and oppression (Lee \& Greene, 2003). Garcia and Van 
Soest (as cited in Abrams \& Moio, 2009) however, argue that faculty must acquire the skills and abilities to put heated and strained issues into perspective when matters related to diversity are discussed.

\section{Culturally Relevant Pedagogy}

For the analytical purposes of this study, the definition of cultural competence extends beyond a mere list of characteristics to be adopted; rather it is seen as a means of creating a positive social environment for all students. This role of cultural competence allows the ideas to be embedded within the concept of CRT. CRT considers the students' cultural attributes, characteristics, knowledge, or backgrounds with the primary purpose of creating a learning environment in which all students can be successful (Gay, 2010). This goal is facilitated by structuring pedagogical interactions in such a manner that allows students to utilize cultural elements, capital, and knowledge while assimilating and accommodating new content and information (Howard, 2012).

CRT is multidimensional in nature and moves beyond the curriculum to inform teacher-student interaction, classroom climate, and school culture. Moreover, it seeks to empower minority students "intellectually, socially, emotionally, and politically by using cultural referents to impart knowledge, skills, and attitudes" (Ladson-Billings, 1994, p.18). It also challenges deficit-based social explanations such as "students of color lacking culture, having a culture of poverty, possessing an oppositional culture, or parents who lack concern for their children's academic aspirations" as a rationale for an absence of academic success for minority students (Howard, 2012, p. 68).

A few early studies addressed issues that fall under the umbrella of CRT, such as cultural appropriateness, congruence, and the like. These includes studies such as that of 
Villegas (1988), who considered the mismatch between language patterns of African Americans and schools in larger urban settings. In particular, she noted that cultural mismatches stem from larger social structures that are reproduced in school; this results in the perpetuation of social inequalities in the mainstream society. She further posited that educational solutions that ignore the cultural and socio-political aspects of schooling are doomed to failure (as cited in Ladson-Billings, 1995).

Building on earlier work, Ladson-Billings (1995) notes that in order to fully address the failure of minority students, both macro and micro analyses is necessary. Teacher-student interpersonal contexts, teacher-student expectations, institutional contexts, and societal contexts must be considered in the endeavor to help students develop the critical perspectives they need to challenge inequities that schools often perpetuate while simultaneously accepting and affirming their own cultural identities.

Recently, Nelson (2001) described the experiences of students of diverse racial and ethnic backgrounds who participated in a writing workshop. The workshop included CRT practices, such as the ownership of writing through an expression of personal lived experiences. According to Nelson (2001), within three weeks, the quality of writing improved to the extent that the students could be considered strong writers. It is suggested that this change occurred because the students wrote about and shared, their lives, and struggles. An unanticipated outcome was the development of a sense of community within the classroom. This result was corroborated by Feger (2006), who found that critical thinking skills and the motivation to read improved for English language learners when the content matter included culturally relevant literature that was related to the lived stories of immigrants and Latinos (as cited in Hanley \& Noblit, 2009). 
Love (2003) conducted a study that examined teachers' beliefs, practices, knowledge and social relations regarding the effective teaching of African American students and the impact of those conceptions on reading achievement. The sample consisted of 244 teachers from 6 urban schools that predominately served African American children. The researcher found five factors that emerged from that data, three of which can be categorized as CRT. These three factors are placing importance on students' racial and cultural identities, utilizing appropriate teaching strategies to help low-achieving students, and stressing the importance of professional commitment to urban education. This observation led to the conclusion that the "reading achievement of African American elementary students was related to teachers' beliefs about the importance of students' cultural identity, students' individual needs and strategies for low-achieving students" (as cited in Hanley \& Noblit, 2009, p. 47).

Wyngaard (2007) articulated the notion of culturally responsive pedagogy in terms of the four R's namely, "relationship, respect, responsibility, and relevancy" (as cited in Hanley \& Noblit, 2009, p. 30). These four Rs emerged from a study in which African American students from a Midwest urban school district were asked to express their understanding and expectation of culturally responsive teaching. Additionally, Wyngaard (2007), considered the relationship between teachers and students as the foundation for culturally responsive pedagogy (as cited in Hanley \& Noblit, 2009).

Therefore, it becomes apparent that culture and learning are inseparable and cultural competence and CRT are inextricably intertwined. Howard (2006) describes this interaction between cultural competence and CRT as transformationist pedagogy. When teaching takes this form, more students—regardless of their cultural differences—obtain 
higher achievement levels without giving up their cultural identities. He further provides a framework that illustrates the intersection of cultural competence with culturally responsive teaching (see Figure 1). It is interesting to note as well that a central element in the development of cultural competence is the teacher-student relationship. From this model, it can be inferred that positive relationships between students and teachers are the launching board for developing cultural competence; this leads to culturally responsive teaching, which in turn produces improved learning outcomes for minority students. Thus, cultural competence and the classroom's social climate (i.e., student-teacher relationship) need to be examined to determine the correlation and interaction between the two to create improved school outcomes for minority students.

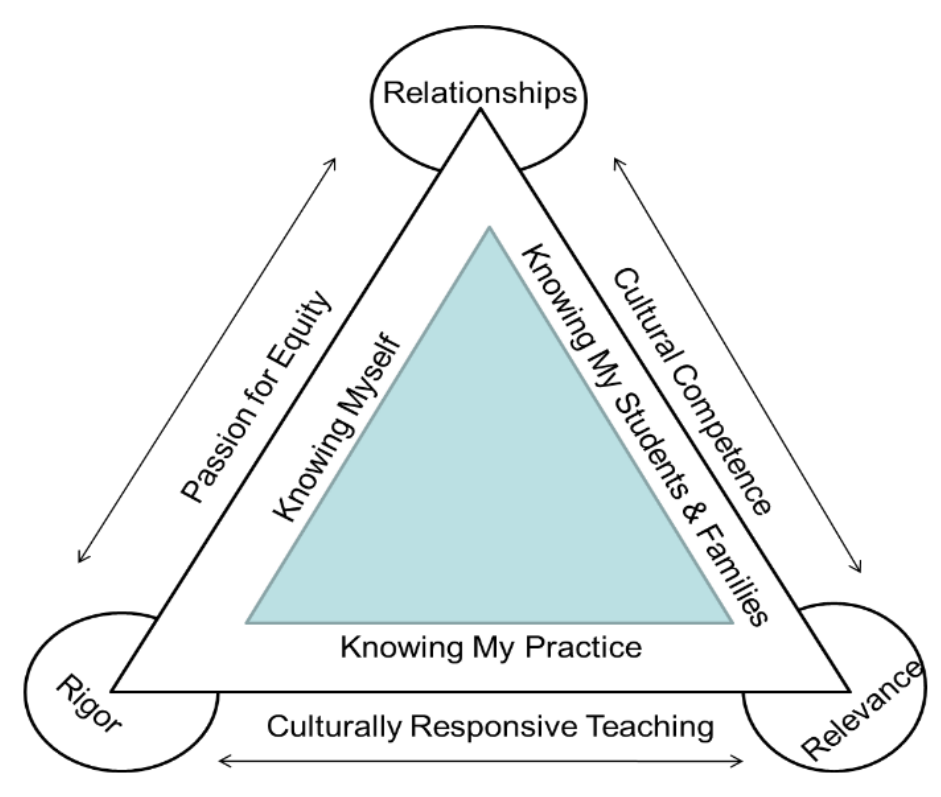

Figure 1. Achievement triangle: This figure illustrates the connection between relationships, cultural competence, and culturally responsive teaching. Reprinted by permission of the Publisher. From Gary R. Howard, We Can't Teach What We Don't Know: White Teachers, Multiracial Schools, $2^{\text {nd }}$ Edition, New York: Teachers College Press. Copyright $\odot 2006$ by Teachers College, Columbia University. All rights reserved. 


\section{Historical/Philosophical Overview of the Social Classroom Climate}

The conceptualization of the classroom climate finds its origins in the social psychology literature. “Murray’s (1938) model, Getzels and Thelen's (1960) view of the classroom as a social system, and Walberg's (1971) model of classroom environments" are a few preliminary studies that explore this concept (as cited in Bennett, 2001, p. 2). From these proponents, the view emerges that "the environment and its interaction with personal characteristics of the individual are determinants of human behavior" (Bennett, 2001, p. 2).

For instance, Murray's (1938) model characterizes the learning environment concept in terms of complex interactions between the environments (referred to as the environmental press). This concept refers to the individual's pursuit of complex personal needs and goals. Murray espoused the notion that the necessities and expectations of the environment give the social system in which individuals interact its own climate. Then, this climate then either fosters or hinders motivational personality characteristics, which is a crucial factor for providing individuals the impetus to move in the direction of desired goals and objectives. Essentially, the model argues that when dissonance between personal needs and the environment exists, it is less likely that individuals will attain their aspirations; however, congruence between these factors produces enhanced outcomes (as cited in Bennett, 2001).

Similarly, Getzels and Thelen's (1960) model focuses on classrooms dynamics. They posited that essential student outcomes, such as behavior and learning, are predicated on personality needs, role expectations, and classroom climates. Furthermore, they position the teacher as a central element when developing of the climate. They also 
recognize the teacher's administrative approach to balancing personality needs and role requirements when determining climate (Deng, 1992, Bennett, 2001). Getzels and Thelen (1960) further conceive the classroom within an ecological context and note that there are links between the social system in the classroom and that of the school, community, and so on. Such links are expressed and delineated through definitions of and performance expectation regarding teaching and learning (Getzels \& Thelen, 1960, Bennett, 2001).

Walberg (1971) argues that it is "the atmosphere of the class as a social group that potentially influences what students learn" (as cited in Bennett, 2001, p. 4). In essence, he believes that student performance is mainly attributed to the aptitude of learners and the learning environment, while other factors have only minimal effects.

Trickett and Moos (1973) and Moos (1979) further posit that the classroom climate is defined by social interactions that occur within a particular classroom environment. They identify the social environment, as measured by the classroom environment scale as one of the main factors affecting student satisfaction and involvement.

Recently, Sinclair and Fraser (2002) articulated the notion that positive social interactions in the classroom engender improved outcomes for students. They define the attributes of a positive classroom climate using five particular types of interactions, four of which are social in nature: task-related cooperation among student; teacher support, which relates to the students' perceptions of the teachers' willingness to help, encourage, and show interest in them; equality of treatment for students; and student involvement in class activities and discussions. This view further solidifies the role of social interaction as a clearly salient factor in student outcomes. This position is validated by the social 
learning theory, which suggests that the meaningfulness of an environment best predicts an individual's actions (Anderson, Hamilton \& Hattie, 2004). In other words, students tend to exhibit adaptive behaviors such as interest, attention, and active participation when the classroom social atmosphere conveys support and respect, this, in turn, fosters successful learning outcomes.

Fraser, Aldridge, and Adolphe (2010) support this view, which has led to refining the concept of the social-psychological, or simply, the social classroom climate. They substantiate this view by highlighting the inherently social nature of the classroom, i.e., it is a place where students and teachers continually interact. Socially, these interactions create norms and rules for social behavior as well as delivering explicit messages that govern interaction with classmates. The social climate is also recognized as distinct from the academic climate. It is an instrumental element that relates to student motivation, engagement, and adaptive academic beliefs and behaviors (Patrick et al., 2011; Patrick et al., 2007; Ryan \& Patrick, 2001).

These models and theories underscore the importance of the social classroom climate. The nature of this climate determines the quality of social relationships as well as the degree of personal motivation and behaviors that consequently lead to students learning. These theories are also particularly significant because they are the foundation of the conceptual and operational definition of the social classroom climate.

Subsequently, they have been utilized to generate other theories regarding the nature of the social classroom climate and its relationship to various predictor and criterion variables (Bennett, 2001). 


\section{Components of the Social Classroom Climate}

Over the years, social classroom climate research has yielded studies that establish various components as factors that comprise the social classroom climate. Adelman and Taylor (2002) list several factors that can be utilized to define this construct. They include "power and control structures, instructional methods, communication of expectations, competition, safety, and 'fit' between learner and classroom demands" (as cited in Evans, Harvey, Buckley, \& Yan, 2009, p. 133). Although they provide a general and broad conceptualization of the classroom climate construct, these factors are inclusive of external factors that are not specifically related to the social classroom climate. Elias and Haynes (2008) also articulate two components that characterize the social climate: perceived social support of teachers and peers teachers. This conceptualization, however, ignores the key features necessary for a holistic representation of the social classroom climate.

Reyes, Brackett, Rivers, White, and Salovey (2012) also posited four elements of the social climate. These include "teachers who are sensitive to students' needs; teacherstudent relationships that are warm, caring, nurturing, and congenial; teachers who take students' perspectives into account; and teachers who refrain from using sarcasm and harsh disciplinary practices" (Reyes et al., 2012, p. 701). Although they offer a wider definition of the elements of the social climate, their focus centers primarily on teachers' behaviors and attitudes, they disregard other major interactions that impact and determine the nature of the social environment.

Through the inclusion of external factors of the social environment or the exclusion of key social interaction, the components mentioned above are defined either 
too broadly or narrowly in the construct of the social classroom climate. Ryan and Patrick (2001), Patrick et al. (2007) and Patrick et al. (2011) however, articulated a four-factor measure that depicts the main elements of the social classroom climate. These factorswhich include teachers' emotional and academic support, mutual respect and task-related interaction - are justified through factor analysis techniques as accurate measures to conceptually and operationally define the social classroom climate construct.

\section{Teacher Support}

Patrick et al. (2007) define teacher emotional support as "the students' perceptions that their teacher cares about and will help them" and provide "emotional or personal support" (p. 84). It includes the perception that the teacher "likes and cares about the student as an individual" (Patrick et al., 2007, p. 84). Teacher academic support refers to the belief "that the teacher cares about students' learning, wants to help them learn, and wants them to do their best" (Patrick et al., 2007, p. 84). Although highly correlated, these two types of support are indeed seen as distinct. Nonetheless, these types of support do relate to a student's effort toward academics and their willingness to engage in cognitive and behavioral academic tasks (Patrick et al., 2011; Ryan \& Patrick, 2001).

The concepts of emotional and academic teacher support have their foundation in the works of Trickett and Moos (1973), Fraser and Fisher (1982), and Wentzel (1994). These studies articulated the notion that there are associations between student motivation and engagement and the perception of being understood and supported by teachers. This perception serves as the basis for improved academic performance. Investigations reveal that teacher support is negatively associated with absenteeism and disruptiveness in the classroom. However, that support is positively related to complying 
with to classroom rules, student effort, asking for help, and applying self-regulated learning strategies, all of which lead to improved academic performance (Patrick et al., 2007; Ryan \& Patrick, 2001; Ryan \& Patrick, 2005; Wentzel, 1994).

\section{Mutual Respect}

Mutual respect refers to the "perception that the teacher expects all students to value one another and their contributions, requires students to be considerate of others' feelings, and prohibits students making fun of each other" (Patrick et al., 2007, p. 85). Additionally, in environments that are characterized as promoting mutual respect, teachers tend to exhibit qualities such as openness, caring, cultural sensitivity, understanding, honesty and being nonjudgmental (Blum, 2005; Rodriguez, 2005). These factors are essential to the social climate because they communicate a psychological comfort against being ridiculed, thereby providing the freedom for deeper engagement in cognitive tasks (Patrick et al., 2007, Patrick et al., 2011).

De Lisi and Golbeck (1999) further stated that respectful environments are conducive to greater student involvement in problem-solving and cognitive risk-taking. This process occurs in environments that promote a sense of safety and comfort; as a result, students tend to be less concerned with errors or mistakes and more likely to engage in effortful and strategic academic behaviors (Turner, Thorpe, \& Meyer, 1998). Stronge (2002) and Wilen, Bosse, Hutchinson, and Kindsvatter (2004) support this position and believe that in an atmosphere of mutual respect, students are uninhibited in their desires to ask questions and express their thoughts and feelings. Ryan and Patrick (2005) also argue that this works in tandem with the resource allocation theory, which suggests that students can better engage in cognitive tasks in a classroom defined by 
mutual respect. This outcome occurs as the result of reducing of task-irrelevant thoughts associated with the distress of uncomfortable and unsafe environments, which can overload working memory and thereby reduce the available cognitive capacity.

\section{Task Related Interaction}

Task-related interaction relates to "the extent to which teachers encourage students to interact and exchange ideas with each other during lessons" (Patrick et al., 2007, p. 85). This interaction influences the nature of the social climate because it encourages students to actively engage in sharing ideas and learning experiences. As a result, students are afforded the opportunity to validate and improve their ideas, evaluate possibilities, and give and receive assistance, all of which are adaptive academic behaviors (Patrick et al., 2007, 2011). Howe and Mercer (2007) similarly note that social interaction between students provides learning and developmental opportunities that are both complementary and distinctive. Particularly, it fosters goal-directed behaviors, dialogue, perspective, and articulation of concepts and opinions among student. Such behaviors are synonymous and consistent with understanding and learning.

Furthermore, these outcomes are expected based on both the Piagetian and Vygotskian theories of learning and development (De Lisi \& Golbeck, 1999). In essence, social interactions among peers can stimulate motivation, confidence, efficacy, sustained interest, and perseverance when experiencing increased levels of task difficulty. Success is also more likely because students can avail themselves to a greater array of skills, aptitudes, and resources rather than solely depending on personal abilities. 


\section{Effects of the Social Classroom Climate on Education}

The nature of the social classroom climate is crucial to schooling and learning. Studies have shown that the social climate of the classroom impacts both academic and social behaviors and perceptions. This includes student interest, engagement, motivation, and academic performance as well as a students' perception of school-life quality, student-teacher relationships, and peer relationships (Bennett, 2001; Evans et al., 2009).

In regard to academic motivation and engagement, studies have shown that a positive social climate increases adaptive behaviors, including higher attendance records, increased engagement, and deep rather than surface learning, improved motivation, and higher grades (Lau \& Lee, 2008; Tapola \& Niemivirta, 2008). For instance, Reyes et al. (2012) collected data from 63 fifth- and sixth-grade classrooms ( $N=1,399$ students). Utilizing a multimethod, multilevel approach, they found a positive relationship between classroom emotional climate, engagement, and grades.

Anderson et al. (2004) examined several factors related to the social classroom climate and the impact on motivational behaviors and student outcomes. The study found that the student perception of affiliation - the sense of classroom relationships - is important to the educational process because it engenders positive motivational behaviors and improved outcomes. Similarly, in their seminal study, Walberg and Anderson (1968) found that students' perception of classroom climate is associated with cognitive growth and achievement, as well as predictive of affective growth and learning. They conclude that a significant relationship exists between class climate and learning. Interestingly, although these studies are separated by 36 years, they still illustrate that social classroom climates significantly impact academic success. These studies provide longitudinal 
evidence of the relationship between the social classroom climate and academic performance.

In their study, which consisted of 282 third-grade students from six elementary schools in a Northwestern urban community, Elias and Haynes (2008) found that social support has a strong influence on academic trajectories. Patrick et al. (2007) examined whether fifth-grade students' $(\mathrm{N}=602)$ perceptions of their classroom social environment were related to their engagement in the classroom. They found statistically significant associations of certain social dimensions to numerous adaptive student beliefs and behaviors.

In addition to academic performance, the social climate can impact student social behaviors. Several studies have demonstrated a positive relationship between pro-social behaviors and positive classroom climates. These prosocial behaviors include decreased bullying, anxiety, and stress as well as greater student co-operation, enjoyment, and school-life quality (Ahnert, Harwardt-Heinecke, Kappler, Eckstein-Madry, \& Milatz, 2012; Avant, Gazelle, \& Faldowski, 2011; Barth, Dunlap, Dane, Lochman, \& Wells, 2004; Evans et al., 2010; Frenzel, Goetz, Lüdtke, Pekrun, \& Sutton, 2009; Roland \& Galloway, 2002).

Roland and Garroway (2002) utilized path analysis to demonstrate that the degree of bullying behavior was directly influenced by the social structure of the classroom. Barth et al. (2004) corroborated this connection and noted that poor social climates are associated with poorer levels of student aggression, peer relations, and academic focus. In a longitudinal study, Avant et al. (2011) employed hierarchical linear modeling procedures to measure the degree of peer exclusion experienced by students with anxious 
solitude. The findings suggest that classrooms with supportive emotional climates reduce peer exclusion for students with both high and low levels of anxious solitude.

Ahnert et al. (2012) measured cortisol levels of students to determine how teacher-student relations buffer or exacerbate stress. They found lower levels of cortisol in students whose classrooms were characterized as supportive and caring. However, in classrooms where teacher-student relationships were conflict loaded, the students were unable to appropriately down-regulate stress. Through multi-level structural equation modeling, Frenzel et al. (2009) provide evidence that supportive social-emotional classrooms lead to increased subject and classroom enjoyment for both students and teachers. Finally, in their overview of the benefits of positive classroom climate, Evans et al. (2009) list greater cooperation and improved quality of life as outcomes of positive student-teacher interaction.

\section{Influence of Demographic Variables}

The impact of demographic characteristics for both teachers and students must also be taken into account. This is imperative because interactions between variables under study do not occur in a vacuum, and extraneous variables have the potential to influence the perception of relationships between these variables. The power and impact of these extraneous variables are illustrated in several studies. Koth, Bradshaw, and Leaf (2008) utilized hierarchical linear modeling analysis to indicate that the individual factors of race and sex account for the largest proportion of variance in perceptions of school climate. Additionally, teacher characteristics such as socioeconomic status and ethnicity are also linked to the perception of school climate (Vieno, Perkins, Smith, \& Santinello, 2005). Barth et al. (2004) also report that race is confounded by measures of classroom 
environment; they indicate that this is likely a result of socio-economic status and socializing forces that were associated with race.

In terms of the disposition of teacher cultural competence, Robinson (2012) explored the impact of teacher demographics, such as ethnicity, years of teaching experience, and education level on cultural competence. The results indicate that ethnicity and years of teaching experience are not significant predictors teachers' education level was a significant predictor of a cultural competence.

In his study of cultural adaptation and job satisfaction, Sims (2011) found that teacher demographics, like gender and ethnicity are not statistically significant predictors; however, years of working in the current school was statistically significant and contributes to model building.

\section{Social Classroom Climate within the Context of Adolescent Development-Ecological Developmental Theory and Cultural Ecological Theory}

In a study of adolescent development and behavior, Eccles et al. (1993) recognized that this stage of human development, more than any other, is characterized by changes on multiple levels. During this phase, individuals undergo physical, cognitive, and social redefinitions. This period is also the transitional phase-from elementary to middle school - and has been identified as a pivotal stage in determining the trajectory of an individual's school success (Balfanz, 2009).

In fact, depending on ethnicity, approximately $15-30 \%$ of adolescents drop out of school. Additionally, adolescents have a higher rate of deviant behavior than any other age group (Eccles et al., 1993). This period is also a crucial phase for student identity development with ethnic identity formation being especially salient. Forming a healthy 
concept of identity is essential to the mental health of an individual (French, Seidman, Allen \& Aber, 2006). Furthermore, educators have recognized that of all the other educational stages, the middle school experience has the greatest impact on either widening or closing achievement gaps (Balfanz, 2009).

To help both teachers and students manage such issues, the National Middle School Association (2006) suggests the creation of school systems that are safe, stimulating, and supportive, with organizational structures that promote high expectations, collaboration, and continual learning. Moreover, supportive relationships between students and adults, extra support to successfully transition through this period, and assistance in meeting challenging course standards are also instrumental for helping students achieve success (Southern Regional Education Board, 2008). Unfortunately, rather than being the benefactors of such experiences many middle school students still receive an inadequate education (National Middle School Association, 2006).

The ecological systems theory suggests that inadequate education is directly associated to the environment in which adolescent students are educated. This theory was first developed and articulated by Urie Bronfenbrenner. He posits that the development of individuals and their actions and beliefs are influenced by the immediate environment as well as interactions with a larger culture in that immediate environment. This framework considers both the uniqueness of each level and the interactions between these complex and overlapping systems, and acknowledges that changes or conflicts in one system will ripple through the others. According to Bronfenbrenner (1976), these interactions take place at four levels — microsystem, mesosystem, exosystem, and macrosystem — with 
each of these systems encompassing the experiences of the immediate environment, community, culture, and current societal demands, respectively.

The first system, microsystem, refers to the "physical setting in which the individual lives, works, and/or socializes" (Bartholomew, 2007, p. 49). It focuses on interpersonal relationships and patterns in habitual activities and physical settings, which have a profound influence on the actions and beliefs of individuals (Bartholomew, 2007). The next system, which is termed the mesosystem, considers interactions that occur between multiple settings in which an individual functions. The relationship between these settings is important, as individuals are generally influenced by the people, activities, and rules that operate within these multiple settings (Bartholomew, 2007).

The exosystem describes the indirect social context that influences an individual. These interactions "affect the activities, beliefs, and actions of their immediate environment and influence the individual's interactions within this environment" (Bartholomew, 2007, p. 50), which is inclusive of the cultural environment. For a teacher or student, this could be a classroom, school, or community culture (Bartholomew, 2007).

The last system articulated by Bronfenbrenner (1976) in his ecological systems theory is the macrosystem. This system incorporates the ideological patterns of society and their influence on individuals and everyday activities. This system is described as ever-changing and constantly affects the beliefs of society and the individual at all system levels. Societal legislations, values, current events, and political movements comprise the macrosystem (Bartholomew, 2007).

Through examining these systems, educational researchers have been able to explore and understand classroom dynamics in addition to the requisite tools and skills 
needed to create optimal learning environments for adolescent students. With this approach, the focus shifts to the human side of school and advocates widening the school's aim from solely economic and academic goals, because success in these areas is dependent on several human elements (Gould, 2007). Moreover, this ecological framework takes into consideration the complex web of individuals, social norms, attitudes, and environmental factors that influence student success, i.e., it addresses complex and interdependent human systems. Therefore, through this approach, the importance of caring and motivational relationships - as well as the creation of friendly, non-coercive, and supportive environments and individual differences - is recognized and taken into account.

This model is critical because it showcases how personal experiences shape the manner in which individuals negotiate intellectual life. This theory is similar to John Ogbu's theory of cultural ecology. In this theory, Ogbu articulates the notion that perceptions of different cultural groups and their treatment in schools and in a larger social context, influence their perception of schools and other social systems, which in turn may affect students' learning and achievement (Gould, 2007). According to Ogbu's theory, this scenario occurs because certain minorities enter school systems with distinctive cultural and language patterns diverged from the dominant culture's norms and expectations. These alternative behaviors, which are often tied to a minority students' sense of identity, tend to lead to cultural clashes in the classroom, which can facilitate academic failure (Foster, 2004).

In an effort to mitigate these challenges, culturally relevant pedagogy is critical. Waits, Campbell, Gau, Jacobs, Rex, and Hess (2006) document this notion in their study 
regarding differences in Latino student performances. In their study, they discovered that schools that utilized customized educational methods to fit individual needs, more than those that adopted a one-size-fits-all approach, had more success in relation to student performance.

Loukas and Robinson (2004) examined the relationship between student perception of the educational climate and adolescent effortful control in conduct problems and depressive symptoms. The study utilized hierarchal regression with 868 10-14-year-old adolescents. The authors found that among boys, there were lower reports of depressive systems, and among girls, fewer conduct problems were reported in classrooms with good, quality climates.

Wang and Holcombe (2010) investigated middle school students' perceptions of the school environment, school engagement, and academic achievement. The sample for this study consisted of 1,046 ethnically diverse, urban students. The study found that students' perceptions of their school environment influenced their academic achievement. This influence had both a direct and indirect impact on three types of school engagement. That is, the students' perceptions of school characteristics in previous grades influenced their school participation, identification with the school, and use of self-regulation strategies in the following grade, which in turn impacted their academic achievements in the higher grade.

Wang and Dishion (2012) examined trajectories of change in adolescents' perceptions of four dimensions of school climate and whether school climate moderated the associations between deviant peer affiliation and adolescent problem behaviors. To achieve this goal, 1,030 adolescents from 8 schools were followed from sixth through 
eighth grade. The researchers found that behavioral problems based on peer affiliation were moderated by the adolescents' perceptions of school climate. They further found that when the quality of the dimension associated with climate declined, deviant peer affiliation and behavioral problems increased.

Wang, Brinkworth, and Eccles (2013) examined the relationship between student characteristics of effortful control and classroom climate, as defined by the studentteacher relationship and parent-adolescent conflict and its impact on adolescent depression and misconduct. The study utilized a sample of 1,400 urban youths ages of 13-18. The results demonstrate that regardless of gender, good student-teacher relationships moderate not only the school's behavior problems, but also the negative effects of conflictive parent-adolescent relationships.

This finding brings the importance of the adolescent period to the forefront. Undoubtedly, adolescence is the most pivotal developmental experience that individuals undergo. Every aspect of the child — physical, mental, emotional, and cognitive —is impacted during this period. The theories and research noted above illustrate that school performance depends heavily on personal experiences and individual nuances such as developmental, social, and cultural experiences. Furthermore, they illustrate that the ecology of classroom climate/environment during this period is a crucial determinant for creating optimal learning conditions, which facilitate student success rather than failure.

\section{Need for Further Study}

This literature review has offered evidence regarding the importance of the social classroom climate and its impact on student performance. It has shown that adolescence is a period when the social environment is of particular importance because it heavily 
influences student trajectories for behavior, mental outlook, and academic performance. It also has provided theories and models which address cultural competence and its role in creating positive social environment in schools.

However, while there is a wide selection of studies related to the social classroom climate, adolescent development, and cultural competence independently, to date there are only a few studies that have investigated the interaction between these variables and their influence on creating a positive social classroom environment (Bear et al., 2011; Brand, et al., 2003; Marks, 2011; Robinson, 2012; Wells-Rivers, 2011). These studies illustrate the connection between student characteristics such as culture and their classroom environment. They emphasize that when students recognize the implementation of fair and equitable rules, both academic achievement and psychological well-being are enhanced, i.e., when teacher exhibit and utilize cultural competency a positive social classroom environment results.

This information is important since cultural mismatches in the classroom can lead to maladaptive behaviors, such as lack of motivation and engagement, behavioral problems, and poor academic performance. These issues, however, can be mitigated by developing a positive social classroom climate, which is indeed particularly important for adolescent students (Barth et al., 2004; Colombo, 2005; Roland \& Galloway 2002; Ryan \&Patrick, 2001). The current study adds to the limited body of literature by providing further perspectives regarding the interactions of cultural competence and its role in influencing students' perceptions of the classroom social environment in culturally different middle schools 


\section{CHAPTER 3}

\section{METHODOLOGY}

This chapter describes the design, methods, and procedures utilized for this research study. It is organized into the following sections: research design, population and sample, definition of variables, instrumentation, data collection, data analysis schedule, and budget. The purpose of this exploratory study is to investigate teachers' levels of cultural competency, their ethnicity, years of teaching experience and level of education as well as the student demographic characteristics of SES, ethnicity and gradelevel and the relationship to students' perception of the social classroom climate in a culturally different middle school.

\section{Research Design}

This study examines the relationship between teacher cultural competency and students' perceptions of the social classroom climate using a quantitative, nonexperimental, correlational, cross-sectional, survey research design. Quantitative analysis is utilized because it facilitates the development of mathematical models, theories, or hypotheses that relate to the phenomena being observed (Thomas, 2003). This research process is central because it provides the possibility of mathematical expression concerning the connection between empirical observations (Thomas, 2003).

Furthermore, this study relies on interpretation, observations or interactions in order to draw conclusions that determine the extent to which the variables are related. 
This is achieved by utilizing survey instruments to quantify the variables under study (McMillan \&Schumacher, 2010). Accordingly, the researcher did not implement a treatment, manipulate a variable, nor use random assignment procedures. The data collected reflects the current atmosphere of the classroom environment as perceived by the sample population of the study. Therefore, the data analysis describes teachers' perceptions of cultural competence and its relationship to students' perceptions of the social classroom environment in this particular environment.

A survey design will be used because it facilitates a quantitative description of trends, attitudes and characteristics of a population sample (Creswell, 2008).

Additionally, generalizations can be made from a sample to a population through survey research (Groves, Fowler, Couper, Lepkowski, Singer, \& Tourangeau, 2004). In this study, the survey is particularly preferential because of its accessibility, costeffectiveness, time efficiency and quick distribution and response cycle (Andrews, Nonnecke, \& Preece, 2003).

There are, however, limitations in regard to the use of surveys. These limitations include the administration of instruments in a relatively uncontrolled, real-world setting or the possibility of confounding variables which can impact survey results. For instance, previous interactions resulting in cross-cultural misunderstandings can lead to inaccurate information relating to the perception of cultural competence on the part of the teacher or the social classroom atmosphere on the part of students. Additionally, because survey methodology utilizes the inferential power of sampling, generalizations can be limited to the sample rather than a larger population (Groves et al., 2004). 


\section{Population and Sample}

The population for this study were the teachers and students of a Public School District in Michigan (MI). This school district included one high school, one middle school, two elementary schools, a virtual and discovery academy as well as a home school partnership program. The MI School Data website reports that in 2013-2014, this district had a K-12 enrollment count of 2,448 students. Of these students, $58.9 \%$ are economically disadvantaged with a gender distribution of $53.27 \%$ male and $46.73 \%$ female. The reported student race/ethnicity breakdown is American Indian .45\%, African American 20.59\%, Asian or Pacific Islander 5.56\%, Hispanic of any race $11.93 \%$, Native Hawaiian $.65 \%$, two or more races $4.45 \%$, White $56.37 \%$. Regarding teachers, the MI School Data website reports a total of 135 teachers with $100 \%$ being categorized as effective or more and 5\% regarded as highly effective.

This study, however, will focus specifically on early adolescent/ middle school students. The MI School Data website reports that the only middle school in the district is comprised of 439 students and 25 teachers. Of these students, $62.41 \%$ are economically disadvantaged with a gender distribution of $53.57 \%$ male and $46.73 \%$ female. The reported student race/ethnicity breakdown is American Indian .46\%, African American 24.6\%, Asian or Pacific Islander 10.02\%, Hispanic of any race 12.98\%, Native Hawaiian $.91 \%$, two or more races $5.69 \%$, White $45.33 \%$. This student population is divided into $6^{\text {th }}, 7^{\text {th }}$, and $8^{\text {th }}$ grade. Submission of consent and assent forms was a self-selection delimiting factor which produced a convenience sample of 24 teachers and 150 students. 


\section{Null Hypotheses}

The null hypotheses which inform this current study are as follows:

1. There is no relationship between the second level variables of teacher cultural competency, ethnicity, educational level, and years of teaching experience and first level variables of student grade-level, gender, SES, and ethnicity in predicting the students' perception of the "teacher emotional support" factor of the social classroom climate in culturally different classrooms in a Midwest Public Middle Schools district.

2. There is no relationship between the second level variables of teacher cultural competency, ethnicity, educational level, and years of teaching experience and first level variables of student grade-level, gender, SES, and ethnicity in predicting the students' perception of the "teacher academic support" factor of the social classroom climate in culturally different classrooms in a Midwest Public Middle Schools district.

3. There is no relationship between the second level variables of teacher cultural competency, ethnicity, educational level, and years of teaching experience and first level variables of student grade-level gender, SES, and ethnicity in predicting the students' perception of the "promotion of mutual respect" factor of the social classroom climate in culturally different classrooms in a Midwest Public Middle Schools district.

4. There is no relationship between the second level variables of teacher cultural competency, ethnicity, educational level, and years of teaching experience and first level variables of student grade-level, gender, SES, and ethnicity in 
predicting the students' perception of the "promotion of task-related interaction" factor of the social classroom climate in culturally different classrooms in a Midwest Public Middle Schools district.

\section{Definition of Variables}

The primary explanatory variable for this study was the measure of cultural competence. "Cultural competence is the ability to successfully teach students who come from cultures other than your own. It entails having awareness and sensitivity to various bodies of knowledge, and skills" (Moule, 2012, p. 19). Twenty items measure the primary explanatory variable. These items included statements such as "I am aware of the diversity of cultural backgrounds in my classroom.", "Teachers have the responsibility to be aware of their students' cultural backgrounds.", "Teaching methods need to be adapted to meet the needs of a culturally diverse student group." (Ponterotto et al., 1998, p.1). This interval variable scores can range from 20-100.

This study also utilizes a social desirability control variable. Thirty items measure this variable. These items included statements such as "Most of my close friends are from my own racial group.", "I think that it is (or would be) important for my children to attend schools that are racially mixed." "In the past few years, there has been too much attention directed towards multicultural issues in business" (Ponterotto et al., 1998, p. 2). This interval variable scores can range from 30-150.

The response variable in this study was students' perception of the social classroom climate. The social classroom climate is the atmosphere of the class as a social group. This is defined by the factors of teacher support, promotion of mutual respect and promotion of task-related interaction (Patrick et al., 2007; Patrick et al., 2011). The 
response variable is interval and measured by the 16 items from four sub-constructs. These include two measures of teacher support, promotion of mutual respect, and promotion of task-related interaction.

The sub-construct of teacher emotional support refers to the "belief that the teacher cared about and liked the student as a person" (Patrick et al., 2007; Patrick et al., 2011). The items included statements such as "Does your teacher try to help you when you are sad or upset?", "Can you count on your teacher for help when you need it?" (Patrick et al., 2007, p. 97). This factor was measured by four items, numbered 1-4 on the SCCM and scores range from 4-20.

Teacher academic support refers the belief that the "teacher cared about how much the student learned and wanted to help him or her learn" (Patrick et al., 2007; Patrick et al., 2011). The items included statements such as, "Does your teacher like to see your work?", "Does your teacher care about how much you learn" (Patrick et al., 2007, p. 97). This factor was measured by four items, numbered 5-8 on the SCCM and scores range from 4-20.

The sub-construct of promoting task-related interaction measures the "extent to which the teacher was perceived as encouraging interaction among peers around academic tasks" (Patrick et al., 2007; Patrick et al., 2011). This factor included statements such as "My teacher encourages us to share ideas with one another in class" (Patrick et al., 2007, p. 97). This factor was measured by five items numbered 9-13 on the SCCM and scores range from 5-25.

Finally, the sub-construct of promoting mutual respect "will assess the extent to which the teacher is perceived as encouraging respect among classmates" (Patrick et al., 
2007, p. 97). Items included statements such as "My teacher makes sure that students don't say anything negative about each other in class" (Patrick et al., 2007; Patrick et al., 2011). This factor was measured by three items numbered $14-16$ on the SCCM and scores range from 3-15.

The teacher demographic variables of ethnicity, educational level, and years of teaching experience and student demographic characteristics of grade-level, gender, SES, and ethnicity are examined. These variables were chosen based on previous research in intercultural sensitivity (Straffon, 2001; Westrick \& Yuen, 2007) and cultural intelligence (Sims, 2011). In regard to SES, Nicholson, Slater, Chriqui, and Chaloupka (2014) reported that free or reduced lunch (FRL) is a valid measure of youth SES. They predicated this argument on a strong research base and their study indicated that FRL was strongly and significantly associated with other measures of SES. As such the current study utilizes FRL as a measure of SES.

\section{Instrumentation}

The central relationship under examination is the extent and manner in which cultural competency predicts students' perceptions of the social classroom climate. This analysis also takes into consideration the students' demographic characteristics of gradelevel, gender, SES, and ethnicity. To achieve the desired result three data collection instruments were utilized for this study.

The first data collection instrument used was the Teacher Multicultural Attitude Survey (TMAS). This instrument is an interview protocol designed to determine the extent to which teachers are prepared to teach culturally diverse student populations. The second was the Quick Discrimination Index (QDI). In the study, this instrument was 
utilized to control social desirability and solidify the results of the TMAS. The final instrument was the Social Classroom Climate Measure (SCCM). This survey was designed to assess students' perceptions of the social classroom climate regarding the factors of teacher support, mutual respect, and promotion of task-related interaction. The particulars of these instruments are outlined below.

\section{Teacher Multicultural Attitude Survey}

The TMAS (1996) survey was developed to evaluate the attitudes of K-12 teachers in regard to their ability to teach culturally diverse student populations. In particular, it was created to reflect on teachers' multicultural awareness, appreciation, and tolerance. The scale was developed from a literature review on multicultural sensitivity and competence (Ponterotto et al., 1998). The 20-item TMAS is a unidimensional measure of teachers' multicultural awareness. It asks respondents for their degree of agreement based upon a 5-point Likert-type scale ranging from strongly agree to strongly disagree, where higher scores reflect a greater degree of multicultural awareness and sensitivity (Uebersax, 2006). Construct validity of the TMAS was supported through convergent correlations with the QDI racial and gender equity subscales, while criterion validity was established using the group differences approach with sample cohort groups (Ponterotto et al., 1995; Ponterotto et al., 1998). Reliability estimates have been reported to be as high as .86; test-retest stability was .80 over a 3 -week period (Ponterotto et al., 1998; Lester \& Bishop, 1997). 


\section{Quick Discrimination Index}

The QDI racial and gender equity subscales were also utilized to control social desirability as it relates to the TMAS (Ponterotto et al., 1995). The QDI is a 30-item test that measures racial and gender bias among late adolescents and adults; it is titled the Social Attitude Survey (SAS). The items are placed on a 5-point Likert-type scale that ranges from 1 (strongly disagree) to 5 (strongly agree). Exploratory and confirmatory factor analyses support the reliability and validity of this measure, with coefficients as high as .85 (Ponterotto et al., 1995; Utsey \& Ponterotto, 1999).

For this research study, the researcher modified the survey instruments to include three demographic questions. These demographic variables were chosen based on previous studies that explored teacher cultural sensitivity and intelligence (Sims, 2011; Straffon, 2001; Westrick \& Yuen, 2007). Permission to use the TMAS and the QDI was granted to the researcher by the developer of both instruments, Joseph G. Ponterotto.

\section{Social Classroom Climate Measure}

The SCCM $(2007,2011)$ survey was developed to assess middle school students' perception of the social classroom climate. This scale has four sub-constructs. The two sub-constructs related to teacher academic and emotional support have been adapted from the Classroom Life Measure developed by Johnson and Johnson (1983) (as cited in Patrick et al., 2007). The other two sub-constructs, mutual respect and promotion of taskrelated interaction were developed and refined by Ryan \& Patrick 2001, 2005, Patrick et al., 2007 and Patrick et al., 2011.

Cronbach's alpha was used to determine the internal consistency of the scales. Of the measures of internal consistency, Cronbach's alpha is the most widely reported 
measure of reliability for attitude and rating scales in psychological research (Ponterotto \& Ruckdeschel, 2007). The four scales, in general, were showed to be internally consistent with coefficients for the various scales ranging from .68 to .84 (Patrick \& Ryan, 2005; Patrick et al., 2011). The teacher emotional support scale, and teacher academic support scale consisted of four items, the classroom mutual respect scale consisted of five items and the task-related interaction scale consisted of three items $\alpha=$ $.84, .76, .68$ and .70 respectively (Patrick et al., 2011).

Reliability of the four scales has been examined through exploratory factor analysis. These factor analyses were conducted on all the scales and separately on gender and ethnicity. The factor loadings for the scales were .44 and above with no cross-loaded items indicating that the scales were reliable (Patrick \& Ryan, 2005). Scores on this scale have been psychometrically strong in other studies and shown to be both reliable and valid across different samples of adolescents (Patrick \& Ryan, 2005). The survey instrument will be modified by the researcher to include four demographic questions relating to grade-level, gender, race/ethnicity and SES. These demographic variables were chosen based on previous studies that explored student-teacher interaction within a cultural context (Sims, 2011; Straffon, 2001; Westrick \& Yuen, 2007). The researcher was granted permission to use the Social Classroom Climate Scale by the developers of the instrument Helen Patrick, Allison Ryan and Avi Kaplan.

\section{Data Collection}

The sample in this study consists of teachers of and students in grades six through eight from a public school, where a high percentage of students identify as culturally diverse. To obtain such a sample, the principal investigator conducted research 
to determine which schools met the criteria. The MI School Data website was utilized to identify schools within a particular Midwest Regional Education Service Agency (RESA) that could be used as the sample population for this study. This RESA was selected on account of its availability and accessibility. This search yielded two schools. The researcher contacted the principals of those schools via voice message and email. Of the two principals contacted, one responded and agreed to a research presentation meeting. After the meeting, the principal granted the researcher permission to conduct the study at the school site. The principal then prepared a letter to be sent to the Andrews University Internal Review Board to inform them that permission to conduct the study at the school site was granted.

This research study is sensitive to both the ethical and moral issues concerning the protection of human subjects. As such, the researcher closely followed procedures established by the Institutional Review Board to gain permission to conduct the research study. The procedures followed are outlined below.

The principal organized a staff meeting at the school site, where the teachers had the opportunity to attend and receive information regarding the study. At this meeting, teachers were given a chance to ask questions as well as clarify any misconceptions regarding the study. The teachers were invited to participate in the study and issued the participant's informed consent. Teachers who agreed to take part in the study returned the informed consent to the researcher. At the staff meeting, teachers who returned the informed consent received a copy of the survey, which they completed and returned to the principal investigator. The survey was placed in a sealed envelope to maintain confidentiality. Through this procedure, the researcher intended to minimize the amount 
of disruption to participants and classroom instruction. Moreover, while an invitation was extended to all teachers, they reserved the right to decline their participation or withdraw from the study at any time.

At the beginning of a designated class period, the teachers who agreed to participate in the study informed students about the research. The teachers then distributed two forms and two letters to the students: the Parental Consent and Student Assent forms as well as two letters from the principal. One letter assured parents that institutional consent had been granted, and the other-from the researcher-informed both the parents and students of the purpose and context of the study. All students were notified that the Parental Consent must be reviewed, signed by a parent/legal guardian, and returned. Students were also told that only those who returned signed consent forms to their teachers by the deadline would be permitted to participate in the study. Students indicated their agreement to participate in the study by placing the signed consent forms in a sealed envelope and turning it in to the school's secretary within one week from the day they received them. The researcher then collected all the returned consent forms from the school secretary.

The Parental Consent included a statement that participation is voluntary and the participant has the right to withdraw at any time. The consent form included the following sections: the purpose of the study, procedures of the study, the benefits of the study, a reassurance of anonymity, the researcher's contact information for questions, and contact information for the researcher's faculty advisor regarding issues of the study. Once the consent forms were returned, a day was selected to collect the survey data. On the chosen day, the principal researcher, along with a research assistant, began the data 
process. Before the data collection, however, the research assistant was informed of the process to be followed and the instructions to be given to students. On the designated day, the researcher was assigned to a classroom. Just before the students' lunch period, the teachers announced to students that those who had returned a consent form and wished to participate in the research project could proceed to the designated classroom; those who did not could proceed to the cafeteria.

The data was collected in a manner that ensured confidentiality and anonymity. The participants of the study were not asked to reveal any personal identification, such as names or social security numbers, on any of the research instruments. Grade-level teachers were nested to students of their entire grade. This was done to ensure that no identifying information could be used to determine which teachers or students were from a particular classroom. Furthermore, only the aggregate results of the study will be available to the school to ensure the confidentiality and anonymity of the participants. The instructions followed on entrance of the assigned classroom were as follows:

- The teacher introduced the researcher and left the room.

- The researcher informed the students that only those who have returned the relevant forms would be allowed to participate.

- Before distributing the questionnaire, the researcher read the assent form and informed the students of their right to refuse participation or withdraw at any point without repercussion. Participants were also told that the questionnaires would be numbered, but no identifying marks were to be placed upon them.

- They were informed that this was done to protect their confidentiality.

- The researcher distributed the survey and read the survey instructions aloud. 
- Participants were given approximately 20 minutes to complete the questionnaire.

- The students were instructed to bring the completed instruments to the front desk to the researcher.

- At the end of this process, the participating teachers and students received their participation incentives.

- Teachers received a $\$ 15.00$ Visa gift certificate and students participated in a pizza party.

The surveys were printed on a form and, once collected by the principal investigator, scanned into a database. The hard copies were placed in envelopes, sealed, and stored in a location accessible only to the principal researcher for the stipulated timeframe; after this time, they will be shredded.

\section{Data Analysis}

The Statistical Program for the Social Sciences (SPSS 22.0) was used as the primary tool for data screening and analysis. This study utilized descriptive, inferential, and multivariate statistical analyses. The research questions posed for the study required

the use of Hierarchical Linear Modeling (HLM). This statistical technique was necessary in this study in order to "analyze variance in the outcome variables [because] the predictor variables are at various hierarchical levels" (Woltman, Feldstain, MacKay, \& Rocchi, 2012, p. 52).

In essence, this statistical method takes into consideration that "students in the classroom share variance according to their common teacher and common classroom" (Woltman et al., 2012, p. 52). This study seeks to examine the variance at these levels. 
Additionally, with a convenience sample, this study is exploratory in nature. As such, there was no manipulation of an independent variable, and the terms predictor and outcome variables are used to describe the relationship between an independent and dependent variable.

\section{Hierarchical Linear Modeling}

Hierarchical data structures consist of lower-level observations nested within higher-level(s) (Kreft \& Leeuw, 1998). For instance, students nested within classes, patients nested within hospitals and the like. Because of such naturally occurring clusters, data is often collected on variables at both the lower-level and the higher-level(s) of the hierarchy. In this study, for example, there are lower-level variables describing students, e.g. gender, ethnicity as well as higher level variables describing teachers e.g. years of teacher experience, educational level. The primary purpose of multilevel models is to capture the particular relationship between the lower-level and the higher-level(s) variables and the outcome variable (Kreft \& Leeuw, 1998).

\section{Advantages of HLM}

The nature of multilevel models allows predictor variables to be conceptually defined at different levels; hypothesized relationships between these predictor variables are able to operate across different levels (Luke, 2004). In essence, the data in multilevel models can be analyzed in the context of the level and relation to the other levels (i.e., within and between groups). Another advantage of using multilevel models relates to the issue of statistical or structural properties of the data. By accounting for "within and between group" variabilities at two or more levels simultaneously, HLM can estimate 
appropriate, unbiased errors (Luke, 2004). In addition, multilevel models allow for an estimation of cross-level interactions between higher-level and lower-level variables on the outcome of interest. Finally, unlike traditional statistical approaches where the sample size must meet specific criteria, multilevel models are powerful because they can handle a relatively small sample size. Although a larger sample size would likely increase the power of the study, multilevel models can be robust if the higher-level sample size is at least 20 (Hox, 1995).

\section{Treatment of Missing Data}

Of the sample collected, there were only a few instances where missing data were found. Because the minimal number of missing cases, the value missing was replaced by the sample mode. This process was completed using SPSS 22.

\section{Descriptive Analysis}

Descriptive statistics such a frequencies and means were computed for the criterion and predictor variables for student level and teacher level. Additionally, figures and tables were used to display distributions of both criterion and predictor variables included in the study. This process was completed using SPSS 22.

\section{Correlation Analysis}

The bivariate relationships between level-1 predictor variables and level-2 predictor variables were also examined. Tables were used to display the relationship between the variables in the study. This process was completed using SPSS 22. 


\section{HLM Analysis}

Both students who were nested to their grade-level teachers and the teachers to whom they were nested provided data for the study. There were approximately six students for every teacher. The data analysis was accomplished using HLM, a multilevel regression technique that is useful when analyzing nested data (Raudenbush \& Bryk, 2002). First, in order to proceed with HLM, the number of levels in the data needed to be specified, and models needed to be constructed.

The study data is best described in two levels: the student level (level-1) and teacher level (level-2). Level-1 was represented by student background variablesgender, ethnicity, and SES, as represented by lunch qualification-and the SCCM, which is described as teacher academic support, teacher emotional support, mutual respect, and promotion of task-related interaction. Level-2 was represented by teacher background variables as represented by ethnicity, years of teaching experience, and educational level as well as the measure of teacher cultural competence.

\section{Recoding Predictor Variables for HLM Analyses}

To improve interpretability of the results, both level-1 and level-2 nominal predictor variables were recoded into dummy variables. In addition, for the level-2 variables of teacher cultural competence, seven scale items were reversed scores, following which the items were summed to attain cultural competence scores. The predictors at both levels also were grand-mean centered. 


\section{Models of the Study}

The intent of this study to the construct HLM models to represent level-1 and level-2 of the data for each of the four factors of the social classroom climate. The following models are the hypothesis models to be built. The first model is the baseline or unconditional model which had no level-1 or level-2 variables. The regression equation is as follows.

$$
\begin{aligned}
& Y_{i j}=\beta_{0 j}+r_{i j} \\
& \beta_{0 j}=\gamma_{00}+u_{0 j}
\end{aligned}
$$

In this model, $Y_{\mathrm{ij}}$ is Social Classroom Climate factor score of student $\mathrm{i}$ with teacher $\mathrm{j}$.

$\beta_{\mathrm{j} 0}$ is regression intercept of teacher $\mathrm{j}$.

$\gamma_{00}$ is the overall average Social Classroom Climate factor score for all teachers.

$\mathrm{u}_{0 \mathrm{j}}$ is the random effect of teacher $\mathrm{j}$.

$r_{i j}$ is the random effect of student I with teacher $\mathrm{j}$.

Each of the student background variables (i.e., gender, grade-level, SES, ethnicity) will then entered separately in the unconditional model to make four level-1 models for each factor with a total of sixteen models. Next, a model will be built to include all the significant student background variables on each of the four Social Classroom Climate factors. This model aimed to examine the extent to which student background variables were associated with each factor. The hypothesized regression equations for level-1 follows. 


\section{Level-1 Models}

Teacher emotional support

Model 2: $Y_{\mathrm{ij}}=\beta_{1 \mathrm{j}}$ Gender $_{\mathrm{ij}}+\mathrm{r}_{\mathrm{ij}}$

Model 3: $Y_{\mathrm{ij}}=\beta_{1 \mathrm{j}}$ Gradelevel $_{\mathrm{ij}}+\mathrm{r}_{\mathrm{ij}}$

Model 4: $\mathrm{Y}_{\mathrm{ij}}=\beta_{1 \mathrm{j}} \mathrm{SES}$ (lunch) ${ }_{\mathrm{ij}}+\mathrm{r}_{\mathrm{ij}}$

Model 5: $Y_{i j}=\beta_{1 j}$ Ethnicity $_{i j}+r_{i j}$

Model 6: $Y_{\mathrm{ij}}=\beta_{0 \mathrm{j}}+\beta_{1 \mathrm{j}}$ Gender $_{\mathrm{ij}}+\beta_{2 \mathrm{j}}$ Gradelevel $_{\mathrm{ij}}+\beta_{3 \mathrm{j}}$ SES (lunch) ${ }_{\mathrm{ij}}+\beta_{4 \mathrm{j}}$ Ethnicity $_{\mathrm{ij}}+\mathrm{r}_{\mathrm{ij}}$

$$
\beta_{\mathrm{pj}}=\gamma_{\mathrm{p} 0}+\mathrm{u}_{\mathrm{pj}}, \text { where } \mathrm{p}=0,1,2,3,4
$$

Teacher academic support

Model 07: $\mathrm{Y}_{\mathrm{ij}}=\beta_{1 \mathrm{j}}$ Gender $_{\mathrm{ij}}+\mathrm{r}_{\mathrm{ij}}$

Model 08: $Y_{\mathrm{ij}}=\beta_{1 \mathrm{j}}$ Gradelevel $_{\mathrm{ij}}+\mathrm{r}_{\mathrm{ij}}$

Model 09: $\mathrm{Y}_{\mathrm{ij}}=\beta_{1 \mathrm{j}} \mathrm{SES}\left(\right.$ lunch) ${ }_{\mathrm{ij}}+\mathrm{r}_{\mathrm{ij}}$

Model 10: $\mathrm{Y}_{\mathrm{ij}}=\beta_{1 \mathrm{j}}$ Ethnicity $_{\mathrm{ij}}+\mathrm{r}_{\mathrm{ij}}$

Model 11: $Y_{i j}=\beta_{0 j}+\beta_{1 j}$ Gender $_{i j}+\beta_{2 j}$ Gradelevel $_{i j}+\beta_{3 j}$ SES (lunch) ${ }_{i j}+\beta_{4 j}$ Ethnicity $_{i j}+r_{i j}$

$$
\beta_{\mathrm{pj}}=\gamma_{\mathrm{p} 0}+\mathrm{u}_{\mathrm{pj}} \text {, where } \mathrm{p}=0,1,2,3,4
$$

Mutual respect

Model 12: $Y_{i j}=\beta_{1 j}$ Gender $_{i j}+r_{i j}$

Model 13: $\mathrm{Y}_{\mathrm{ij}}=\beta_{1 \mathrm{j}}$ Gradelevel $_{\mathrm{ij}}+\mathrm{r}_{\mathrm{ij}}$

Model 14: $\mathrm{Y}_{\mathrm{ij}}=\beta_{1 \mathrm{j}} \mathrm{SES}\left(\right.$ lunch) ${ }_{\mathrm{ij}}+\mathrm{r}_{\mathrm{ij}}$

Model 15: $\mathrm{Y}_{\mathrm{ij}}=\beta_{1 \mathrm{j}}$ Ethnicity $\mathrm{ij}_{\mathrm{j}}+\mathrm{r}_{\mathrm{ij}}$

Model16: $Y_{i j}=\beta_{0 j}+\beta_{1 j}$ Gender $_{i j}+\beta_{2 j}$ Gradelevel $_{i j}+\beta_{3 j}$ SES (lunch) ${ }_{i j}+\beta_{4 j}$ Ethnicity $_{i j}+r_{i j}$

$$
\beta_{\mathrm{pj}}=\gamma_{\mathrm{p} 0}+\mathrm{u}_{\mathrm{pj}} \text {, where } \mathrm{p}=0,1,2,3,4
$$


Task-related interaction

Model 17: $\mathrm{Y}_{\mathrm{ij}}=\beta_{1 \mathrm{j}}$ Gender $_{\mathrm{ij}}+\mathrm{r}_{\mathrm{ij}}$

Model 18: $\mathrm{Y}_{\mathrm{ij}}=\beta_{1 \mathrm{j}}$ Gradelevel $_{\mathrm{ij}}+\mathrm{r}_{\mathrm{ij}}$

Model 19: $\mathrm{Y}_{\mathrm{ij}}=\beta_{1 \mathrm{j}} \mathrm{SES}(\text { lunch })_{\mathrm{ij}}+\mathrm{r}_{\mathrm{ij}}$

Model 20: $Y_{i j}=\beta_{1 j}$ Ethnicity ${ }_{i j}+r_{i j}$

Model 21: $Y_{i j}=\beta_{0 j}+\beta_{1 j}$ Gender $_{i j}+\beta_{2 j}$ Gradelevel $_{i j}+\beta_{3 j}$ SES (lunch) ${ }_{i j}+\beta_{4 j}$ Ethnicity $_{i j}+r_{i j}$ $\beta_{\mathrm{pj}}=\gamma_{\mathrm{p} 0}+\mathrm{u}_{\mathrm{pj}}$, where $\mathrm{p}=0,1,2,3,4$

In Model 2-21, $\mathrm{Y}_{\mathrm{ij}}, \beta_{0 \mathrm{j}}, \gamma_{00}, \mathrm{u}_{0 \mathrm{j}}$, and $\mathrm{r}_{\mathrm{ij}}$ are as defined in the Baseline Model above. $\beta_{1 \mathrm{j}}$ to $\beta 6 \mathrm{j}$ refer to regression slopes of teacher $\mathrm{j}$ $\gamma_{0 p}$ refer to the level 2 fixed effects $\mathrm{u}_{\mathrm{pj}}$ refer to the level 2 random effects

Similarly, at level-2, each of the teacher background variables (i.e., cultural competency, ethnicity, educational level and years of teaching experience) will be entered separately in Models $6,11,16 \& 21$. Additionally, to estimate the amount of variance for which this set of variables accounts, combined models may also be constructed. Finally, Models 26, 31, 36, 41 represented the full model which will include all significant level-2 variables and cross-level interaction terms that were statistically significant in earlier models. All level-2 models included random errors. The purpose of the level-2 models was to examine the relationship of teacher cultural competency, ethnicity, educational level and years of teaching experience as well as possible crosslevel interactions of these variables and student perception of the social classroom climate. The regression equations for these models follows. 


\section{Level-2 Models}

Teacher emotional support

Model 22: $\beta_{\mathrm{pj}}=\gamma_{\mathrm{p} 0}+\gamma_{\mathrm{p} 1}$ Cultural Competency $+\mathrm{u}_{\mathrm{pj}}$

Model 23: $\beta_{\mathrm{pj}}=\gamma_{\mathrm{p} 0}+\gamma_{\mathrm{p} 1}$ Ethnicity $+\mathrm{u}_{\mathrm{pj}}$,

Model 24: $\beta_{\mathrm{pj}}=\gamma_{\mathrm{p} 0}+\gamma_{\mathrm{p} 1}$ Education level $+\mathrm{u}_{\mathrm{pj}}$

Model 25: $\beta_{\mathrm{pj}}=\gamma_{\mathrm{p} 0}+\gamma_{\mathrm{p} 1}$ Teaching experience $+\mathrm{u}_{\mathrm{pj}}$,

Model 26: $\beta_{\mathrm{pj}}=\gamma_{\mathrm{p} 0}+\gamma_{\mathrm{p} 1}$ Cultural Competency $+\gamma_{\mathrm{p} 2}$ Ethnicity $+\gamma_{\mathrm{p} 3}$ Education level $+\gamma_{\mathrm{p} 4}$ Teaching experience $+\mathrm{u}_{\mathrm{pj}}$

Teacher academic support

Model 27: $\beta_{\mathrm{pj}}=\gamma_{\mathrm{p} 0}+\gamma_{\mathrm{p} 1}$ Cultural Competency $+\mathrm{u}_{\mathrm{pj}}$,

Model 28: $\beta_{\mathrm{pj}}=\gamma_{\mathrm{p} 0}+\gamma_{\mathrm{p} 1}$ Ethnicity $+\mathrm{u}_{\mathrm{pj}}$,

Model 29: $\beta_{\mathrm{pj}}=\gamma_{\mathrm{p} 0}+\gamma_{\mathrm{p} 1}$ Education level $+\mathrm{u}_{\mathrm{pj}}$,

Model 30: $\beta_{\mathrm{pj}}=\gamma_{\mathrm{p} 0}+\gamma_{\mathrm{p} 1}$ Teaching experience $+\mathrm{u}_{\mathrm{pj}}$,

Model 31: $\beta_{\mathrm{pj}}=\gamma_{\mathrm{p} 0}+\gamma_{\mathrm{p} 1}$ Cultural Competency $+\gamma_{\mathrm{p} 2}$ Ethnicity $+\gamma_{\mathrm{p} 3}$ Education level $+\gamma_{\mathrm{p} 4}$ Teaching experience $+\mathrm{u}_{\mathrm{pj}}$

Mutual respect

Model 32: $\beta_{\mathrm{pj}}=\gamma_{\mathrm{p} 0}+\gamma_{\mathrm{p} 1}$ Cultural Competency $+\mathrm{u}_{\mathrm{pj}}$

Model 33: $\beta_{\mathrm{pj}}=\gamma_{\mathrm{p} 0}+\gamma_{\mathrm{p} 1}$ Ethnicity $+\mathrm{u}_{\mathrm{pj}}$,

Model 34: $\beta_{\mathrm{pj}}=\gamma_{\mathrm{p} 0}+\gamma_{\mathrm{p} 1}$ Education level $+\mathrm{u}_{\mathrm{pj}}$,

Model 35: $\beta_{\mathrm{pj}}=\gamma_{\mathrm{p} 0}+\gamma_{\mathrm{p} 1}$ Teaching experience $+\mathrm{u}_{\mathrm{pj}}$,

Model 36: $\beta_{\mathrm{pj}}=\gamma_{\mathrm{p} 0}+\gamma_{\mathrm{p} 1}$ Cultural Competency $+\gamma_{\mathrm{p} 2}$ Ethnicity $+\gamma_{\mathrm{p} 3}$ Education level $+\gamma_{\mathrm{p} 4}$ Teaching experience $+\mathrm{u}_{\mathrm{pj}}$ 
Task-related interaction

Model 37: $\beta_{\mathrm{pj}}=\gamma_{\mathrm{p} 0}+\gamma_{\mathrm{p} 1}$ Cultural Competency $+\mathrm{u}_{\mathrm{pj}}$

Model 38: $\beta_{\mathrm{pj}}=\gamma_{\mathrm{p} 0}+\gamma_{\mathrm{p} 1}$ Ethnicity $+\mathrm{u}_{\mathrm{pj}}$,

Model 39: $\beta_{\mathrm{pj}}=\gamma_{\mathrm{p} 0}+\gamma_{\mathrm{p} 1}$ Education level $+\mathrm{u}_{\mathrm{pj}}$,

Model 40: $\beta_{\mathrm{pj}}=\gamma_{\mathrm{p} 0}+\gamma_{\mathrm{p} 1}$ Teaching experience $+\mathrm{u}_{\mathrm{pj}}$,

Model 41: $\beta_{\mathrm{pj}}=\gamma_{\mathrm{p} 0}+\gamma_{\mathrm{p} 1}$ Cultural Competency $+\gamma_{\mathrm{p} 2}$ Ethnicity $+\gamma_{\mathrm{p} 3}$ Education level $+\gamma_{\mathrm{p} 4}$ Teaching experience $+\mathrm{u}_{\mathrm{p} j}$,

In Model 22-42, $\mathrm{Y}_{\mathrm{ij}}, \beta_{0 \mathrm{j}}, \gamma_{00}, \mathrm{u}_{0 \mathrm{j}}$, and $\mathrm{r}_{\mathrm{ij}}$ are as defined in the baseline model above. $\beta_{1 \mathrm{j}}$ to $\beta 4 \mathrm{j}$ and $\mathrm{u}_{\mathrm{pj}}$ are as defined in the Level 1 models $\gamma_{\mathrm{p} 0}$ to $\gamma_{\mathrm{p} 4}$ refer to the level 2 fixed effects

\section{Summary}

In summary, hypothesis 1 was addressed by using statistical results from the unconditional model, models 2-6 and 22-26. This allowed for inferences to be made about the extent to which student background variables (i.e., gender, grade-level, ethnicity, and SES) and teacher background variables (i.e., cultural competency, ethnicity, educational level and teaching experience) were associated with student perception of the "teacher emotional support" factor. As for hypothesis 2, findings from the unconditional model, Models 7-11 and 27-31 will be used to make inferences about the extent to which student background variables and teacher background variables were associated with student perception of the "teacher academic support" factor of social classroom climate. Regarding hypothesis 3, inferences will be made regarding the extent to which student background variables and teacher background variables are associated with student perception of the mutual respect factor of social classroom climate. This will 
be achieved by using statistical results from the unconditional model and Models 12-12

and 32-36. Finally, Model 17-21 and 37-41 and the unconditional model will address hypothesis 4 regarding the relationship between the student and teacher-related variables on the promotion of task-related interaction factor of social classroom climate. By examining such patterns of relationships, this study intends to identify significant trends or relationships that may exist between these variables. 


\title{
CHAPTER 4
}

\section{RESULTS}

\begin{abstract}
Sample
Submission of consent and student assent forms was a self-selection delimiting factor which produced a convenience sample of 24 teachers and 150 students. Of the sample collected, there were only of few instance where missing data was found. Because the minimal number of missing cases, the value missing was replaced by the sample mode. This process was completed using SPSS 22. This sample reflects $96 \%$ of the teacher population and $33 \%$ of the student population of the middle school under study.
\end{abstract}

\section{Descriptive Analysis}

A descriptive examination of level-1 variables was conducted. Of the complete sample of 150 students, $77(51.3 \%)$ were female and $73(48.7 \%)$ were male. Also, $59(39.3 \%)$ were 6th-grade students, $49(32.7 \%)$ were 7 th-grade students and $42(28 \%)$ were 8th-grade students. On the variable of ethnicity 67(44.66\%) were Caucasian, 37(24.67\%) were African American/Black, 21(14\%) were 2+ Races, 12(8\%) were Hispanic and13 $(8.67 \%)$ belonged to Other Races. The SES variable was measured by the students' qualification for free or reduced lunch. Of the sample, 72 (48\%) qualified for free lunch, 18(12\%) qualified for reduced lunch and 60 (40\%) received a paid lunch. 
Table 1

Demographic Characteristic of Participating Students $(n=150)$

\begin{tabular}{lll}
\hline \multicolumn{1}{c}{ Variable } & F & $\%$ \\
\hline Gender & 73 & 48.7 \\
Male & 77 & 51.3 \\
Female & & \\
& & \\
Grade-level & 59 & 39.3 \\
6th & 49 & 32.7 \\
7th & 42 & 28 \\
8th & & \\
& & \\
Lunch & 72 & 48 \\
Free & 18 & 12 \\
Reduced & 60 & 40 \\
Paid & & \\
& & \\
Ethnicity & 67 & 44.66 \\
Caucasian & 37 & 24.67 \\
African American/Black & 12 & 8 \\
Hispanic & 13 & 14 \\
Other races & 21 & \\
Two+ races & & \\
\hline
\end{tabular}

Regarding the outcome variable of Social Classroom Climate (SCCM), the first factor, Teacher Emotional Support (TES) $\mathrm{M}=14.46, \mathrm{SD}=3.67$ with a minimum and maximum of 4 and 20 respectively. For the second-factor Teacher Academic Support (TAS) $\mathrm{M}=18.19, \mathrm{SD}=2.1$ with a minimum and maximum of 10 and 20 respectively. On the Mutual Respect (MR) factor, $\mathrm{M}=22.01, \mathrm{SD}=3.49$ with a minimum and maximum of 11 and 25 respectively. Finally, the promotion of Task-Related Interaction (TRI) factor had $\mathrm{M}=11.46, \mathrm{SD}=2.3$ with a minimum and maximum of 3 and 15 respectively. These descriptives are listed in Table 2. This data suggests that teacher academic and support 
and did not meet normality, with skewness values at -1.51 and -1.34 respectively and kurtosis at 2.01 for teacher academic support.

Table 2

Descriptive Characteristics of Outcome Variable

\begin{tabular}{lcccccccc}
\hline Variable & $M$ & $S D$ & Min. & Max. Skewness & Log R & Kurtosis & Log R \\
\hline Emotional support & 14.46 & 3.67 & 4 & 20 & -.32 & & -.36 & \\
Academic support & 18.19 & 2.10 & 10 & 20 & -1.51 & .34 & 2.01 & -.94 \\
Mutual respect & 22.01 & 3.49 & 11 & 25 & -1.34 & .24 & .98 & -1.14 \\
Task interaction & 11.46 & 2.61 & 3 & 15 & -.63 & & .59 & \\
\hline
\end{tabular}

Similarly, a descriptive analysis was conducted on variables at level-2 as evidenced in Table 3. The respondents teaching experience ranged from less than one year to thirty-six years. In addition, ten respondents (41.7\%) held a Bachelor's degree and fourteen respondents (58.3\%) held a Master's degree. Caucasians comprised $75 \%$ of the sample with $25 \%$ representing other races.

On the variable of cultural competence $\mathrm{M}=80.75, \mathrm{SD}=5.04$ with a minimum of 72 and a maximum of 82 . With the possibility of scores on cultural competence ranging from 20-100. It can be stated that this sample of teachers reported a moderately highly level of cultural competence. In order to control of social desirability effect, the score of the QDI was also recorded. For this variable $\mathrm{M}=108.63 \mathrm{SD}=11.02$. 
Table 3

Demographic Characteristic of Participating Teachers

\begin{tabular}{lll}
\hline Variable & F & $\%$ \\
\hline Teaching experience & $0-36$ & 100 \\
Educational Level & & \\
Bachelor's degree & 10 & 41.7 \\
Master's degree & 14 & 58.3 \\
Teacher Ethnicity & 6 & 75 \\
Caucasian & 6 & 25 \\
Non-Caucasian & 18 & \\
\hline
\end{tabular}

The QDI was also moderately correlated to the cultural competence score, $r=.54$. These variables approximated normality, with skewness and kurtosis values within the range of -1.00 and 1.00. These descriptives are listed in Table 4.

Table 4

Descriptive Characteristic of Level 2 Variables

\begin{tabular}{lrccccc}
\hline \multicolumn{1}{c}{ Variable } & $M$ & $S D$ & Min & Max & Skewness & Kurtosis \\
\hline Cultural Competence & 80.75 & 5.04 & 72 & 89 & .09 & -.91 \\
Social Desirability & 108.63 & 11.02 & 88 & 130 & -.12 & -.58 \\
\hline
\end{tabular}

\section{Bivariate Analysis}

An examination of bivariate relationships between variables was performed at each level. The results of weighted correlations among eight level-1 variables (i.e., gender, grade, ethnicity, SES TES, TAS, MR, PI) are presented in Table 5. It appeared from these results that the correlation coefficients for level-1 outcome variables were 
moderately correlated, since measuring the same construct, with $\mathrm{r}$ ranging from .38 to .54. Additionally, there were several small correlations between the outcome and predictor variables. TES was correlated to grade-level, Hispanic and $2+$ races students $r=$ $-.16, .18,-.17$ respectively. For TAS $\mathrm{r}=-.24,17$ for grade-level and $2+$ races respectively. Mutual respect showed a correlation with African American and 2+races with $r=17$ and .18 . The coefficient for task-related interaction was .18 with Hispanic students and -.24 with grade-level.

Table 5

Correlations for Key Level 1 Variables

\begin{tabular}{|c|c|c|c|c|c|c|c|c|c|c|c|}
\hline & TAS & MR & PI & Gen. & Grade & SES & $\mathrm{C}$ & AA & $\mathrm{H}$ & $2+$ & $\mathrm{O}$ \\
\hline TES & $-.54 * *$ & $-.53 * *$ & $.38 * *$ & -.04 & $-.16^{*}$ & .05 & .06 & -.08 & $.18^{*}$ & $-.17 *$ & .07 \\
\hline TAS & & $.54 * *$ & $-.39 * *$ & .14 & $.24 * *$ & .08 & .01 & -.09 & -.06 & $.17 *$ & -.03 \\
\hline MR & & & $-.36 * *$ & .07 & .13 & .09 & .11 & $.17 *$ & -.11 & $.18^{*}$ & -.04 \\
\hline PI & & & & -.08 & $-.24 * *$ & -.03 & -.13 & .10 & $.18^{*}$ & -.12 & .06 \\
\hline Gender & & & & & .14 & .14 & .12 & -.16 & -.04 & .07 & -.02 \\
\hline Grade & & & & & & .07 & .09 & -.10 & -.05 & .07 & -.05 \\
\hline SES & & & & & & & $.29 * *$ & $-.27 * *$ & -.05 & -.07 & .03 \\
\hline Cauc. & & & & & & & & $.29 * *$ & $-.27 * *$ & $-.36 * *$ & $.28 * *$ \\
\hline AA/Black & & & & & & & & & $-.51 * *$ & $-.23 * *$ & $-.18 *$ \\
\hline Hispanic & & & & & & & & & & -.12 & -.09 \\
\hline $2+$ Races & & & & & & & & & & & -.12 \\
\hline Other & & & & & & & & & & & \\
\hline
\end{tabular}

$* p<.05 . * * p<.01$.

At level-2, unweighted bivariate relationships were estimated for five predictor variables. The correlation matrix for these variables can be found in Table 6 . The correlation coefficients of level-2 variables were uncorrelated to each other except for the control variable and cultural competence which were, as anticipated, moderately correlated to each other $\mathrm{r}=.54$. 
Table 6

Correlations Between Key Level 2 Variables

\begin{tabular}{lccccc}
\hline & CC & SD & Exp. & Educ. & Ethn. \\
\hline Cultural Competence & & $.54^{*}$ & .24 & .04 & .11 \\
Social Desirability & & & .28 & .31 & .20 \\
Teaching Experience & & & & .26 & .12 \\
Educ. Level & & & & .10 \\
Ethnicity & & & & \\
\hline
\end{tabular}

$* p<.05$

\section{Evaluation of HLM Assumptions}

In order to improve interpretability of the results, both level-1 and level-2 nominal predictor variables were recoded into dummy variables. In addition, for the level-2 variable of teacher cultural competence, seven scale items were reversed scored, following which the items were summed to attain cultural competence scores. The predictors at both levels also were grand-mean centered.

To conduct the HLM analysis student clusters for each grade were created. The process was completed via random assignment of the students to grade-level clusters. The clusters were then randomly assigned to a teacher of that particular grade. This resulted in nine $6^{\text {th }}$ grade, eight $7^{\text {th }}$ grade and seven $8^{\text {th }}$ grade clusters with an average of six students per group.

To ensure the tenability of the study results, an evaluation of HLM assumptions through analysis of level-1 outcome variables and level-2 variable of cultural competence was performed. This was done to determine whether there was normality of distribution. The data from the Table 2 above suggests that two level-1 variables were not normally distributed. To correct for this, a Log R transformation was performed which adjusted for 
the skewness. These figures reflected in Table 2 above indicate this adjustment. In summary, analyses of both level-1 and level-2 variables suggested that the assumptions of normality and homogeneity of level-1 and level-2 variables were satisfied.

\section{Hypothesis Testing}

\section{Hypothesis 1}

The unconditional model for the first hypothesis was conducted. The hypothesis explored whether: The teacher characteristics of cultural competency, ethnicity, educational level and years of teaching experience and student demographic characteristics of grade-level, gender, SES, and ethnicity are significant predictors of the students' perception of the teacher emotional support factor of the social classroom climate in culturally different middle school classrooms in a Midwest Public Schools system.

In the HLM unconditional model no predictors are included in the model. The results of the unconditional model are presented in Table 7. For TES, the fixed effect for the intercept was $14.46(\mathrm{SE}=0.25, \mathrm{p}<.001)$. The average level of teacher emotional support is not significantly different across teacher $\left({ }^{\tau} 00=0.004, \mathrm{SE}=0.07, \mathrm{p}>.500\right)$. Between teachers and students, the amount of unexplained variance was larger than within teachers $\left(\sigma^{2}=13.48, \mathrm{SE}=3.67\right)$. The computed intra-class correlation $(\mathrm{ICC})$ of .0003 indicates that little or no natural clustering of students with teachers. In other words, approximately $.03 \%$ of the total variance in teacher emotional support occurred between teachers and students. This analysis indicated that the hypothesis under investigation was not amenable to further HLM model building. 
That is, the HLM analysis did not demonstrate the hypothesized relationship between the second-level variables of teacher level of cultural competency, ethnicity, educational level and years of teaching experience and first-level variables of student grade-level, gender, SES and ethnicity in predicting the students' perception of the teacher emotional support factor of the social classroom climate in the culturally different middle school classroom examined by this researcher.

Table 7

Parameter Estimates for Unconditional Model 1a

\begin{tabular}{cllcccc}
\hline Model & Effect & Parameter & Estimates & SE & $t$ & $p$ \\
\hline $1 \mathrm{a}$ & Fixed & ICC & .0003 & & & \\
& & INT & 14.46 & 0.25 & 58.60 & $<0.001$ \\
& \multirow{2}{*}{ Random } & $\tau 00$ & 0.004 & 0.07 & & $>0.500$ \\
& & $\sigma 2$ & 13.48 & 3.67 & & \\
& & & & & & \\
\hline
\end{tabular}

As a result of the absence of the initially hypothesized relationship between level1 and level-2 variables utilizing HLM analysis, hypothesis testing was continued using MLR analysis. This analysis was performed to determine the relationships between variables at level-1 on this outcome variable. The result of the MLR showed that the full regression equation was not statistically significant $\mathrm{R}^{2}=.032$, Adjusted $\mathrm{R}^{2}=.006, F=(4$, $145)=1.21, \mathrm{p}=.309$. The model, however, did indicate that the grade-level predictor was statically significant $\mathrm{p}=.05$. A reduced second model was conducted with this predictor which indicated $\mathrm{R}^{2}=.026$, Adjusted $\mathrm{R}^{2}=.019, F=(4,148)=3.951, \mathrm{p}=.049$. 
Based on the result, it can be hypothesized that grade-level is a significant predictor of teacher emotional support. That is, the grade-level of the student impacts the students' perceptions of received teacher emotional support. In this case, the data indicates that students at lower grade-levels perceive higher levels of teacher emotional support. However, it explains only $2.6 \%$ of the variance in teacher emotional support.

Table 8

Results of Regression of TES Criterion on Level 1 Predictor Variables

\begin{tabular}{crrrr}
\hline Predictor Variables & $B$ & $\beta$ & $t$ & $p$ \\
\hline Model 1 & & & & \\
Constant & 15.638 & & 14.596 & .000 \\
Grade-level & -.720 & -.160 & -1.939 & .050 \\
Gender & -.198 & -.027 & -.324 & .746 \\
SES & .272 & .070 & .842 & .401 \\
Ethnicity & -.097 & -.035 & -.429 & .669 \\
Model 2 & & & & \\
Constant & 15.837 & & 21.015 & .000 \\
Grade-level & -.725 & -.161 & -1.988 & .049 \\
\hline
\end{tabular}

Note. Model 1, $\mathrm{R}^{2}=.032 ; \mathrm{R}^{2} \Delta=.006$ for Model $2, \mathrm{R}^{2}=.026 ; \mathrm{R}^{2} \Delta=.019 ; \mathrm{p}=.049$

\section{Hypothesis 2}

The unconditional model for the second hypothesis was conducted. This hypothesis investigates whether the teacher characteristics of level of cultural competency, ethnicity, educational level, and years of teaching experience and student demographic characteristics of grade-level, gender, SES, and ethnicity are significant predictors of the students' perception of the teacher academic support factor of the social 
classroom climate in a culturally different middle school classrooms in a Midwest Public Schools system examined. The results of the unconditional model are presented in Table 9.

For TAS, the fixed effect for the intercept was $0.35(\mathrm{SE}=0.027, \mathrm{p}<.001)$. The average level of teacher academic support was not significantly different across teachers $\left({ }^{\tau} 00=0.005, \mathrm{SE}=0.07, \mathrm{p}=0.11\right.$. Between teachers and students, the amount of unexplained variance was $\left(\sigma^{2}=0.83, \mathrm{SE}=0.29\right)$. The computed ICC of .046 was indicative of little or no natural clustering. In other words, approximately only $4.6 \%$ of the total variance in teacher academic support occurred with teachers and students, this low percentage of variance, however, can be attributable to random errors.

Table 9

Parameter Estimates for Unconditional Model $1 \mathrm{~b}$

\begin{tabular}{ccccccc}
\hline Model & Effect & Parameter & Estimates & SE & $t$ & $p$ \\
\hline $1 \mathrm{~b}$ & Fixed & ICC & .046 & & & \\
& & & & & & \\
& & INT & 0.35 & 0.027 & 12.91 & $<0.001$ \\
& Random & $\tau_{00}$ & 0.005 & 0.07 & & 0.111 \\
& & $\sigma^{2}$ & 0.083 & 0.29 & & \\
\hline
\end{tabular}

The analysis of this unconditional model also indicates that hypothesis two is not amenable to HLM model building. In other words, the analysis of hypothesis two did not demonstrate a significant relationship between the second level variables of teacher level of cultural competency, ethnicity, educational level, and years of teaching experience and first level variables of student grade-level, gender, SES, and ethnicity in predicting the 
students' perception of the "teacher academic support" factor of the social classroom climate in the examined culturally different middle school classroom.

With this result, an MLR analysis was performed to determine the relationship between variables on level-1 with this outcome variable. This analysis indicated $\mathrm{R}^{2}=$ .076 , Adjusted $\mathrm{R}^{2}=.05, F=(4,145)=2.97, \mathrm{p}=.022$. Although this result indicates that the equation is statistically significant, only the grade-level predictor in this equation is significant $\mathrm{p}=.006$. A second model was conducted with only this predictor. The results showed that the second model was statistically significant and accounted for a significant percentage of the variance with $\mathrm{R}^{2}=.059$, Adjusted $\mathrm{R}^{2}=.052, F=(4,148)=9.231, \mathrm{p}=$ .003 .

Table 10

Results of Regression of TAS Criterion on Level 1 Predictor Variables

\begin{tabular}{lllll}
\hline Predictor Variables & $B$ & $\beta$ & $t$ & $p$ \\
\hline Model 1 & & & & \\
Constant & .167 & & 1.902 & .059 \\
Grade-level & .081 & .225 & 2.786 & .006 \\
Gender & .061 & .103 & 1.267 & .207 \\
SES & .015 & .046 & .573 & .567 \\
Ethnicity & .024 & .018 & 1.377 & .171 \\
Model 2 & & & & \\
$\quad$ Constant & .179 & & & .003 \\
$\quad$ Grade-level & .088 & .242 & 3.001 & .003 \\
\hline
\end{tabular}

Note. Model $1, \mathrm{R}^{2}=.076 ; \mathrm{R}^{2} \Delta=.050 ; \mathrm{p}=.022$ : for Model $2, \mathrm{R}^{2}=.059 ; \mathrm{R}^{2} \Delta=.052 ; * \mathrm{p}<.05$, 
As with the previous variable, TAS can be predicted by the grade-level predictor variable. However, unlike the first factor, students at the higher grade-levels perceive a greater degree of teacher academic support. This variable explains 5.9\% of the variance in teacher academic support.

\section{Hypothesis 3}

The unconditional model for this hypothesis showed similar results. This hypothesis asked whether the teacher characteristics of level of cultural competency, ethnicity, educational level, and years of teaching experience and student demographic characteristics of grade-level, gender, SES, and ethnicity are significant predictors of the students' perception of the "mutual respect" factor of the social classroom climate in culturally different classrooms in the examined Public Middle Schools system. The results are presented below.

Table 11

Parameter Estimates for Unconditional Model 1c

\begin{tabular}{cllclll}
\hline Model & Effect & Parameter & Estimates & SE & $t$ & $p$ \\
\hline $1 \mathrm{c}$ & Fixed & ICC & .03 & & & \\
& & & & & \\
& & INT & 0.45 & 0.03 & 14.08 & $<0.001$ \\
& Random & $\tau_{00}$ & 0.004 & 0.06 & .230 \\
& & $\sigma^{2}$ & 0.13 & 0.36 & \\
\hline
\end{tabular}

For MR, the fixed effect for the intercept was $0.45(\mathrm{SE}=0.03, \mathrm{p}<.001)$. The average level of promotion of mutual respect was not significantly different across 
teachers $\left({ }^{\tau} 00=0.004, \mathrm{SE}=0.06, \mathrm{p}=.230\right)$. Between teachers and students, the amount of unexplained variance was $\left(\sigma^{2}=0.13, \mathrm{SE}=0.36\right)$. The computed ICC of .03 was indicative of little clustering. That is, approximately $3 \%$ of the total variance in the promotion of mutual respect occurred between teachers and students. Consequently, it was determined that hypothesis three is also not amenable to HLM model building. From these results, it can be concluded, the analysis does not indicate the hypothesized relationship between the second level variables of teacher level of cultural competency, ethnicity, educational level, and years of teaching experience and first level variables of student grade-level, gender, SES, and ethnicity in predicting the students' perception of the "promotion of mutual respect" factor of the social classroom climate in a culturally different middle school classroom in the examined Public Schools district.

Table 12

Results of Regression of MR Criterion on Level 1 Predictor Variables

\begin{tabular}{lllll}
\hline Predictor Variables & $B$ & $\beta$ & $t$ & $p$ \\
\hline
\end{tabular}

Model 1

$\begin{array}{lcccc}\text { Constant } & .293 & & 2.602 & .010 \\ \text { Grade-level } & .055 & .037 & 1.483 & .140 \\ \text { Gender } & .029 & .061 & .896 & .639 \\ \text { SES } & .029 & .033 & .896 & .372 \\ \text { Ethnicity } & .039 & .142 & 1.742 & .084\end{array}$

Note. Model $1, \mathrm{R}^{2}=.026 ; \mathrm{R}^{2} \Delta=.00 ; \mathrm{p}=.418$

Based on the outcome of the HLM analysis, an MLR analysis was performed to ascertain the relationship between level-1 variables and this outcome variable. The 
results showed $\mathrm{R}^{2}=.026$, Adjusted $\mathrm{R}^{2}=.00, F=(4,145)=.984, \mathrm{p}=.418$. These results indicated that the four level-1 variables are not significant predictors of this outcome variable. That is, the MLR analysis also did not indicate a relationship between the outcome and predictor variables.

\section{Hypothesis 4}

The unconditional model for this hypothesis was conducted. This hypothesis explored the whether the teacher characteristics of level of cultural competency, ethnicity, educational level, and years of teaching experience and student demographic characteristics of grade-level, gender, SES, and ethnicity are significant predictors of the students' perception of the "promotion of task-related interaction" factor of the social classroom climate in culturally different middle school classrooms in the examined Public Schools system. The results of this final unconditional model are presented in Table 13.

The fixed effect for the intercept was $11.45(\mathrm{SE}=0.25, \mathrm{p}<.001)$. The average level of promotion of task-related interaction was significantly significant $\left({ }^{\tau} 00=0.55, \mathrm{SE}\right.$ $=0.74, \mathrm{p}=.04)$. The amount of between teachers and students unexplained variance was $\left.\sigma^{2}=6.27, \mathrm{SE}=2.5\right)$. The computed ICC of .08 was indicative of natural clustering of students occurred between teachers. In other words, approximately $8 \%$ of the total variance in the promotion of task-related interaction occurred between teachers and students. 
Table 13

Parameter Estimates for Unconditional Model 1d

\begin{tabular}{cllllll}
\hline Model & Effect & Parameter & Estimates & SE & $t$ & $p$ \\
\hline $1 \mathrm{~d}$ & Fixed & ICC & .08 & & & \\
& & INT & 11.45 & 0.25 & 45.91 & $<0.001$ \\
& \multirow{2}{*}{ Random } & $\tau_{00}$ & 0.55 & 0.74 & & 0.041 \\
& & $\sigma^{2}$ & 6.27 & 2.50 & & \\
\hline
\end{tabular}

These results indicate a relationship between the second level variables of teacher level of cultural competency, ethnicity, educational level, and years of teaching experience and first level variables of student grade-level, gender, SES, and ethnicity in predicting the students' perceptions of the "promotion of task-related interaction" factor of the social classroom climate in the examined culturally different Public Middle Schools district.

The next step of examining this hypothesis was entering student background variables into the model to predict promotion of task-related interaction. The variables that indicate significance in Models 2-6 remained in the equation to predict promotion of task-related interaction. Level-two variables were then entered (Models 7-10), the significant predictors from level-one and level-two were then entered as a group to predict promotion of task-related interaction. Finally, to evaluate model fit in terms of the proportion of variance accounted for, a pseudo $\mathrm{R}^{2}$ was computed for the current model against previously constructed models.

The data from Table 14 suggested that the level-1 variables of grade-level ( $\gamma=$ 0.77, $\mathrm{SE}=0.31, \mathrm{p}=.013)$ and student ethnicity $($ Caucasian $\gamma=3.31, \mathrm{SE}=1.09, \mathrm{p}=.003$; 
African American $/$ Black $\gamma=3.33, \mathrm{SE}=0.99, \mathrm{p}=.001$; Hispanic $\gamma=4.47, \mathrm{SE}=1.22, \mathrm{p}$ $=.<001$; Other races $\gamma=3.68, \mathrm{SE}=1.27, \mathrm{p}=.005$; Two races $\gamma=2.54, \mathrm{SE}=1.20, \mathrm{p}=.036$ ) are statistically significant. These two variables were entered into a final model for level one variables. These variables were also included in the next step of model building with level-2 variables.

Table 14

Parameter Estimates Models 2-6

\begin{tabular}{|c|c|c|c|c|c|c|c|c|c|}
\hline Model & Effect & Parameter & Estimates & $S$ SE & $t$ & $p$ & $\tau_{00}$ & \multicolumn{2}{|c|}{$\sigma^{2}$} \\
\hline \multirow[t]{8}{*}{2} & Fixed & INT & 11.44 & 0.19 & 59.96 & $<0.001$ & & & \\
\hline & & Caucasian & 3.31 & 1.09 & 3.05 & 0.003 & & & \\
\hline & & AA/Black & 3.33 & 0.99 & 3.37 & 0.001 & & & \\
\hline & & Hispanic & 4.47 & 1.22 & $3.66<$ & $<0.001$ & & & \\
\hline & & Other races & s 3.68 & 1.27 & 2.89 & 0.005 & & & \\
\hline & & $2+$ races & 2.54 & 1.20 & 2.11 & 0.036 & & & \\
\hline & Random $\tau_{0}$ & $\tau_{00}$ & 0.02 & 0.14 & & 0.500 & & & \\
\hline & & $\sigma^{2}$ & 6.18 & 2.49 & & & & & \\
\hline \multicolumn{2}{|c|}{ Pseudo $\mathrm{R}^{2}$} & & & & & & 0.97 & 0.0 & \\
\hline \multirow[t]{5}{*}{3} & Fixed & INT & 12.93 & 0.50 & 25.75 & $<0.001$ & & & \\
\hline & & Grade & -0.77 & 0.31 & 2.52 & 0.013 & & & \\
\hline & Random & $\tau_{00}$ & 0.16 & 0.40 & & 0.304 & & & \\
\hline & & $\sigma^{2}$ & 6.30 & 2.51 & & & & & \\
\hline & Pseudo $\mathrm{R}^{2}$ & & 0.71 & -.0 .01 & & & & & \\
\hline \multirow[t]{5}{*}{4} & Fixed & INT & 11.45 & 0.24 & 46.79 & $<0.001$ & & & \\
\hline & & Gender & -0.27 & 0.38 & 2.11 & 0.712 & & & \\
\hline & Random & $\tau 00$ & 0.49 & 0.70 & & 0.60 & & & \\
\hline & & $\sigma 2$ & 6.34 & 2.52 & & & & & \\
\hline & Pseudo $\mathrm{R}^{2}$ & & & & & & 0.11 & & -0.0 \\
\hline \multirow[t]{5}{*}{5} & Fixed & INT & 11.45 & 0.25 & 46.08 & $<0.001$ & & & \\
\hline & & SES & -0.06 & 0.22 & -0.26 & 0.795 & & & \\
\hline & Random & $\tau 00$ & 0.55 & 0.74 & & 0.046 & & & \\
\hline & & $\sigma 2$ & 6.31 & 2.51 & & & & & \\
\hline & Pseudo $\mathrm{R}^{2}$ & & & & & & 0.00 & & -0.0 \\
\hline 6 & Fixed & INT & 11.46 & 50.17 & 68.24 & $4<0.001$ & & & \\
\hline
\end{tabular}


Table 14-Continued

Parameter Estimates Models 2-6

\begin{tabular}{|c|c|c|c|c|c|c|c|c|}
\hline \multirow[t]{2}{*}{ Model } & \multirow[t]{2}{*}{ Effect } & Parameter & Estimates & \multirow{2}{*}{$\frac{S E}{0.87}$} & \multirow{2}{*}{$\frac{t}{3.25}$} & \multirow{2}{*}{$\frac{p}{0.001}$} & \multirow[t]{2}{*}{$\tau_{00}$} & \multirow[t]{2}{*}{$\sigma^{2}$} \\
\hline & & Caucasian & 2.83 & & & & & \\
\hline & & AA/Black & 2.84 & 0.73 & 3.87 & $<0.001$ & & \\
\hline & & Hispanic & 3.97 & 0.93 & 4.26 & $<0.001$ & & \\
\hline & & Other races & 3.16 & 1.11 & 2.86 & 0.005 & & \\
\hline & & $2+$ races & 2.15 & 0.99 & 2.17 & 0.032 & & \\
\hline & & Grade & -0.55 & 0.24 & -2.28 & 0.024 & & \\
\hline & Random & $\tau_{00}$ & 0.003 & 0.06 & & $>0.500$ & & \\
\hline & & $\sigma^{2}$ & 6.04 & 2.46 & & & & \\
\hline & Pseudo R & & & & & & 0.99 & 0.04 \\
\hline
\end{tabular}

Table 15 indicates that of the level-2 variables teacher ethnicity $(\gamma=-0.80, \mathrm{SE}$ $=0.39, \mathrm{p}=.05)$ is statistically significant predictor. In summary, the data from Model 10 suggests that student ethnicity is a predictor of student's perceptions promotion of taskrelated interaction. The coefficient of each ethnicity, as reported, indicates the predictive value to which each ethnic group perceives the promotion of task-related interaction. Additionally, student grade-level is also a predictor of student perception of the outcome variable. The inverse relationship indicated between grade-level and the outcome variable suggests students at lower grade-levels tend to perceive higher levels of the promotion of task-related interaction.

Finally, the results evidence that teacher ethnicity is a predictor of promotion of task-related interaction. That is, there is an increase in task-related interaction for the higher category ethnicity. In essence, where (Caucasian $=0$, Non-Caucasian $=1)$ it can be 
stated that students perceive that non-Caucasian teachers tend to promote task-related interaction more than their Caucasian counterparts.

Model 15

Parameter Estimates Models 7-10

\begin{tabular}{|c|c|c|c|c|c|c|c|c|}
\hline Model & Effect & Parameter & Estimates & $\mathrm{SE}$ & $t$ & $p$ & $\tau 00$ & $\sigma 2$ \\
\hline \multirow[t]{12}{*}{7} & \multirow[t]{8}{*}{ Fixed } & INT & 11.49 & 0.23 & 48.21 & $<0.001$ & & \\
\hline & & Caucasian & 2.84 & 0.87 & 3.27 & 0.001 & & \\
\hline & & AA/Black & 2.85 & 0.73 & 3.90 & $<0.001$ & & \\
\hline & & Hispanic & 3.98 & 0.93 & 4.28 & $<0.001$ & & \\
\hline & & Other races & 3.17 & 1.11 & 2.86 & 0.005 & & \\
\hline & & $2+$ races & 2.17 & 0.99 & 2.20 & 0.030 & & \\
\hline & & Grade-level & -0.55 & 0.23 & -2.36 & 0.020 & & \\
\hline & & Teaching Exp & 0.00 & 0.01 & -0.22 & 0.829 & & \\
\hline & \multicolumn{2}{|c|}{ Random $\tau 00$} & 0.00 & 0.07 & & $>0.500$ & & \\
\hline & & $\sigma 2$ & 6.09 & 2.47 & & & & \\
\hline & \multicolumn{2}{|c|}{ Pseudo R2 } & & & & & 0.00 & 0.03 \\
\hline & \multicolumn{3}{|c|}{ Compared to Model 6} & & & & 0.00 & 0.00 \\
\hline \multirow[t]{12}{*}{8} & \multirow[t]{8}{*}{ Fixed } & INT & 11.29 & 0.90 & 12.59 & $<0.001$ & & \\
\hline & & Caucasian & 2.86 & 0.89 & 3.22 & 0.002 & & \\
\hline & & AA/Black & 2.87 & 0.77 & 3.70 & $<0.001$ & & \\
\hline & & Hispanic & 4.01 & 0.95 & 4.24 & $<0.001$ & & \\
\hline & & Other races & 3.19 & 1.11 & 2.82 & 0.006 & & \\
\hline & & $2+$ races & 2.17 & 0.99 & 2.17 & 0.032 & & \\
\hline & & Grade-level & -0.54 & 0.24 & -2.26 & 0.026 & & \\
\hline & & Edu. Level & 0.07 & 0.35 & 0.19 & 0.852 & & \\
\hline & \multirow[t]{2}{*}{ Random } & $\mathrm{m} \tau 00$ & 0.00 & 0.06 & & $>0.500$ & & \\
\hline & & $\sigma 2$ & 6.09 & 2.47 & & & & \\
\hline & \multicolumn{3}{|c|}{ Pseudo R2 } & & & & 0.00 & 0.03 \\
\hline & \multicolumn{3}{|c|}{ Compared to Model 6} & & & & 0.00 & 0.00 \\
\hline
\end{tabular}


Table 15-Continued

Parameter Estimates Models 7-10

\begin{tabular}{|c|c|c|c|c|c|c|c|c|}
\hline Model & Effect & Parameter & Estimates & $\mathrm{SE}$ & $t$ & $p$ & $\tau 00$ & $\sigma 2$ \\
\hline \multirow[t]{13}{*}{9} & \multirow[t]{9}{*}{ Fixed } & INT & 11.46 & 0.17 & 69.24 & $<0.001$ & & \\
\hline & & Caucasian & 2.84 & 0.90 & 3.14 & 0.002 & & \\
\hline & & AA/Black & 2.87 & 0.84 & 3.39 & $<0.001$ & & \\
\hline & & Hispanic & 4.03 & 0.98 & 4.09 & $<0.001$ & & \\
\hline & & Other races & 3.11 & 1.09 & 2.86 & 0.005 & & \\
\hline & & $2+$ races & 2.14 & 1.05 & 2.05 & 0.043 & & \\
\hline & & Grade-level & -0.56 & 0.23 & -2.46 & 0.015 & & \\
\hline & & Ctur'al Comp. & 0.01 & 0.05 & -0.20 & 0.844 & & \\
\hline & & Social Desire & 0.02 & 0.02 & 0.90 & 0.380 & & \\
\hline & \multicolumn{2}{|c|}{ Random $\tau 00$} & 0.00 & 0.07 & & $>0.500$ & & \\
\hline & & $\sigma 2$ & 6.10 & 2.47 & & & & \\
\hline & \multicolumn{3}{|c|}{ Pseudo R2 } & & & & 0.00 & 0.03 \\
\hline & \multicolumn{3}{|c|}{ Compared to Model 6} & & & & 0.00 & 0.00 \\
\hline \multirow[t]{12}{*}{10} & \multirow[t]{8}{*}{ Fixed } & INT & 11.26 & 0.19 & 59.60 & $<0.001$ & & \\
\hline & & Caucasian & 3.13 & 0.78 & 3.27 & $<0.001$ & & \\
\hline & & AA/Black & 3.12 & 0.61 & 3.90 & $<0.001$ & & \\
\hline & & Hispanic & 4.36 & 0.84 & 4.28 & $<0.001$ & & \\
\hline & & Other races & 3.46 & 0.97 & 2.86 & $<0.001$ & & \\
\hline & & $2+$ races & 2.43 & 0.87 & 2.20 & 0.006 & & \\
\hline & & Grade-level & -0.59 & 0.22 & -2.69 & 0.008 & & \\
\hline & & Teacher ethn. & 0.80 & 0.39 & 2.02 & 0.05 & & \\
\hline & \multirow[t]{2}{*}{ Random } & $\tau 00$ & 0.002 & 0.05 & & $>0.500$ & & \\
\hline & & $\sigma 2$ & 5.97 & 2.44 & & & & \\
\hline & \multicolumn{3}{|c|}{ Pseudo R2 } & & & & 0.99 & 0.05 \\
\hline & \multicolumn{3}{|c|}{ Compared to Model 6} & & & & 0.01 & 0.33 \\
\hline
\end{tabular}

An evaluation of model fit was also conducted between the first level variables, models 2-6, through an examination of pseudo $\mathrm{R}^{2}$ across these models. This analysis suggests that the addition of individual predictors separately to the unconditional model 
(Model 1) to predict promotion of task-related interaction resulted in a reduction of among teachers variance ranging from 0\% (Model 5) to 99\% (Model 6). For the between teachers and students variance, however, the amount of reduction was smaller, up to $4 \%$ (Model 6). In fact, in some models, the amount of within teacher and student variance slightly increased (1\% for Models 3, 4 and 5). Model 6 appeared to be the most efficient first level model because the amount of explained variance, $99 \%$ between teacher and $4 \%$ between teachers and students.

The models with the second level variables entered (7-10) were also evaluated for model fit. To achieve this, the pseudo $\mathrm{R}^{2}$ was also calculated in comparison to Model 6 . The results indicated that Model 10 accounts for $99 \%$ of among teacher variance and 5\% of the between teacher and student variance. This slightly increased the percentage of variability accounted for when compared with Model 6. As indicated above, Model 10 accounts for a $1 \%$ increase of among teacher variance and a $33 \%$ increase of between teacher and student variance when compared to Model 6. In sum, Model 10 was more efficient than earlier models in predicting the promotion of task-related interaction. 


\section{CHAPTER 5}

\section{DISCUSSION, CONCLUSIONS AND RECOMMENDATIONS}

\section{Introduction}

This study explores whether a relationship exists between teachers' cultural competence, educational level, years of experience, and ethnicity, and students' perception of the social classroom climate. This study also examines the student demographic variables of grade-level, ethnicity, SES and gender as possible influencing predictors for student's perception of the social classroom climate. The main variables under investigation, however, are teachers' cultural competence and students' perception of their classroom climate.

Accordingly, the study explains that the social classroom climate is a fundamental element in the classroom because it has a direct influence on the extent to which learners are successful. This study also identifies teacher emotional support, teacher academic support, promotion of mutual respect and promotion of task-related interaction as important factors and correlates in the creation of a social climate wherein students are interested, motivated, and engaged in learning. It further highlights the importance of the teacher's role the creation a positive social environment in culturally different classrooms. This role is drastically increased because working in culturally different classrooms requires teachers who have cultural knowledge regarding the various means of knowing, communicating, and doing that exist within the homes of their minority 
students (Colombo, 2005). In essence, working with culturally different students requires teachers who possess cultural competence.

An extensive literature review served as the framework for the four hypothesis that guided this study. It hypothesized that there is a relationship between the second level variables of teacher level of cultural competency, ethnicity, educational level and years of teaching experience and the first level variables of student grade-level, gender, SES, and ethnicity when predicting students' perceptions of each of the four factors of the social classroom climate in a culturally different middle school classroom.

The TMAS was used to measure teachers' perceptions of their cultural competency. The TMAS established a quantified measure of cultural competency. Additionally, the SCCM measured students' perceptions of the social classroom climate for four sub-constructs: Teacher Emotional Support, Teacher Academic Support, Promotion of Mutual Respect, and Promotion of Task-Related Interaction. The SCCM provided a quantified measurement of social classroom climate as perceived by students.

The discussion of this research is presented in four sections. The first section offers a summary of the findings. In the second section, the implications of the study are analyzed. The third section addresses recommendation for practice and future research. The final section discusses several limitations of the study.

\section{Purpose of the Study}

The purpose of this exploratory study is to examine teachers' levels of cultural competency—while taking into consideration teacher ethnicity, years of teaching experience, and level of education as well as the student demographic characteristics 
SES, ethnicity, and grade-level—and the relationship between students' perception of the classroom social climate in a culturally different middle school.

\section{Summary of the Problem}

As teachers and students come from different cultural backgrounds, the classroom is increasingly becoming the place where social interactions if not appropriately managed can result in a social classroom climate not conducive to learning (Black, 2006). Several authors suggest that, cultural competence is the antecedent to implementing effective practices when working in a culturally different environment because it equips professionals not only with knowledge, but also the capability to apply that knowledge appropriately (Gay, 2010; Moule, 2012). The result of such practice can lead to the creation of a supportive and efficient social classroom climate. This is crucial as classroom social climate is a fundamental factor for fostering favorable and enhanced learning experiences for all students. The role of cultural competence in the creation of such an environment needs to be keenly analyzed so as to sustain and continually foster these favorable conditions.

\section{Summary of Literature Review}

The focus of this study was to draw a connection between the variables under study. The following studies provided the framework to explore these variables in this cohesive manner. Bear et al. (2011) and Brand et al. (2003) illustrate the importance of the connection between individual characteristics such as culture and their environments, in particular, the educational environment. They note that when students perceive the presence of respect for diversity among students, and the teacher implements fair and 
equitable rules for all students, both academic achievement and psychological well-being are enhanced. Obgu (2003) also highlights the importance of race and ethnicity in the classroom environment. He suggests it be included in the educational climate framework since race is socially constructed, and indeed, it does impact student identity and experiences.

Valencia (as cited in Eccles \& Roeser, 2009) concludes "a mismatch of both the values of the school and the materials being taught contributed to the poor performance and high dropout rates among Latino youth in the high school they studied" (as cited in Eccles \& Roeser, 2009, p. 132).

Similarly, Deyhle and LeCompte (1999) argue that in the context of traditional middle schools, Native American youths tend to perform poorly. The authors ascribe this poor performance to "the misfit between the needs of young adolescents and the nature of junior high school environments" (as cited in Eccles \& Roeser, 200, p.132). These studies highlight the importance of cultural competence and its connection to the social classroom climate. They reveal that culture must be taken into consideration in the effort to create social environments that are motivating, engaging and facilitate learning.

\section{Methodology}

This study examined the relationship between teacher cultural competency and their students' perceptions of the social classroom climate using a quantitative, nonexperimental, correlational, cross-sectional, survey research design. Furthermore, this study draws conclusions on the extent to which its variables are related. This is achieved by utilizing survey instruments to quantify the variables under study (McMillan \& Schumacher, 2010). The data collected was specifically analyzed through descriptive 
statistics as well as through the use of HLM and MLR techniques. The outcome variables explored were the four factors of the Social Classroom Climate Measure: 1) teacher emotional support 2) teacher academic support 3) promotion of mutual respect 4) the promotion of task-related interaction. The level-1 student predictor variables were gradelevel, gender, SES, and ethnicity. The level-2 teacher predictor variables were level of cultural competency, ethnicity, educational level, and years of teaching experience for teachers.

\section{Population and Sample}

The population under study were teachers and students of a middle school in a Public School District in the Midwest. The MI School Data website reports that the only middle school in the district is comprised of 439 students and 25 teachers. Of these students, $62.41 \%$ are economically disadvantaged and $53.57 \%$ are male and $46.73 \%$ female. The reported student race/ethnicity breakdown of the district is American Indian $.46 \%$, African American 24.6\%, Asian or Pacific Islander $10.02 \%$, Hispanic of any race $12.98 \%$, Native Hawaiian $.91 \%$, two or more races $5.69 \%$, White $45.33 \%$. This student

population is divided into $6^{\text {th }}, 7^{\text {th }}$, and $8^{\text {th }}$ grade. Submission of consent and assent forms was a self-selection delimiting factor which produced a convenience sample of 24 teachers and 150 students.

\section{Summary of the Findings}

All four hypotheses were initially explored through HLM modeling. In the first factor TES, the unconditional model indicates that the average level of teacher emotional support is not different across teachers. In addition, the amount of unexplained variance 
between teachers, 0.003 , indicates that little or no natural clustering of students occurred with teachers. In other words, approximately $.03 \%$ of the total variance in teacher emotional support occurred between teachers and students. This result suggests that the initially hypothesized relationship was not present.

Consequently, the analysis continued utilizing MLR procedures. The best-fit MLR model indicates that grade-level is a significant predictor of teacher emotional support. This infers that the students' grade-levels impact their perceptions of received teacher emotional support. In essence, the results allow for the conclusion that students in lower grade-levels perceive a higher level of teacher emotional support.

The analysis of the second hypothesis yielded similar results. The fixed effect for the TAS intercept was not different across teachers. The computed ICC of .046 is indicative of little or natural clustering. This implies that this hypothesized relationship is not demonstrated. As with hypothesis one, an MLR analysis was conducted to determine the nature of the relationship between level-one variables on the outcome variable. This analysis illustrates that TAS can be predicted by the grade-level variable. However, unlike the first factor, students in higher grade-levels report a greater degree of teacher academic support.

Hypothesis three reflects results similar to the previous two hypotheses. The average level of promotion of mutual respect is not significantly different across teachers $\left(00^{\tau}=0.004, \mathrm{SE}=0.06, \mathrm{p}=.230\right)$. Between teachers and students, the amount of unexplained variance is $2^{\sigma}=0.13, \mathrm{SE}=0.36$. The computed ICC of .03 is indicative of little clustering. The follow-up MLR analysis indicates that level-one variables are not shown to be predictors of the outcome variable of mutual respect. Essentially, the data 
does not reflect the hypothesized relationship for level-one or level-two variables on the outcome variable of mutual respect.

Finally, the fourth unconditional model demonstrates a significant association regarding the outcome variable of task-related interaction $\left(00^{\tau}=0.55, \mathrm{SE}=0.74, \mathrm{p}=.04\right.$; $\left.2^{\sigma}=6.27, \mathrm{SE}=2.5 ; \mathrm{ICC}=.08\right)$. Based on this result, further model building was conducted. Level-one variables were entered into the HLM model. The analysis indicates that the student variables of ethnicity and grade-level are predictors of students' perceptions of the promotion of task-related interaction. That is, the coefficient of each ethnicity, as reported, is indicative of the predictive value to which each ethnic group perceives the promotion of task-related interaction. Additionally, there is an inverse relationship between grade-level and the outcome variable. This indicates that students at lower grade-levels tend to perceive a higher level of promotion task-related interaction.

Further model building was conducted, and the second-level teacher variables were entered. The results are evidence that teacher ethnicity is also a predictor of the promotion of task-related interaction. That is, there is an increase in the promotion of task-related interaction for the higher category of ethnicity. In essence, where Caucasian $=0$ and non-Caucasian $=1$, students perceive that non-Caucasian teachers promote taskrelated interaction more than their Caucasian counterparts.

With the intention of identifying the most efficient model to predict students' perceptions of the social classroom climate in multicultural classrooms, the final model was built and compared with the two previous models: the unconditional model and model six. It is worth noting that the final model only includes fixed and random effects that were statistically significant in earlier models. The results of these comparisons 
suggest that the final model is the best model for predicting students' perceptions of the outcome variable.

The results of exploring the four hypotheses show a striking departure from existing literature (Gay, 2010; Howard, 2012; Ryan \& Patrick, 2001; Patrick et al., 2011) that suggests cultural competence is associated with the social classroom climate. In fact, Gay (2010) notes that the primary purpose of culturally relevant teaching is to create a learning environment in which all students can be successful. Ladson Billing (1994) also posits that culturally relevant teaching informs both teacher-student interaction and classroom climate. Nieto and Bode (2012) further highlight the fact that teachers need to develop skills in multicultural communication and understanding. This cultural knowledge and awareness can have a substantive impact and make a major difference in a student's environment and learning.

This result is not uncommon in research that explores cultural competency. A recent study examining student engagement found that studying teacher cultural competency through the lens of students' perceptions yielded significant results in relation to student engagement. On the other hand, teacher self-reports indicated no relationship between cultural competence and student engagement. In essence, students' estimations of their teachers' cultural competence, rather than the teachers' evaluations of their own level of cultural competence, was shown to impact student engagement (Robinson, 2012).

Brace (2011) experienced a similar result in a study related to teacher cultural competence and its impact on student achievement. Quantitative data from this study indicates that teachers' scores on cultural competence did not correlate with students' 
academic achievement. However, qualitative analysis illustrates that relationships between teachers and students can impact student academic achievement. In essence, gaining more understanding of the effect of cultural competence must involve the student perspective.

\section{Conclusions and Discussions}

This study was the first to explore the relationship between cultural competency and the social classroom climate in multicultural middle school classrooms. Previous research has focused on teacher cultural competency or the social classroom climate. In addition, exploring the relationship of cultural competence with educational outcomes has typically focused on professional development, achievement, and engagement, rather than the actual learning environment. This study provides empirical support for both cultural competency and the social classroom climate, as quantified by the Teacher Multicultural Attitude Survey and the Social Classroom Climate Measure.

In addition, the first hypothesis shows that grade-level is a significant predictor of teacher emotional support. This finding is a noted phenomenon. Younger children often have a greater need for emotional support. As Furman and Buhrmester (1992) note, significant adults, such as teachers, "often serve as secondary attachment figures, helping to fulfill children's needs for nurturance and assistance"; this need, however, "typically diminishes with age" (p. 105). It is probable that this dynamic is the underlying factor that accounts for a higher perception of teacher emotional support among students in lower grades.

Other than the grade-level relationship, the hypothesized relationship with cultural competence, as measured in this study, was not indicated. Several explanations 
can account for this discrepancy. First, it is possible that correlational studies cannot account well for the impact of teacher cultural competence on emotional support because of the indirectness of the relationship between those variables.

Another potential explanation is that good teaching and CRT are so intertwined as factors that it is difficult to differentiate between the effect of cultural competence and general pedagogical strategies as they relate to the provision of emotional support. Ladson-Billings (1995) suggests that culturally relevant pedagogy is simply good teaching. She highlights that there is no 'magic bullet' or intricate formula and steps for instruction" (p. 159) when it comes to culturally appropriate teaching; rather, it is comprised of general teaching strategies that are a natural part of good teaching. What she questions is why good teaching rarely occurs in classrooms populated by minority students (Ladson-Billings, 1995a).

Third, teacher cultural competence may not have a direct impact on a student's perceptions of the emotional support factor of the classroom social climate, as measured in this study. It is possible that other instruments with differing conceptualizations and factors for the social classroom climate can be used to explore the relationship between these variables still further. This possibility exists because there is strong theoretical support for this relationship.

The exploration of the second hypothesis also indicates a relationship between grade-level and academic support. Ahmed, Minnaert, Van der Werf, and Kuyper (2010) recognize the importance of teacher support and its role in academic achievement. They posit that adolescents who have supportive social teacher relationships fare better academically. Further, they note that the presence or absence of teacher social support 
may precipitate positive or negative affective experiences, which in turn influence achievement. The current study, which indicates a relatively high perception of teacher academic support $(\mathrm{M}=18.19)$, reflects this link between academic support and social support. As students increasingly experience positive social relationships with their teachers, the subsequent result will be positive perceptions of teacher academic support.

With the exception of the grade-level variable, this factor did not indicate a relationship between the other predictor variables, particularly the hypothesized relationship to cultural competence. As outlined above, there are a few possible reasons for this outcome. An indirect relationship between the variables, difficulty differentiating between the effect of cultural competence, and deliberate pedagogical strategies that are geared toward academic support or the possibility of teacher cultural competence not having a direct impact on student perception of teacher support, as measured in this study.

In a similar fashion to the two previous hypotheses, hypothesis three did not indicate a relationship between the predictor variables and the mutual respect factor. Besides previous rationales for this outcome, Gaffney (2005) advances the view that mutual respect, in particular, is not determined by such characteristics as race, SES, and the like; rather, is negotiated within each classroom between the students and teachers. Additionally, mutual respect is not static but fluid, as it is continually tested through various situations and circumstances. Therefore, it is possible that the fluid nature of mutual respect, as described by Gaffney (2005), actually impacted the results of this study. That is, mutual respect is not a correlate of the variables identified in this study, but rather, it is a process that is negotiated on a daily and continual basis. Thus, it can be 
difficult for correlational studies to determine how this factor is impacted by extraneous variables, such as those identified in the current study.

The exploration of the fourth hypothesis, using HLM model building, indicates that the student variables of grade-level and ethnicity and teacher ethnicity were significant predictors for the promotion of task-related interaction. Interestingly, this connection between grade-level and student ethnicity ties into literature, which supports the idea that during adolescence, the need and perception of peer support peaks to the maximum (Furman \& Buhrmester, 1992). Additionally, during this developmental phase, those students who customarily have interactions with peers from different ethnic groups tend to engage comfortably and seek support from peers across racial groups. This view is supported by Fontanella (2008), who found that, despite a slight difference between racial groups regarding the extent to which interactions occurred, students were very comfortable regarding their peer interactions with students from other ethnic groups, particularly those who had regular interactions with diverse individuals. It is possible that the relationship between grade-level and student ethnicity, and the promotion of taskrelated interaction, as revealed in the current study, denotes the needs and unique trajectories associated with the adolescent phase of development.

In regard to teachers' ethnicities, McIntyre (1996) — through his research on teaching culturally different students - supports the view that teacher's ethnicities have an impact on task-related interaction. He suggests that Caucasian teachers tend to cultivate and advance field-independent teaching and learning. This involves the promotion of individualized work, personal achievement, and competition between students. On the other hand, culturally diverse individuals have an orientation toward 
field-dependent teaching and learning styles, which are often group oriented. This notion is reflected in the data, which indicates that non-Caucasian teachers promote task-related interaction to a greater degree than their Caucasian counterparts. Although the results are indicative of a relationship between task-related interaction and the three variables, the major premise - teacher cultural competence impacts students' perceptions of the social classroom climate - was not exhibited in this factor.

The results derived for the four hypothesized relationships lead to an overall implication for consideration. The teacher self-reporting perspective alone is not sufficient to provide an accurate perspective of teacher cultural competency, given the limited nature of a self-report methodology. Geron (2002) has urged researchers to include the clients' evaluations of their provider's cultural competency. He argues that the greatest weakness of current cultural competency measures is that practitioners base it solely on self-reports.

This position is supported by Kumas-Tan, Beagan, Loppie, MacLeod, and Frank (2007). These authors argue that measures of cultural competence are too often focused on teacher awareness and knowledge of culturally competent practice, while the actual use of this knowledge in practice is left unexamined. Essentially, it is necessary to evaluate both the teacher's and students' perspectives of a teacher's cultural competence.

The relationship between the student demographic variable of grade-level on three of the factors of the social classroom climate, as well as student and teacher ethnicity on the task-related factor of the classroom social climate, indicates the existence of a relationship between the variables. As such, it is possible that students' perspectives on cultural competence would serve to further highlight this relationship. This supposition 
has significant implications for student success. As both cultural competency and classroom climate are considered malleable to various conditions, the possibility as a potential factor for impacting the classroom environment and, consequently, student learning should motivate teachers and administrators to further explore the importance of culturally competent teachers (Moule, 2012).

\section{Recommendations for Practice}

Gay (2011) argues that the quality of interpersonal relationships has a tremendous effect on the total caliber of teaching and learning. Based on the results of the study, it can be argued that a student's perception of such relationships can be affected by a student's characteristics, including grade-level and ethnicity. This supports the push to place students at the center of learning and pedagogical decisions. This notion is at the heart of cultural competency because it requires teachers to have knowledge of the students, particularly the way in which each student learns the best. Culturally responsive pedagogy accommodates this notion because it notes, validates, facilitates, liberates, and empowers ethnically diverse students by simultaneously cultivating their cultural integrity, individual abilities, and academic success (Gay, 2010).

Students reported an overall positive social environment regarding all four factors, including student-teacher relationships. As noted above, such a positive environment is crucial to teaching and learning (Gay, 2010) because it validates the need to monitor, improve, and maintain a positive perception of the classroom social climate as the result of its influence and effect on motivation and learning. 


\section{Recommendations for Future Research}

As a result of this study, a number of future research studies can be conducted. First of all, this study can be replicated with schools in various districts. However, the students' perspectives of teacher cultural competence should be further measured to determine its impacts on the social classroom climate. Second, the data from the MI School Data website indicates that the cultural composition of a school population can vastly differ by district. For instance, whereas one school may have a very diverse student population, another may have a more homogenous student population, with the majority of students belonging to one particular ethnic group or another. Future research could include the perspectives of students from these different populations in order to maximize variance. Third, future research can be conducted using different survey instruments. Because different surveys tend to provide different contextual and background variables, it will be interesting to observe how the findings will be impacted by the use of similar models with different factors. Fourth, because the current study did not explain why certain relationships between the social classroom climate and contextual and background variables were either present or absent, further studies can be conducted to gain a deeper understanding of reasons underlying these relationships. Finally, this research study follows the self-report methodology used in previous studies on cultural competency and classroom social climate. The survey method, although simple to administer and efficient for data collection, lacks the depth that a mixed methodology will provide. The inclusion of triangulation - multiple ways of observing data - through the implementation of a mixed methodology would allow for a more intensive study of the variables and provide more conclusive data. 
Cultural competence and culturally competent practices are both complex and comprehensive. The study of this construct is still in its inchoate stages, although it is steadily progressing toward maturity as a scientifically respectable construct (Lum, 2011). This study is an initial exploration of the relationship between teacher cultural competency and the classroom social climate. Further advancements in the cultural competency arena will be beneficial to both teachers and students alike. With an everincreasing diversity of the student population, understanding the role of cultural competency when creating classroom environments where all students are motivated to learn is becoming increasingly important. This view was long espoused by Nieto (1999), who recognizes the connection between the classroom social environment and learning. She states, "learning cannot be separated from the context within which it takes place" (Nieto, 1999, p. 11).

\section{Limitations of the Study}

First, the result concerning the exploratory variable of teacher cultural competency, suggests an internal validity issue. Teacher self-reported cultural competency did not show a statistically significant relationship to the classroom social climate. It is possible that a confounding variable prevented a precise illustration of the association between teacher self-reports of cultural competence and the classroom environment. For example, recent professional development, reading in cultural competency or cross-cultural issues may have influenced the results. Moreover, the respondents may have chosen responses based on their need to produced socially desirable results, and these may have also confounded the results. It may also be the case that the teacher respondents were more likely to have the self-perception of possessing 
the knowledge, skills and attitudes necessary for cultural competency simply because they worked with multicultural students.

According to Rosenberg, Greenfield, and Dimick (2006), self-reported data have several potential sources of bias. These include selective memory, which is, remembering or not remembering past experiences, telescoping, which involves recalling the timing of events erroneously; and social desirability, which entails reporting behaviors and attitudes that are widely accepted rather than actual behaviors. Thus, it is important to interpret all findings of this study with these limitations in mind.

Secondly, the non-experimental design of this study also reduces its generalizability. The methodology employed a convenience sample of middle school students in Grades 6 to 8, and their teachers. With self-selection as a delimiting factor, the study sample comprised of 24 teachers and 150 students. The response rate for the teachers was $96 \%$ while the response rate for students was $34 \%$. Regardless, these findings cannot be generalized far beyond this specific sample. Future studies would benefit from expanding the effort to additional schools and districts and also providing additional motivation for student participation.

Finally, HLM research has addressed the importance of sample size at each level when estimating multilevel models. The HLM analysis for this study utilized 24 level-2 units (teachers) with a cluster size of approximately 6 level-1 units (students). Researchers, such as Browne and Draper (2000) and Raudenbush and Bryk (2002), both report that sample sizes of 24-30 provide adequate power to produce reasonable variance estimates. Browne and Draper (2000) further note that in general the number of groups bears more importance than the number of individuals per group. This study met the 
minimum sample size requirement for reasonable variance estimates. However, it is possible that a larger sample size would have created a more robust estimate.

Because of these limitations, this study should be viewed as an initial exploration of the relationship between cultural competency and the classroom social climate. As a first step, these findings must be examined within the context of similar studies using middle school teachers and students in various multicultural settings. Future studies should also seek a larger sample size to generalize the findings. 
APPENDIX A

VARIABLE TABLE 


\begin{tabular}{|c|c|c|c|}
\hline Variable & $\begin{array}{l}\text { Conceptual } \\
\text { Definition }\end{array}$ & $\begin{array}{c}\text { Instrumental } \\
\text { Definition }\end{array}$ & Operational Definition \\
\hline $\begin{array}{l}\text { Teacher } \\
\text { Cultural } \\
\text { Comp. }\end{array}$ & $\begin{array}{l}\text { Cultural } \\
\text { competency is } \\
\text { the ability to } \\
\text { successfully } \\
\text { teach students } \\
\text { who come from } \\
\text { cultures other } \\
\text { than your own. } \\
\text { For this study, it } \\
\text { entails mastering } \\
\text { awareness and } \\
\text { sensitivity to } \\
\text { other cultures, } \\
\text { various bodies of } \\
\text { knowledge, and }\end{array}$ & $\begin{array}{l}\text { Scores on the } 20 \\
\text { item Teacher } \\
\text { Multicultural } \\
\text { Attitude Survey } \\
\text { (TMAS) on a } \\
\text { five point Likert } \\
\text { Scale ranging } \\
\text { from: } \\
\text { 1 = Strongly } \\
\text { Disagree } \\
\text { 2= Disagree } \\
3 \text { = Uncertain } \\
\text { 4= Agree } \\
\text { Items: See } \\
\text { Appendix B } \\
\text { Agree } \\
\text { Strongly }\end{array}$ & $\begin{array}{l}\text { An interval variable with } \\
\text { scores ranging between } 20 \\
\text { and } 100 \text { on the TMAS scale. }\end{array}$ \\
\hline $\begin{array}{l}\text { Control } \\
\text { Variable- } \\
\text { QDI/ }\end{array}$ & $\begin{array}{l}\text { Measures racial } \\
\text { and gender bias } \\
\text { among late } \\
\text { adolescents and } \\
\text { adults. }\end{array}$ & $\begin{array}{l}\text { Scores on the } 30 \\
\text { item Quick } \\
\text { Discrimination } \\
\text { Index (QDI) on a } \\
\text { five point Likert }\end{array}$ & $\begin{array}{l}\text { An interval variable with } \\
\text { scores ranging between } 30 \\
\text { and } 150 \text { on the QDI/SAS } \\
\text { scale. }\end{array}$ \\
\hline
\end{tabular}




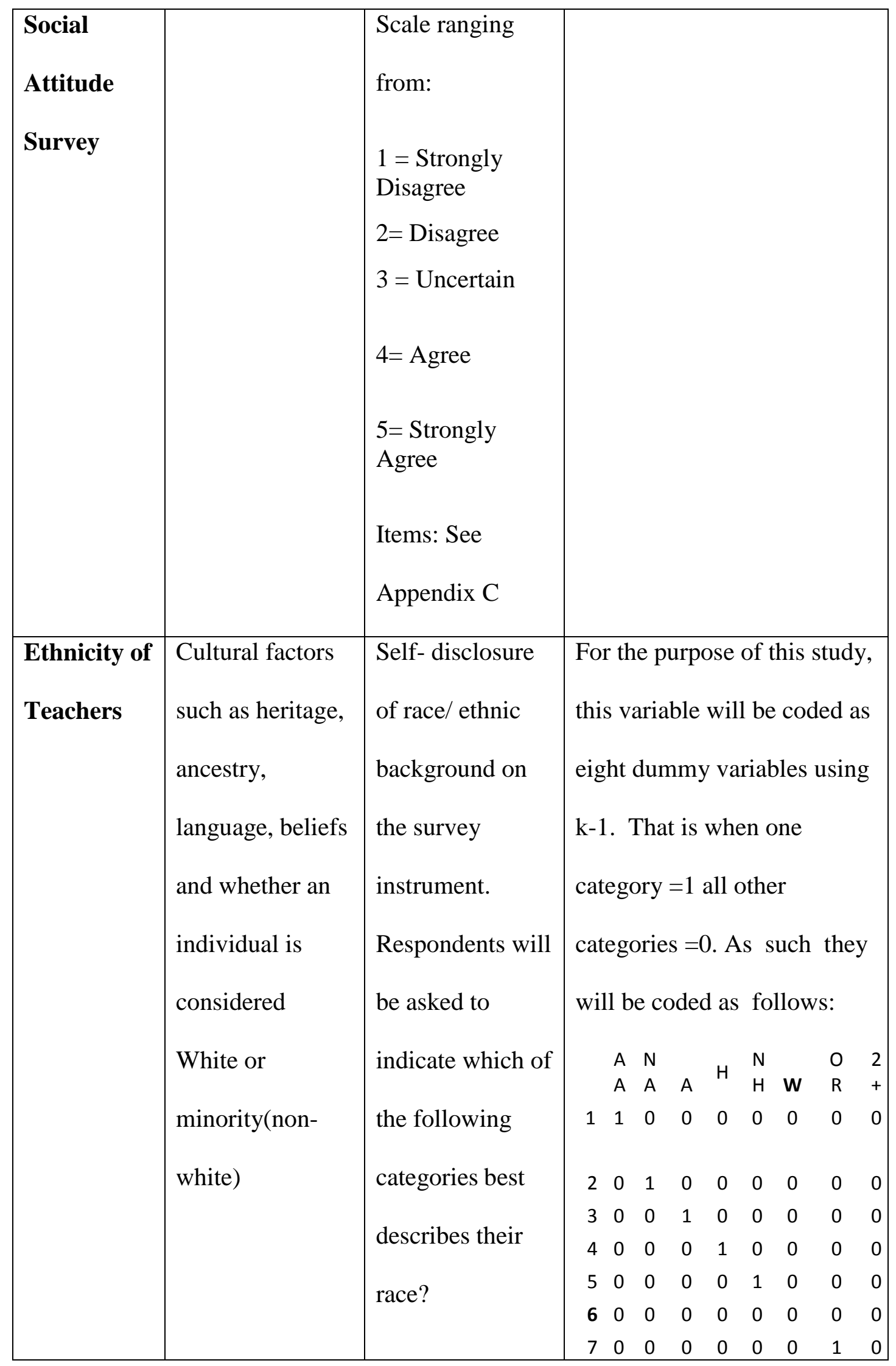




\begin{tabular}{|c|c|c|c|}
\hline & & $\begin{array}{l}\square \text { African } \\
\text { American } \\
\text { /Black } \\
\square \text { American } \\
\text { Indian/ Native } \\
\text { American } \\
\square \text { Asian } \\
\square \text { Hispanic or } \\
\text { Latino } \\
\square \text { Native } \\
\text { Hawaiian / } \\
\text { Pacific } \\
\text { Islander } \\
\square \text { White/Caucasi } \\
\text { an } \\
\square \text { Other race } \\
\square \text { 2+ Races }\end{array}$ & $\begin{array}{lllllllll}8 & 0 & 0 & 0 & 0 & 0 & 0 & 0 & 1\end{array}$ \\
\hline $\begin{array}{l}\text { Teacher } \\
\text { Edu. } \\
\text { Level }\end{array}$ & $\begin{array}{l}\text { The highest } \\
\text { educational } \\
\text { degree obtained. }\end{array}$ & $\begin{array}{l}\text { Self- disclosure } \\
\text { educational } \\
\text { level. Coded as: } \\
\square \quad \text { 1=Associa } \\
\text { te degree } \\
\square \quad \text { 2=Bachel } \\
\text { or's } \\
\text { degree } \\
\quad \begin{array}{l}3=\text { Master' } \\
\text { s degree } \\
4=\text { Doctora } \\
\text { te degree }\end{array}\end{array}$ & $\begin{array}{l}\text { An ordinal variable with } \\
\text { scores between } 1-4 \text {. }\end{array}$ \\
\hline
\end{tabular}




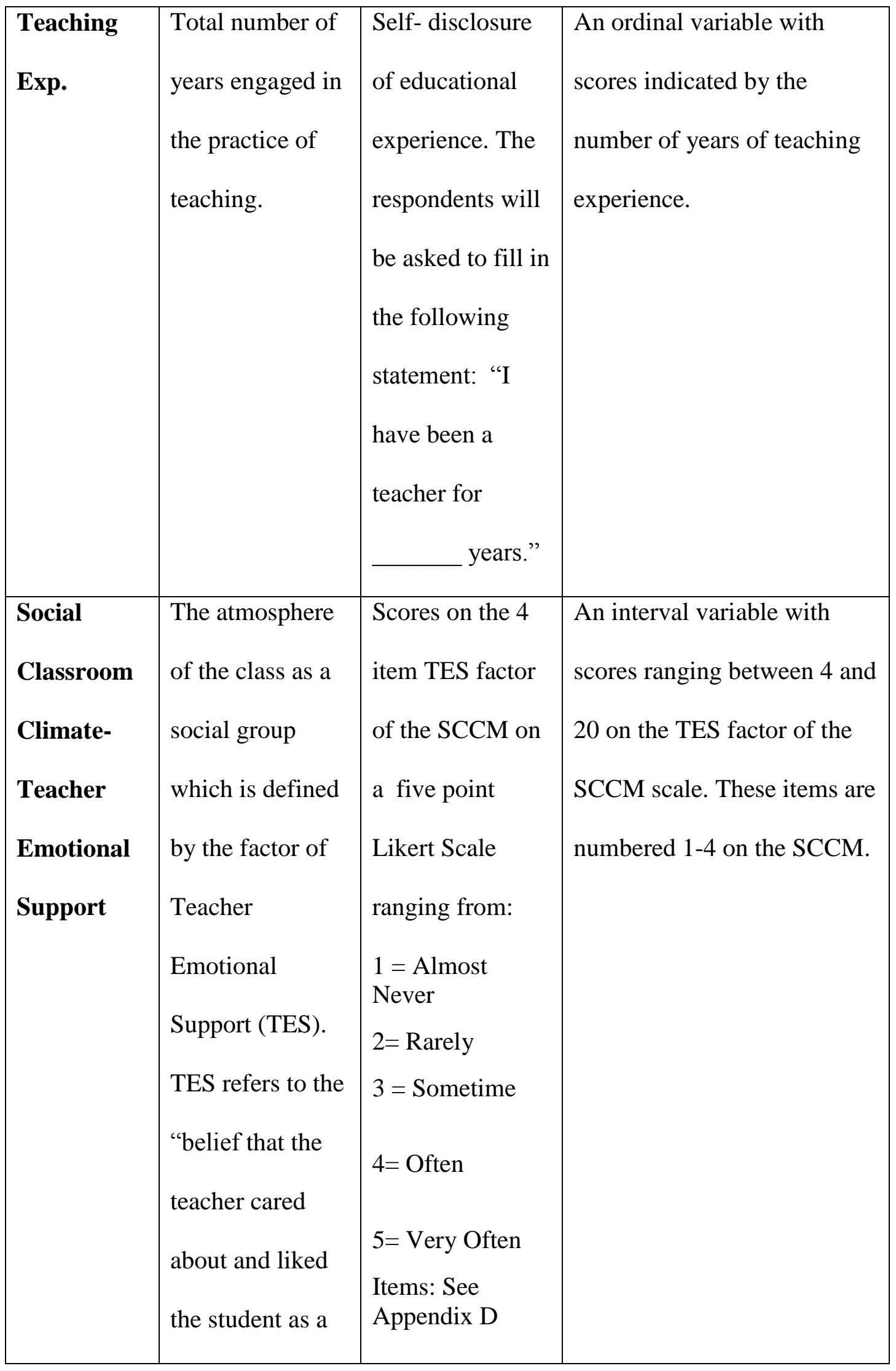




\begin{tabular}{|c|c|c|c|}
\hline & $\begin{array}{l}\text { person" (Patrick } \\
\text { et al., 2007, } \\
\text { 2011). }\end{array}$ & & \\
\hline $\begin{array}{l}\text { Social } \\
\text { Classroom } \\
\text { Climate- } \\
\text { Teacher } \\
\text { Academic } \\
\text { Support }\end{array}$ & $\begin{array}{l}\text { The atmosphere } \\
\text { of the class as a } \\
\text { social group } \\
\text { which is defined } \\
\text { by the factor of } \\
\text { Teacher } \\
\text { Academic } \\
\text { Support (TAS). } \\
\text { TAS refers the } \\
\text { belief that the } \\
\text { "teacher cared } \\
\text { about how much } \\
\text { (Patrick et al., } \\
\text { the student } \\
\text { learned and } \\
\text { wanted to help }\end{array}$ & $\begin{array}{l}\text { Scores on the } 4 \\
\text { item TAS factor } \\
\text { of the SCCM on } \\
\text { a five point } \\
\text { Likert Scale } \\
\text { ranging from: } \\
1=\text { Almost } \\
\text { Never } \\
2=\text { Rarely } \\
3=\text { Sometime } \\
4=\text { Often } \\
\text { 5= Very Often } \\
\text { Items: See } \\
\text { Appendix D }\end{array}$ & $\begin{array}{l}\text { An interval variable with } \\
\text { scores ranging between } 4 \text { and } \\
20 \text { on the TAS factor of the } \\
\text { SCCM scale. These items are } \\
\text { numbered } 5-8 \text { on the SCCM. }\end{array}$ \\
\hline $\begin{array}{l}\text { Social } \\
\text { Classroom }\end{array}$ & $\begin{array}{l}\text { The atmosphere } \\
\text { of the class as a }\end{array}$ & $\begin{array}{l}\text { Scores on the } 5 \\
\text { item PRM factor }\end{array}$ & $\begin{array}{l}\text { An interval variable with } \\
\text { scores ranging between } 5 \text { and }\end{array}$ \\
\hline
\end{tabular}




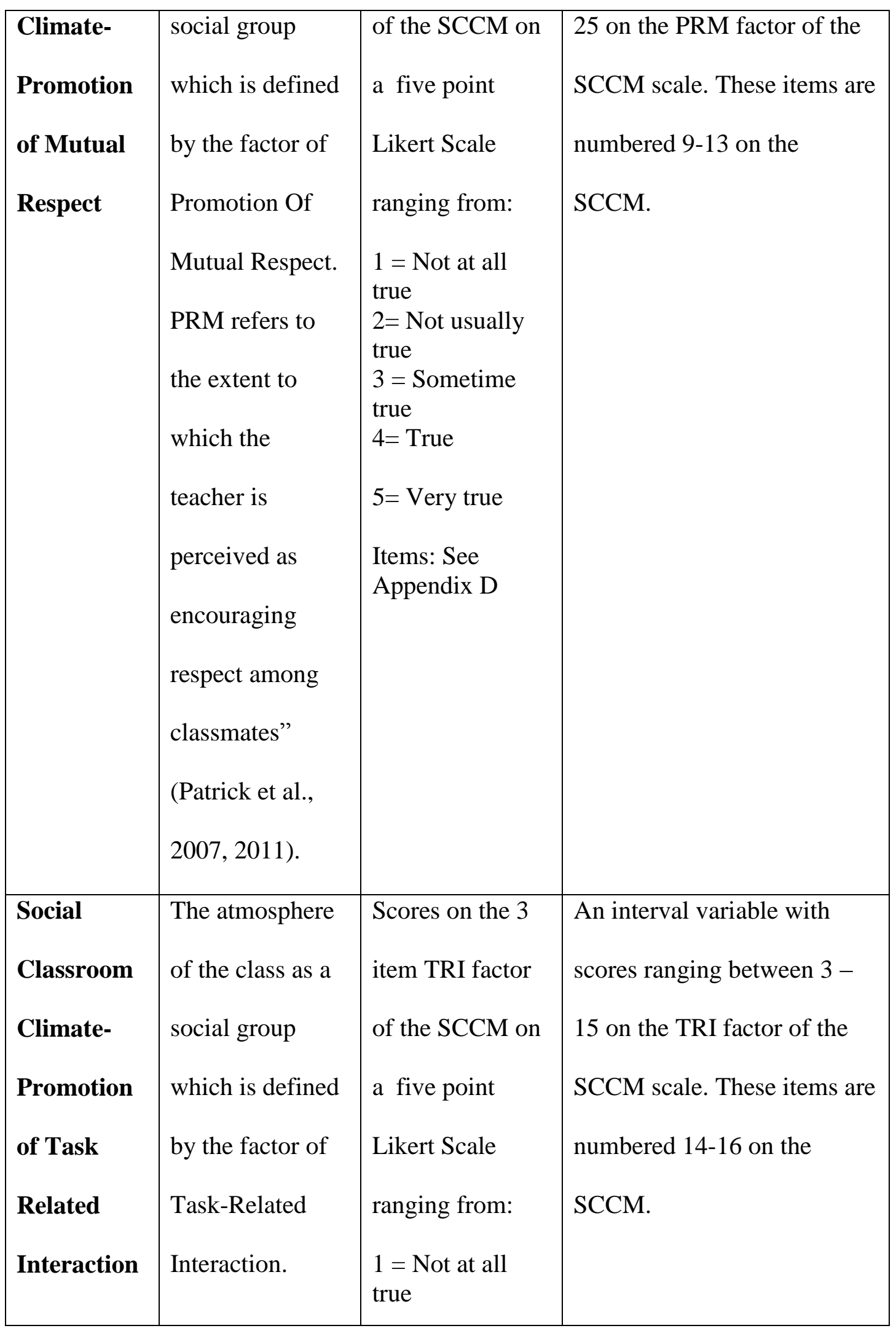




\begin{tabular}{|c|c|c|c|}
\hline & & 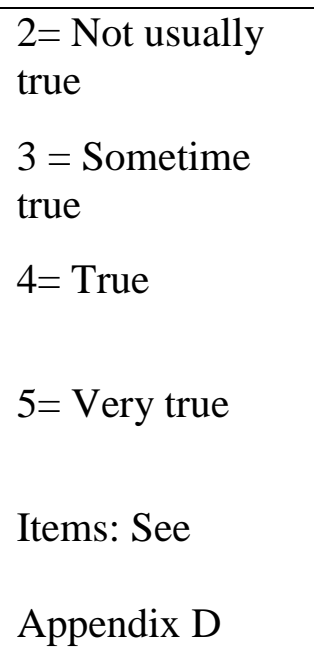 & \\
\hline $\begin{array}{l}\text { Student } \\
\text { Grade }\end{array}$ & $\begin{array}{l}\text { The student } \\
\text { current grade- } \\
\text { level. }\end{array}$ & $\begin{array}{l}\text { Student self- } \\
\text { disclosure of } \\
\text { grade. Coded as: } \\
\square \quad 6^{\text {th }} \text { grade } \\
\square \quad 7^{\text {th }} \text { grade } \\
\square \quad 8^{\text {th }} \text { grade }\end{array}$ & $\begin{array}{l}\text { An ordinal variable with } \\
\text { scores between } 1-3 \text {. }\end{array}$ \\
\hline $\begin{array}{l}\text { Student } \\
\text { Gender }\end{array}$ & $\begin{array}{l}\text { The behavioral, } \\
\text { cultural, and } \\
\text { psychological } \\
\text { traits typically } \\
\text { associated with } \\
\text { one's sex. }\end{array}$ & $\begin{array}{l}\text { Student self- } \\
\text { disclosure of } \\
\text { gender. } \\
\text { Respondents will } \\
\text { be asked to } \\
\text { indicate which of } \\
\text { the following } \\
\text { categories best } \\
\text { describes their } \\
\text { gender. }\end{array}$ & $\begin{array}{l}\text { For the purpose of this study, } \\
\text { this variable will be coded as } \\
\text { a dummy variable. That is } \\
\text { when one category }=1 \text { the } \\
\text { other category }=0 \text {. As such it } \\
\text { will be coded as follows: } \\
\text { Male }=1 \\
\text { Female }=0\end{array}$ \\
\hline
\end{tabular}




\begin{tabular}{|c|c|c|c|c|c|c|c|c|c|c|c|}
\hline & & $\begin{array}{l}\square \quad \text { Male } \\
\square \quad \text { Female }\end{array}$ & & & & & & & & & \\
\hline $\begin{array}{l}\text { Student } \\
\text { SES }\end{array}$ & $\begin{array}{l}\text { The approximate } \\
\text { economic status } \\
\text { of the students. }\end{array}$ & $\begin{array}{l}\text { Student self- } \\
\text { disclosure being } \\
\text { a recipient of a } \\
\text { free/ reduced } \\
\text { lunch. Coded as } \\
\square \quad \text { Free } \\
\square \quad \text { Reduced } \\
\square \quad \text { Paid }\end{array}$ & & bres & be & we & en & $1-3$ & wit & & \\
\hline $\begin{array}{l}\text { Student } \\
\text { Ethnicity }\end{array}$ & $\begin{array}{l}\text { Cultural factors } \\
\text { such as heritage, } \\
\text { ancestry, } \\
\text { language, beliefs } \\
\text { and whether an } \\
\text { individual is } \\
\text { considered } \\
\text { White or } \\
\text { minority (non- } \\
\text { white). }\end{array}$ & $\begin{array}{l}\text { Student self- } \\
\text { disclosure of } \\
\text { race/ ethnic } \\
\text { background. } \\
\text { Respondents will } \\
\text { be asked to } \\
\text { indicate which of } \\
\text { the following } \\
\text { categories best } \\
\text { describes their } \\
\text { race? } \\
\square \text { African } \\
\text { American } \\
\text { /Black }\end{array}$ & $\begin{array}{l}\text { cat } \\
\text { cat } \\
\text { wi }\end{array}$ & ego & $\begin{array}{l}0 \\
0 \\
0 \\
0\end{array}$ & $\begin{array}{l}A \\
0 \\
0 \\
1 \\
0 \\
0 \\
0 \\
0 \\
0\end{array}$ & $\begin{array}{l}0 \\
0 \\
0 \\
1 \\
0 \\
0 \\
0 \\
0\end{array}$ & $\begin{array}{l}0 \\
0 \\
0\end{array}$ & $\begin{array}{c}\mathbf{W} \\
0 \\
0 \\
0 \\
0 \\
0 \\
0 \\
0 \\
0\end{array}$ & $\begin{array}{l}\text { tudy } \\
\text { ed a } \\
\text { usins } \\
\text { they } \\
\text { s: }\end{array}$ & $\begin{array}{l}2 \\
+ \\
0 \\
0 \\
0 \\
0 \\
0 \\
0 \\
0 \\
1\end{array}$ \\
\hline
\end{tabular}




\begin{tabular}{|l|l|l|}
\hline & $\square$ American \\
Indian/ Native \\
American \\
$\square$ Asian \\
$\square$ Hispanic or \\
Latino \\
$\square$ Native \\
Hawaiian / \\
Pacific \\
Islander \\
$\square$ White/Caucasi \\
an \\
$\square$ Other race \\
$\square$ 2+ Races \\
\\
\end{tabular}


APPENDIX B

SURVEYS 


\section{TEACHER MULTICULTURAL ATTITUDE SURVEY (TMAS)}

\section{Copyright by Joseph G. Ponterotto et al. (1995)}

Demographic Questions- Please complete the following question before proceeding to fill out the survey.

Q. Education: What is the highest degree or level of school you have completed? If currently enrolled, highest degree received.
Associate degree
Bachelor's degree
$\square \quad$ Master's degree
$\square \quad$ Doctorate degree

Q. Experience: Please specify in the blank area the total number of years you have been a teacher.

I have been a teacher for years.

Q. Which of the following best describes your race?

African American /Black

$\square$ American Indian/ Native American

$\square$ Asian

$\square$ Hispanic or Latino

$\square \quad$ Native Hawaiian / Pacific Islander

$\square \quad$ White/Caucasian

$\square \quad$ Other race

$\square \quad 2+$ Races 
Please respond to all items in the survey. Remember there are no right or wrong answers. The survey is anonymous; do not put your name on the survey. Please circle the appropriate number below.

Use the following scale to rate each item.

$\begin{array}{lllll}1 & 2 & 3 & 4 & 5 \\ \text { Strongly } & \text { Disagree } & \text { Uncertain } & \text { Agree } & \text { Strongly } \\ \text { Disagree } & & & & \text { Agree }\end{array}$

1. I find teaching a culturally diverse student group rewarding.

$\begin{array}{lllrr}1 & 2 & 3 & 4 & 5\end{array}$

2. Teaching methods need to be adapted to meet the needs of a culturally diverse student group.
1
2
3
4
5

3. Sometimes I think there is too much emphasis placed on multicultural awareness and training for teachers.
1
2
3
4
5

4. Teachers have the responsibility to be aware of their students' cultural backgrounds.
1
2
3
4
5

5. I frequently invite extended family members (e.g., cousins, grandparents, godparents, etc.) to attend parent-teacher conferences.
1
2
3
4
5

6. It is not the teacher's responsibility to encourage pride in one's culture.

$\begin{array}{lllrr}1 & 2 & 3 & 4 & 5\end{array}$

7. As classrooms become more culturally diverse the teacher's job becomes increasingly challenging.
1
2
3
4
5

8. I believe the teacher's role needs to be redefined to address the needs of students from culturally diverse backgrounds.
1
2
3
4
5

9. When dealing with bilingual students, some teachers may misinterpret different communication styles as behavioral problems.
1
2
3
4 
Use the following scale to rate each item.

$\begin{array}{lllll}1 & 2 & 3 & 4 & 5 \\ \text { Strongly } & \text { Disagree } & \text { Uncertain } & \text { Agree } & \text { Strongly } \\ \text { Disagree } & & & & \text { Agree }\end{array}$

10. As classrooms become more culturally diverse, the teacher's job becomes increasingly rewarding.

$\begin{array}{lllll}1 & 2 & 3 & 4 & 5\end{array}$

11. I can learn a great deal from students with culturally different backgrounds.

$\begin{array}{lllll}1 & 2 & 3 & 4 & 5\end{array}$

12. Multicultural training for teachers is not necessary.

$\begin{array}{lllll}1 & 2 & 3 & 4 & 5\end{array}$

13. In order to be an effective teacher, one needs to be aware of cultural differences present in the classroom.

$\begin{array}{lllll}1 & 2 & 3 & 4 & 5\end{array}$

14. Multicultural awareness training can help me work more effectively with a diverse population.

$\begin{array}{lllll}1 & 2 & 3 & 4 & 5\end{array}$

15. Students should learn to communicate in English only.

$\begin{array}{lllll}1 & 2 & 3 & 4 & 5\end{array}$

16. Today's curriculum gives undue importance to multiculturalism and diversity

$\begin{array}{lllll}1 & 2 & 3 & 4 & 5\end{array}$

17. I am aware of the diversity of cultural backgrounds in my classroom.

$\begin{array}{lllll}1 & 2 & 3 & 4 & 5\end{array}$

18. Regardless of the racial and ethnic makeup of my class, it is important for all students to be aware of multicultural diversity.
1
2
3
$4 \quad 5$

19. Being multiculturally aware is not relevant for the subject I teach.

$\begin{array}{llllll}1 & 2 & 3 & 4 & 5\end{array}$

20. Teaching students about cultural diversity will only create conflict in the classroom.
1
2
3
4
5 
Do you have any thoughts or comments about this survey, or about the research topic? 


\title{
QUICK DISCRIMINATION INDEX
}

Copyright by Joseph G. Ponterotto et al. (1995)

\author{
Social Attitude Survey
}

Please respond to all items in the survey. Remember there are no right or wrong answers. The survey is completely anonymous, do not put your name on the survey. Please circle the appropriate number to the right.

\section{Strongly Disagree Not Agree Strongly Disagree Sure Agree}

1. I do think it is more appropriate for the mother of a newborn baby, rather than the father, to stay home with the baby during the first year.

2. It is as easy for women to succeed in business as it is for men.

$\begin{array}{lllll}1 & 2 & 3 & 4 & 5\end{array}$

3. I really think affirmative action programs

$\begin{array}{lllll}1 & 2 & 3 & 4 & 5\end{array}$
on college campuses constitute reverse discrimination.

4. I feel I could develop an intimate relationship with someone from a different race.

5. All Americans should learn to speak two languages.

6. I look forward to the day when a woman is President of the United States.

$\begin{array}{lllll}1 & 2 & 3 & 4 & 5\end{array}$

7. Generally speaking, men work harder than

$1 \quad 2 \quad 3 \quad 4$
women.

8. My friendship network is very racially mixed. $\begin{array}{lllllll}1 & 2 & 3 & 4 & 5\end{array}$

$\begin{array}{llllllll}\text { 9. I am against affirmative action programs } & 1 & 2 & 3 & 4 & 5\end{array}$ in business. 


\section{Strongly Disagree Not Agree Strongly Disagree Sure Agree}

10. Generally, men seem less concerned with building relationships than do women.

11. I would feel O.K. about my son or daughter $\begin{array}{llllll}1 & 2 & 3 & 4 & 5\end{array}$ dating someone from a different race.

12. I was very happy when an African American $\begin{array}{llllll}1 & 2 & 3 & 4 & 5\end{array}$ (Barack Obama) was elected President of the United States on November 4, 2008.

13. In the past few years there has been too much attention directed toward multicultural issues in education.

14. I think feminist perspectives should be an integral part of the higher education curriculum.

15. Most of my close friends are from my own racial group.

16. I feel somewhat more secure that a man rather than a woman, is currently President of theUnited States.

17. I think that it is (or would be) important for $\begin{array}{lllllll}1 & 2 & 3 & 4 & 5\end{array}$ my children to attend schools that are racially mixed.

18. In the past few years there has been too much attention directed towards multicultural issues in business.

19. Overall, I think racial minorities in America complain too much about racial discrimination.

20. I feel (or would feel) very comfortable having a woman as my primary physician. 


\section{Strongly Disagree Not Agree Strongly Disagree Sure Agree}

21. I think the President of the United States should make a concerted effort to appoint $\begin{array}{lllll}1 & 2 & 3 & 4 & 5\end{array}$ more women and racial minorities to the country's Supreme Court.

22. I think white people's racism toward racial minority groups still constitutes a major problem in America.

23. I think the school system, from elementary 1

2

3
school through college, should encourage minority and immigrant children to learn and fully adopt traditional American values.

24. If I were to adopt a child, I would be happy to adopt a child of any race.

25. I think there is as much female physical violence towards men as there is male physical violence toward women.

26. I think the school system, from elementary school through college, should promote values representative of diverse cultures.

27. I believe that reading the autobiography of Malcolm X would be of value.

28. I would enjoy living in a neighborhood consisting of a racially diverse population (e.g., Asians, Blacks, Hispanics, Whites).

29. I think it is better if people marry within their own race.

30. Women make too big of a deal out of sexual harassment issues in the workplace. 


\section{SOCIAL CLASSROOM CLIMATE MEASURE}

Adapted from Patrick, Kaplan \& Ryan, 2007

Demographic Questions- Please complete the following question before proceeding to fill out the survey.

Q. Grade: Please indicate your current grade-level

$\square \quad 6^{\text {th }}$ grade

$\square \quad 7^{\text {th }}$ grade

$\square \quad 8^{\text {th }}$ grade

Q. Gender: Please specify your gender.

$\square \quad$ Male

$\square \quad$ Female

Q. Which of the following best describes your race?

$\square \quad$ African American /Black

$\square$ American Indian/ Native American

$\square \quad$ Asian

$\square \quad$ Hispanic or Latino

$\square \quad$ Native Hawaiian / Pacific Islander

$\square \quad$ White/Caucasian

$\square$ Other race

$\square \quad 2+$ Races

Q. Please indicate the type of lunch you receive.

Free

$\square \quad$ Reduced

$\square$ Paid 
Please respond to all items in the survey. Remember, there are no right or wrong answers. The survey is anonymous; do not put your name on the survey. Please circle the appropriate number below.

Instructions: Use the following values of a 5 point scale to score each of the questions on the questionnaire:

5 The statement is always or almost always true for you (around 100\%)

4 The statement is often true for you (around 75\%)

3 The statement is sometimes true for you (around 50\%)

2 The statement is rarely true for you (around 25\%)

1 The statement is never or almost never true for you (around 0\%)

$\begin{array}{lcccc}1 & 2 & 3 & 4 & 5 \\ \text { Not true } & \text { Usually } & \text { Sometime } & \text { Often } & \text { Very True } \\ \text { At all } & \text { not true } & \text { True } & \text { True } & \end{array}$

1. Does your teacher respect your opinion?

1

2

3

4

5

2. Does your teacher really understand how you feel about things?

1

2

3

4

5

3. Does your teacher try to help you when you are sad or upset?

1

2

3

4

5

4. Can you count on your teacher for help when you need it?

1

2

3

4

5

5. Does your teacher like to see your work?

1

2

3

4

5

6. Does your teacher care about how much you learn?

1

2

3

4 


$\begin{array}{lcccc}1 & 2 & 3 & 4 & 5 \\ \text { Not true } & \text { Usually } & \text { Sometime } & \text { Often } & \text { Very True } \\ \text { At all } & \text { not true } & \text { True } & \text { True } & \end{array}$

7. Does your teacher want you to do your best in school?

$\begin{array}{lllll}1 & 2 & 3 & 4 & 5\end{array}$

8. Does your teacher like to help you learn?

$\begin{array}{lllll}1 & 2 & 3 & 4 & 5\end{array}$

9. My teacher wants us to respect each other's opinions.

$\begin{array}{lllll}1 & 2 & 3 & 4 & 5\end{array}$

10. My teacher does not allow students to make fun of other students' ideas in class.

$\begin{array}{lllll}1 & 2 & 3 & 4 & 5\end{array}$

11. My teacher makes sure that students don't say anything negative about each other in class.

$\begin{array}{lllll}1 & 2 & 3 & 4 & 5\end{array}$

12. My teacher does not let us make fun of someone who gives the wrong answer.

$\begin{array}{llllll}1 & 2 & 3 & 4 & 5\end{array}$

13. My teacher wants all students to feel respected.

$\begin{array}{lllll}1 & 2 & 3 & 4 & 5\end{array}$

14. My teacher allows us to discuss our work with classmates.

$\begin{array}{lllll}1 & 2 & 3 & 4 & 5\end{array}$

15. My teacher encourages us to share ideas with one another in class.

$\begin{array}{lllll}1 & 2 & 3 & 4 & 5\end{array}$

16. My teacher lets us ask other students when we need help with our work.

$\begin{array}{lllll}1 & 2 & 3 & 4 & 5\end{array}$ 
APPENDIX C

IRB APPROVAL LETTER 


\section{Andrews $\$$ University}

February 24, 2015

Olivia Spence

Tel: $\mathrm{xxx}$

Email: $\underline{\mathrm{xxx}}$

RE: APPLICATION FOR APPROVAL OF RESEARCH INVOLVING HUMAN

SUBJECTS IRB Protocol \#: 15-011 Application Type: Original Dept.: Teaching, Learning \& Curriculum Review Category: Full Action Taken: Approved

Advisor: Elvin Gabriel

Title: Teachers' cultural competence and students' perception of the social classroom climate in culturally different middle school classrooms.

This letter is to advise you that the Institutional Review Board (IRB) has reviewed and approved your IRB application for research involving human subjects entitled: "Teachers' cultural competence and students' perception of the social classroom climate in culturally different middle school classrooms" IRB protocol number 15-011 under Full category.

This approval is valid until February 24, 2016. If your research is not completed by the end of this period you must apply for an extension at least four weeks prior to the expiration date. We ask that you inform IRB Office whenever you complete your research. Please reference the protocol number in future correspondence regarding this study.

Any future changes (see IRB Handbook pages 10-11) made to the study design and/or consent form require prior approval from the IRB before such changes can be implemented. To request for an extension, modification and completion of your study please use the attached form.

While there appears to be no more than minimum risk with your study, should an incidence occur that results in a research-related adverse reaction and/or physical injury, (see IRB Handbook page 11) this must be reported immediately in writing to the IRB. Any project-related physical injury must also be reported immediately to the University physician, Dr. Reichert, by calling (269) 4732222.

We wish you success in your research project. Please feel free to contact our office if you have questions.

Sincerely,

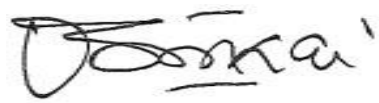

Mordekai Ongo

Research Integrity \& Compliance Officer

Institutional Review Board - 4150 Administration Dr Room 322 - Berrien Springs, MI 49104-0355

Tel: (269) 471-6361 Fax: (269) 471-6543 E-mail: irb @ andrews.edu 


\title{
Andrews $\$$ University \\ Office of Research \& Creative Scholarship
}

February 24, 2015

Olivia Spence

Email: $\underline{\mathrm{xxx}}$

\begin{abstract}
RE: APPLICATION FOR APPROVAL OF RESEARCH INVOLVING HUMAN SUBJECTS IRB Protocol \#: 15-011 Application Type: Original Dept.: Teaching, Learning \& Curriculum Review Category: Full Action Taken: Approved Advisor: Elvin Gabriel
\end{abstract}

Title: Teachers' cultural competence and students' perception of the social classroom climate in culturally different middle school classrooms.

This letter is to advise you that the Institutional Review Board (IRB) has reviewed and approved your IRB modification application for research involving human subjects entitled: 'Teachers' cultural competence and students' perception of the social classroom climate in culturally different middle school classrooms" IRB protocol number 15-011 under Full category. This approval is valid until February 24, 2016. If your research is not completed by the end of this period you must apply for an extension at least four weeks prior to the expiration date. We ask that you inform IRB Office whenever you complete your research. Please reference the protocol number in future correspondence regarding this study.

Any future changes (see IRB Handbook pages 10-11) made to the study design and/or consent form require prior approval from the IRB before such changes can be implemented. To request for extension, modification and completion of your study please use the attached form.

While there appears to be no more than minimum risk with your study, should an incidence occur that results in a research-related adverse reaction and/or physical injury, (see IRB Handbook page 11) this must be reported immediately in writing to the IRB. Any project-related physical injury must also be reported immediately to the University physician, Dr. Reichert, by calling xxx

We wish you success in your research project. Please feel free to contact our office if you have questions.

Sincerely,

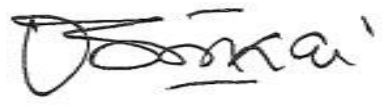

Mordekai Ongo

Research Integrity \& Compliance Officer

Institutional Review Board - 4150 Administration Dr Room 322 - Berrien Springs, MI 49104-0355 E-mail: irb@andrews.edu 
APPENDIX D

INSTITUTIONAL CONSENT 

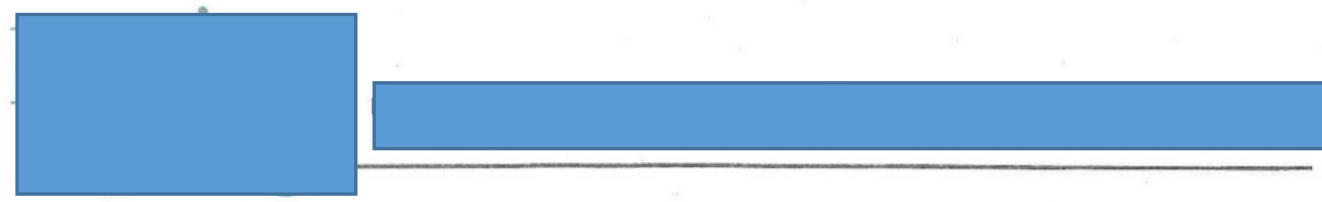

Institutional Review Board

Andrews University

4150 Administrative Drive, Room 322

Berrien Springs, MI 49104-0355

Attn: Andrews University Institutional Review Board

I have reviewed Ms. Olivia Spence research protocol titled "Teachers' Cultural Competence and Students' Perception of the Social Classroom Climate in Culturally Different Middle School Classrooms", including letters of consent and assent.

I understand what she is asking of the individuals and grant her permission to conduct her study at $\square$. I have the authority to grant such permission. The scope of the permission granted to Ms. Spence is outlined below:

- To administer a survey to all students at the whose parents/guardians have consented and will assent to participate in the study.

- The students who will not participate will be allowed to stay in the classroom and will be asked to read a chapter designated by the teacher.

- The research assistants who will administer the survey to the students will be introduced to the class.

- The teacher will then leave to a designated area and will return when the research assistant indicates to the teacher that the students are finished.

- Teachers who have consented to participate in the study will complete their surveys in a designated area.

I am aware that if I have any further questions about this research study Ms. Spence can be I also understand that if I have any questions regarding this IRB approval or the rights of research participants I can also contact $\mathrm{H}$
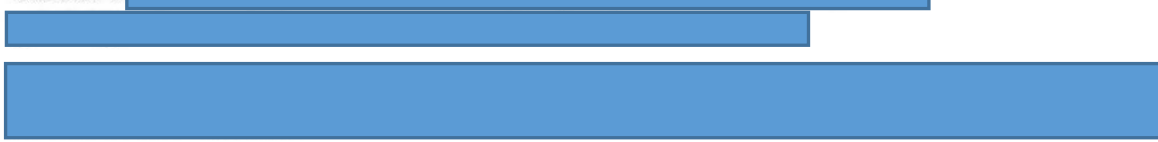

(SIGNATURF)

(Date)

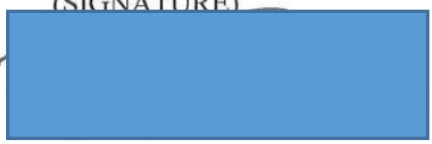

Tanumry 28,2015 
APPENDIX E

INFORMED CONSENTS 


\section{Andrews University}

\section{TEACHER INFORMED CONSENT FORM}

My name is Olivia Spence, I am conducting a research study as part of my dissertation project, in partial fulfillment of my Ph.D. program at Andrews University, Berrien Springs, Michigan. Your participation in this study is greatly appreciated.

Research Title: Teachers' Cultural Competence and Students' Perception of the Social Classroom Climate in Culturally Different Middle School Classrooms.

Purpose of Study: The purpose of this research is to measure students' perception of the social classroom climate as influenced by teacher-student relationships. In particular, the study will investigate whether teachers' self-reported ability to manage relationships within diverse student populations impacts students' reported perceptions of the social climate.

Duration of participation in the study: I understand that I will be asked to complete two surveys which will take approximately 15 minutes of my time to complete.

Procedures I have been informed that teachers from the XXX Middle School will be asked to respond to one survey relating to their self-perception of cultural competence and another relating to social attitude.

Benefits: I understand that there are no direct benefits to me, however, there may be benefits to be derived from the outcomes of the study.

Risks: I understand that the study involves no more than minimal risks.

Voluntary Participation: I have been informed that my participation in this study is completely voluntary, refusal to participate will involve no penalty or loss of benefits to which I am otherwise entitled. That I may discontinue participation at any time without penalty or loss of benefits to which I may otherwise be entitled.

Confidentiality: I understand that no personal identifiers will be collected. I understand that my identity in this study will not be disclosed in any published document. And that the researcher will keep the records in private and secured storage for a period not less than 3 years.

Contact: I am aware that I can contact the supervisor of this study Dr. Elvin Gabriel at xxx for answers to questions related to this study.

I have read the contents of this consent and know that I can receive verbal explanations to questions I may have. I hereby give my voluntary consent to participate in this study. I am fully aware that if I have any additional questions I can contact Olivia Spence at XXX and/or the supervisor of this study. 
Phone Contact

Date

Researcher Name

Researcher Signature

Date

Please sign, keep a copy and return a copy to the researcher. 


\section{Andrews University}

\section{PARENTAL INFORMED CONSENT FORM}

My name is Olivia Spence, I am conducting a research study as part of my dissertation project, in partial fulfillment of my Ph.D. program at Andrews University, Berrien Springs, Michigan. Your child's participation in this study is greatly appreciated.

Research Title: Teachers' Cultural Competence and Students' Perception of the Social Classroom Climate in Culturally Different Middle School Classrooms.

Purpose of Study: The purpose of this research is to measure students' perception of the social classroom climate as influenced by teacher-student relationships. In particular, the study will investigate whether teachers' self-reported ability to manage relationships within diverse student populations impacts students' reported perceptions of the social climate.

Duration of participation in the study: I understand that my child will be asked to complete a survey which will take approximately 15 minutes to complete.

Procedures I have been informed that students from the XXX Middle School will be asked to respond to the survey relating to their self-perception of the social classroom climate.

Benefits: I understand that there are no direct benefits to my child, however, there may be benefits to be derived from the outcomes of the study.

Risks: I understand that the study involves no more than minimal risks.

Voluntary Participation: I have been informed that my child's participation in this study is completely voluntary, refusal to participate will involve no penalty or loss of benefits to which your child is otherwise entitled. That your child may discontinue participation at any time without penalty or loss of benefits to which he/she may otherwise be entitled.

Confidentiality: I understand that no personal identifiers will be collected. I understand that my child's identity in this study will not be disclosed in any published document. And that the researcher will keep the records in private and secured storage for a period not less than 3 years.

Contact: I am aware that I can contact the supervisor of this study Dr. Elvin Gabriel for answers to questions related to this study.

I have read the contents of this consent form and know that I can receive verbal explanations to questions I may have. I hereby give my voluntary consent for my child to participate in this study. I am fully aware that if I have any additional questions I can contact Olivia Spence and/or the supervisor of this study.

Permission: As parent or legal guardian, I authorize participant in the research study described in this form. (child's name and grade) to become a 
Parent's Name

Phone Contact

Researcher Name

Please sign, keep a copy and return a copy return to the school secretary.
Signature

Date

Researcher Signature

Date 


\section{Andrews University \\ STUDENT ASSENT FORM}

My name is Olivia Spence and I am doing a study to learn about your beliefs concerning the classroom relationship between students and teachers. I am asking you to help because it will allow me to understand what you think about your teachers and the classroom environment. The title of the study is Teachers' Cultural Competence and Students' Perception of the Social Classroom Climate in Culturally Different Middle School Classrooms. This means that I will be examining whether your teachers' beliefs about their ability to manage relationships with diverse student affects your beliefs about classroom relationships between students and teachers.

If you agree to be in the study, I am going to ask you some questions about your teachers. I want to know if you think they care about you and the other students. For example, I will ask if you think your teacher wants you to do your best. If you decide at any time not to finish you can stop at any time.

This study will take up 15 minutes of your time. You can ask me questions about this study at any time. All students of the class will then be invited to participate in a pizza party upon completion of the survey.

The questions asked are only about what you think. There are no right or wrong answers because this is not a test. Your responses are anonymous and there are no identifying codes linking you to the survey.

If you sign this paper, it means that you have read this and that you want to be in the study. If you don't want to be in the study, do not sign this paper. Being in the study is up to you, and no one will be upset if you do not participate in the study.

Thank you for providing me with feedback!

Your printed name:

Your signature:

Date 
Dear Parent/Legal Guardian,

\section{Re: Recruitment Letter Parent/Legal Guardian}

I am writing to request your permission to allow your child to participate in my research study. My name is Olivia Spence, I am a doctoral candidate from the Teaching, Learning and Curriculum Department at Andrews University, Berrien Springs, MI. This study is part of my dissertation project, which partially fulfills of the requirements of the Ph.D. program.

As indicated in the attached letter, this research project has been approved by the school principal, Mr. Ryan Pesce. This study is titled Teachers' Cultural Competence and Students' Perception of the Social Classroom Climate in Culturally Different Middle School Classrooms.

The purpose of this study is to measure students' perception of the social classroom climate as influenced by teacher-student relationships. In particular, the study will investigate whether teachers' self-reported ability to manage relationships within diverse student populations impacts students' reported perceptions of the social climate.

Your child's participation involves completing a 15-minute survey relating to selfperception of the social classroom climate. Additionally, your child will be invited to participate in a pizza party upon completion of the survey.

If you have any questions or concerns about the research please feel free to contact: Principal investigator, Olivia Spence or faculty advisor Dr. Elvin Gabriel at

If you agree to allow your child to participate in the study please sign and return the attached Parental Informed Consent Form to the school secretary.

Thank you in advance for giving your time and attention to this endeavor.

Sincerely,

Olivia Spence, Ph.D. Candidate

Andrews University 


\section{REFERENCE LIST}

Abrams, L. S., \& Moio, J. (2009). Critical race theory and the cultural competence dilemma in social work education. Journal of Social Work Education, 45(2), 245 261.

Ahmed, W., Minnaert, A., Van der Werf, G., \& Kuyper, H. (2010). Perceived social support and early adolescents' achievement: The mediational roles of motivational beliefs and emotions. Journal of Youth and Adolescence, 39(1), 3646.

Ahnert, L., Harwardt-Heinecke, E., Kappler, G., Eckstein-Madry, T., \& Milatz, A. (2012). Student-teacher relationships and classroom climate in first grade: How do they relate to students' stress regulation? Attachment \& Human Development, 14(3), 249-263.

Anderson, A., Hamilton, R. J., \& Hattie, R. (2004). Classroom climate and motivated behavior in secondary schools. Learning Environments Research, 7(3), 211-225.

Andrews, D., Nonnecke, B., \& Preece, J. (2003). Electronic survey methodology: A case study in reaching hard-to-involve Internet users. International Journal of HumanComputer Interaction, 16(2), 185-210.

Avant, T. S., Gazelle, H., \& Faldowski, R. (2011). Classroom emotional climate as a moderator of anxious solitary children's longitudinal risk for peer exclusion: A child $\times$ environment model. Developmental Psychology, 47(6), 1711-1727. doi: http://dx.doi.org/10.1037/a0024021

Balfanz, R. (2009). Putting middle grades students on the graduation path: A policy and practice brief. Westerville, $\mathrm{OH}$ : National Middle School Association. Retrieved from https://www.amle.org/portals/0/pdf/articles/Policy_Brief_Balfanz.pdf

Banks, J. A. \& Banks, C. A. M. (Eds.). (2004). Handbook of research on multicultural education (2nd ed.). San Francisco: Jossey-Bass.

Barth, J. M., Dunlap, S. T., Dane, H., Lochman, J. E., \& Wells, K. C. (2004). Classroom environment influences on aggression, peer relations, and academic focus, Journal of School Psychology, 42(2), 115-133. 
Bartholomew, C. (2007). Teachers' perceptions of school and classroom influences on their support for student self- determination: an ecological approach. (Doctoral Dissertation). Retrieved from ProQuest Dissertations and Theses. (3302983)

Bear, G.G., Gaskins, C., Blank, J., \& Chen, F.F. (2011). Delaware school climate survey: Its factor structure, concurrent validity, and reliability. Journal of School Psychology, 49(2), 157-174. doi.org/10.1016/j.jsp.2011.01.001

Bennett, J. M. (2001). The relationship between classroom climate and student achievement (Doctoral Dissertation). Retrieved from ProQuest Dissertations and Theses. (304714963)

Betancourt, J. R. (2003). Cross-cultural medical education: Conceptual approaches and frameworks for evaluation. Academic Medicine, 78(6), 560-569.

Bierman, K. L., Coie, J. D., Dodge, K. A., Greenberg, M. T., Lochman, J. E., McMahon, R. J., \& Pinderhughes, E. (2010). The effects of a multiyear universal socialemotional learning program: The role of student and school characteristics. Journal of Consulting and Clinical Psychology, 78(2), 156-168. doi: http://dx.doi.org/10.1037/a0018607

Black, S. (2006). Respecting differences. American School Board Journal, 193(1), 34-36.

Bodrova, E., \& Leong, D.J. (2007). Tools of the mind: The Vygotskian approach to early childhood education (2nd ed.). New York: Merrill/Prentice Hall.

Brace, A. (2011).Cultural competence and its impact on student academic achievement in urban elementary schools (Unpublished doctoral dissertation). Knoxville, TN: University of Tennessee.

Brand, S., Felner, R., Shim, M., Seitsinger, A., \& Dumas, T. (2003). Middle school improvement and reform: Development and validation of a school-level assessment of climate, cultural pluralism, and school safety. Journal of Educational Psychology, 95(3), 570-588. doi:10.1037/0022-0663.95.3.570

Bronfenbrenner, U. (1974). Developmental research, public policy and the ecology of childhood. Child Development, 45(1), 1-5.

Bronfenbrenner, U. (1979). The ecology of human development: Experiments by nature and design. Cambridge, MA: Harvard University Press.

Bronstein, L. R., Berman-Rossi, T., \& Winfield, B. (2002). Beyond cultural specificity: Teaching the impact of oppression on all clients' lives. Journal of Progressive Human Services, 13(2), 43-59. 
Browne, W. J. \& Draper, D. (2000). Implementation and performance issues in the Bayesian and likelihood fitting of multilevel models. Computational Statistics, 15(3), 391-420.

Bustamante, R., Nelson, J., \&Onsuegbuzie, A. (2009). Assessing school-wide cultural competence: Implications for school leadership preparation. Educational Administration Quarterly, 45(5), 793-827.

Calloway-Thomas, C. (2010). Empathy in the global world: An intercultural perspective. Thousand Oaks, CA: Sage.

Carnegie Council on Adolescent Development (1995).Great transitions: Preparing adolescents for a new century. New York: Carnegie Corporation.

Coello, H., Casaňas, J., Rocco, T., \& Parsons, M. (2003). Using critical race theory: An analysis of cultural differences in healthcare education. In S. Nielsen \& T. Rocco (Eds.), Proceedings of Supporting Interdisciplinary Inquiry: The 2nd annual college of education research conference (pp. 46-51). Miami: Florida International University. Retrieved from http://education.fiu.edu/research_conference/docs/proceedings/2003_COERC_Pr oceedings.pdf

Coggins, P., \& Campbell, S. D. (2008). Using cultural competence to close the achievement gap. The Journal of Pan African Studies, 2(4), 44-58.

Cohen, L. \& Manion, L. (1994). Research methods in education (4th ed.). London: Routledge.

Collie, R. J., Shapka, J. D., \& Perry, N. E. (2012). School climate and social-emotional learning: Predicting teacher stress, job satisfaction, and teaching efficacy. Journal of Educational Psychology, 104(4), 1189-1204. doi: http://dx.doi.org/10.1037/a0029356

Colombo, M. W. (2005). Empathy and cultural competence: Reflections from teachers of culturally diverse children. Young Children, 60(6), 44-46. Retrieved from http://www.naeyc.org/files/yc/file/200511/ColomboBTJ1105.pdf

Creswell, J. W. (1994). Research design: Qualitative and quantitative approaches. Thousand Oaks, CA: Sage.

Creswell, J. W. (2008). Educational research: Planning, conducting and evaluating quantitative and qualitative research. Upper Saddle River, N.J: Pearson/Merrill Prentice Hall. 
Cross, T., Bazron, B., Dennis, K., \& Isaacs, M. (1989). Towards a culturally competent system of care, Vol. I. Washington, DC: Georgetown University Child Development Center, Child and Adolescent Service System Program (CASSP) Technical Assistance Center.

Davis, K. (1997). Exploring the intersection between cultural competency and managed behavioral health care policy: Implications for state and county mental health agencies. Alexandria, VA: National Technical Assistance Center for State Mental Health Planning.

Delgado, R., \& Stefanicic, J. (2001). Critical race theory: An introduction. New York: New York University Press.

De Lisi, R. \& Golbeck, S. L.(1999). Implication of Piaget's theory for peer-learning. In O’Donnell, A. M. \& King, A. (Eds.) Cognitive perspectives on peer-learning. Mahwah, New Jersey: Lawrence Erlbaum Associates.

Delpit, L. (1995). Other people's children: Cultural conflict in the classroom. New York: The New York Press.

Delpit, L. (2006). Other people's children: Cultural conflict in the classroom (2nd ed.). New York: The New York Press.

Deng, B. (1992). A multilevel analysis of classroom climate effects on mathematics achievement of fourth-grade students. (ERIC Document Reproduction Service No. Ed 348 222)

Diamond, A., Barnett, W. S., Thomas J., \& Munro, S. (2007). Preschool program improves cognitive control. Science, 318(5855), 1387-1388. Retrieved from http://thesciencenetwork.org/docs/BrainsRUs/Education\%20Forum_Diamond.pdf

Diamond, J.B., Randolph, A. \& Spillane, J.P. (2008). Teachers' expectations and sense of responsibility for student learning: The importance of race, class, and organizational habitus. Anthropology and Education Quarterly, 35(1), 75-98.

Diller, J., \& Moule, J. (2005).Cultural competence: A primer for educators. Portland, OR: Book News.

Eccles, J., Midgley, C., Wigfield, A., Buchanan, C. M., Reuman, D., Flanagan, C., \& Mac Iver, D. (1993). Development during adolescence: The impact of stage environment fit on young adolescents' experience in schools and families. American Psychologist, 48(2), 90-101. 
Eccles, J. S., \& Roeser, R. W. (2009). Schools, academic motivation, and stageenvironment fit. In R. M. Lerner \& L. Steinberg (Eds.), Handbook of adolescent psychology, Vol 1: Individual bases of adolescent development (3rd ed.) (pp. 404434). Hoboken, NJ: John Wiley \& Sons Inc.

Edwards, P. T. (2010). Eighth-grade students' perceptions of school climate based on school diversity, ethnicity, educational category, socioeconomic status, and achievement (Doctoral Dissertation). Retrieved from ProQuest Dissertations \& Theses. (744098909)

Elias, M. J., \& Haynes, N. M. (2008). Social competence, social support, and academic achievement in minority, low-income, urban elementary school children. School Psychology Quarterly, 23(4), 474-495. doi: http://dx.doi.org/10.1037/10453830.23.4.474

Ellerbrock, C. R., \& Kiefer, S. M. (2013). The interplay between adolescent needs and secondary school structures: Fostering developmentally responsive middle and high school environments across the transition. High School Journal, 96(3), 170194.

Erickson, F. (1987). Transformation and school success: The politics and culture of educational achievement. Anthropology \& Educational Quarterly, 18(4), 335356.

Evans, I. M., Harvey, S. T., Buckley, L. \& Yan, E. (2009). Differentiating classroom climate concepts: Academic, management, and emotional environments, Kotuitui: New Zealand Journal of Social Sciences Online, 4(2), 131-146, doi:10.1080/1177083X.2009.9522449

Federal Interagency Forum on Child and Family Statistics. (2013). America's children: Key national indicators of well-being, 2013. Retrieved from http://www.childstats.gov/americaschildren/demo.asp

Feger, M. (2006). "I want to read": How culturally relevant texts increase student engagement in reading. Multicultural Education, 13(3), 18.

Figueroa-Sanchez, M. (2008). Building emotional literacy: Groundwork to early learning. Childhood Education, 84(5), 301-304.

Fontanella, J. F. (2008). Impact of racial, ethnic, and socioeconomic diversity: Student perceptions of educational outcomes in a Northern Virginia Public School system. (Doctoral dissertation). Retrieved from http://digitalcommons.liberty.edu/doctoral/128. 
Fraser, B. J., Aldridge, J. M., \& Adolphe, F. S. G. (2010). A cross-national study of secondary science classroom environments in Australia and Indonesia. Research in Science Education, 40(4), 551-571. doi: 10.1007/s11165-009-9133-1

French, S. E., Seidman, E., Allen, L. \& Aber, J.L. (2006). The development of ethnic identity during adolescence. Developmental Psychology, 42(1), 1-10. doi: $10.1037 / 0012-1649.42 .1 .1$

Frenzel, A. C., Goetz, T., Lüdtke, O., Pekrun, R., \& Sutton, R. E. (2009). Emotional transmission in the classroom: Exploring the relationship between teacher and student enjoyment. Journal of Educational Psychology, 101(3), 705-716. doi: http://dx.doi.org/10.1037/a0014695

Furman, W., \& Buhrmester, D. (1992). Age and sex differences in perceptions of networks and personal relationships. Child Development, 63(1), 103-115.

Furness, S. (2005). Shifting sands: Developing cultural competence. Practice, 17, $247-$ 256.

Gaffney, J. (2005). Mutual respect and its influence on classroom culture: A short review of a field experience in a local high school. (Unpublished manuscript). Raleigh, NC: North Carolina State University. Retrieved from http://www4.ncsu.edu/ jdgaffne/respect.pdf

Gallegos, J. S., Tindall, C., \& Gallegos, S.A. (2008). The need for advancement in the conceptualization of cultural competence. Advances in Social Work, 9(1), 51-62.

Gay, G. (2000). Culturally responsive teaching: Theory, research, and practice. New York: Teachers College Press.

Gay, G. (2003). Curriculum theory and multicultural education. In J.A. Banks \& C. A. McGee-Banks (Eds.), Handbook of research on multicultural education (2nd ed.) (pp. 30-49). San Francisco, CA: Jossey-Bass.

Gay, G. (2010).Culturally responsive teaching: Theory, research, and practice (2 $2^{\text {nd }}$ ed.). New York: Teachers College Press.

Geron, S. M. (2002). Cultural competency: How is it measured? Does it make a difference? Generations, 26(3), 39-45.

Getzels, J., \& Thelen, H. (1960). The classroom as a unique social system. National Society for the Study of Education Yearbook, 59(1), 53-81.

Gies, E. A. (2010). A case study of cultural competency: The transformation of individuals and collective perception and practice (Doctoral dissertation).Retrieved from ProQuest Dissertations and Theses. (828353768) 
Gould, R. (2007). An ecological approach to national education reform:

Recommendations for the reauthorization of No Child Left Behind. Journal of the National Center for Youth Law, 28(2), 1-26. Retrieved from

http://youthlaw.org/publication/an-ecological-approach-to-national-educationreform/

Grant, C.A. \& Ladson-Billings, G. (Eds.). (1997). Dictionary of multicultural education. Phoenix, Arizona: The Oryx Press.

Gray, P. \& Thomas, D.J. (2006). Critical reflections on culture in nursing. Journal of Cultural Diversity, 13(2), 76-82.

Griner, A., \& Stewart, M. (2013). Addressing the achievement gap and disproportionality through the use of culturally responsive teaching practices. Urban Education, 48(4), 585-621. doi:10.1177/0042085912456847

Groves, R. M., Fowler, F. J., Couper, M. P., Lepkowski, J. M., Singer, E., \& Tourangeau, R. (2004). Survey methodology. Hoboken, NJ: John Wiley \& Sons.

Hanley, M. S. \& Noblit, G. W. (2009). Cultural responsiveness, racial identity and academic success: A review of literature. Arlington, VA: The Heinz Endowments. Retrieved from http://www.heinz.org/UserFiles/Library/Culture-Report_FINAL.pdf

Haynes, B. G. F. (2008). Enriching the fabric: The role of cultural competency in higher education (Doctoral Dissertation). Retrieved from ProQuest Dissertations and Theses. (304833091)

Hofstede, G. J. (2005). Cultures and organizations: Software of the mind (Revised and expanded 2nd ed.). New York: McGraw-Hill.

Howard, G. R. (2006). We can't teach what we don't know: White teachers, multiracial schools (2nd ed.). New York: Teachers College Press.

Howard, T. (2012). Culturally responsive pedagogy. In J.A. Banks (Ed.), Encyclopedia of Diversity in Education. Thousand Oaks, CA: Sage.

Howe, C. \& Mercer, N. (2007).Children's social development, peer interaction and classroom learning. Primary Review Research Reports. Cambridge: University of Cambridge. Retrieved from http://cprtrust.org.uk/wp-content/uploads/2014/06/Primary_Review_21b_briefing_Social_development_learning_071214.pdf 
Hox, J. J. (1995). Applied Multilevel Analysis (2nd ed.). Amsterdam, Netherlands: TTPublikaties.

Irvine, J. J. (2009). Relevant: Beyond the basics. Teaching Tolerance, 36, 40-44

Jay, M. (2003). Critical race theory, multicultural education and the hidden curriculum of hegemony. Multicultural Perspectives, 5(4), 3-9.

Kreft, I. \& de Leeuw, J. (1998). Introducing Multilevel Modelling. London: Sage Publications.

Koplow, L. (2002). Creating schools that heal: Real-life solutions. New York: Teachers College Press.

Koth, C. W., Bradshaw, C. P., \& Leaf, P. J. (2008). A multilevel study of predictors of student perceptions of school climate: The effect of classroom-level factors. Journal of Educational Psychology, 100(1), 96-104. doi: http://dx.doi.org/10.1037/00220663.100.1.96

Kumas-Tan Z, Beagan B, Loppie C, MacLeod A, \& Frank B. (2007). Measures of cultural competence: Examining hidden assumptions. Academic Medicine, 82(6), 548-57. Retrieved from

http://culturalmeded.stanford.edu/pdf\%20docs/KurmasTan\%20Examining\%20Hi dden\%20Assumptions.pdf

La Salle, T. P. (2013). Cultural and ecological considerations within the context of school climate (Doctoral dissertation). Retrieved from ProQuest Dissertations and Theses. (1448561172)

Ladson-Billings, G. (1990). Culturally relevant teaching: Effective instruction for Black students. The College Board Review, 7(15), 20-25.

Ladson-Billings, G. (1994). The Dreamkeepers: Successful teachers of African-American children. San Francisco: Jossey-Bass.

Ladson-Billings, G. (1995a).Toward a theory of culturally relevant pedagogy. American Educational Research Journal, 32(3), 465-491.

Ladson-Billings, G. (1995b). But that's just good teaching! The case for culturally relevant pedagogy. Theory Into Practice, 34(3), 159-16.

Ladson- Billings, G. (2003). New directions in multicultural education: Complexities boundaries and critical race theory. In J.A. Banks \& C. A. McGee-Banks (Eds.), Handbook of research on multicultural education (2nd ed.) (pp. 50-67). San Francisco, CA: Jossey-Bass. 
Ladson-Billings, G. (2005). The evolving role of critical race theory in educational scholarship. Race Ethnicity and Education, 8(1), 115-119 doi: 10.1080/1361332052000341024

Lau, K. \& Lee, J. (2008). Examining Hong Kong students' achievement goals and their relations with students' perceived classroom environment and strategy use. Educational Psychology, 28(6), 357-372.

Lee, M. Y. \& Greene, G. J. (2003). A teaching framework for transformative multicultural social work education. Journal of Ethnic \& Cultural Diversity in Social Work, 12(3), 1-28.

Lester, P. E. \& Bishop, L. K. (1997). Handbook of tests and measurement in education and the social sciences. Lancaster, PA: Technomic Pub. Co.

Lewis, C.W., James, M., Hancock, S., \& Hill-Jackson, V. (2008). Framing African American students' success and failure in urban settings: A typology for change. Urban Education, 43(2), 127-153.

Lindsey, R. B., Nuri-Robins, K., \& Terrell, R. D. (2003). Cultural proficiency: A manual for school leaders (2nd ed.). Thousand Oaks, CA: Corwin Press.

Lindsey, R. B., Nuri-Robins, K., Lindsey, D. B., \& Terrell, R. D. (2009). Cultural proficiency: Changing the conversation. Leadership, 38(4), 12.

Loukas, A. \& Robinson, S. (2004). Examining the moderating role of perceived school climate in early adolescent adjustment. Journal of Research on Adolescence, 14(2), 209-233. doi:10.1111/j.1532-7795.2004.01402004.x

Luke, D. (2004). Multilevel modeling. Newbury Park, CA: Sage Publications.

Lum, D. (2011). Culturally competent practice: A framework for understanding diverse groups and justice issues. Belmont, CA: Brooks/Cole Publishing Company.

Marks, A. N. (2011). Cultural Competence: What teachers know and perceive (Doctoral dissertation).Retrieved from ProQuest Dissertations and Theses. (863675186)

McIntyre. T. (1996). Does the way we teach create behavior disorders in culturally different students? Education and Treatment of Children, 19(3), 354-370.

Retrieved from

http://www.behavioradvisor.com/C-Learn.html

McMillan, J.H. \& Schumacher, S. (2010). Research in education: Evidence-based inquiry (7th ed.). New Jersey: Pearson Education Inc. 
Meyer, D. K. \& Turner, J. C. (2006). Re-conceptualizing emotion and motivation to learn in classroom contexts. Educational Psychology Review, 18(4), 377-390.

Moos, R. (1973). Conceptualizations of human environments. American Psychologist, 28(8), 652-664.

Moos, R. (1979). Evaluating educational environments: Procedures, measures, findings, and policy implications. San Francisco: Jossey-Bass.

Moule, J. (2012). Cultural competence: A primer for educators (2nd ed.). Belmont, CA: Wadsworth Cengage Learning.

National Center for Cultural Competence. (2013). Curricula enhancement module series. Retrieved from http://www.nccccurricula.info/culturalcompetence.html

National Center for Education Information. (2012). Profile of teachers in the U.S. 2011. Retrieved from http://www.ncei.com/Profile_Teachers_US_2011.pdf

National Center for Education Statistics. (2013). The condition of education, 2013. Retrieved from http://nces.ed.gov/pubs2013/2013037.pdf

National Council for Accreditation of Teacher Education. (2008). Professional standards for the accreditation of teacher preparation institutions. Retrieved from http://www.ncate.org/documents/standards/NCATE\%20Standards\%202008.pdf

National Middle School Association. (2006). Success in the middle: A policymaker's guide to achieving quality middle level education. Retrieved from http://www.wamle.com/Articles/NMSA_Policy_Guide\%20Success\%20in\%20the $\% 20$ MIddle.PDF

Nelson, G. L. (2001). Writing beyond testing: The word as an instrument of creation. The English Journal, 91(1), 57-61.

Nicholson, L. M., Slater, S. J., Chriqui, J. F. \& Chaloupka, F. (2014). Validating adolescent socioeconomic status: Comparing school free or reduced price lunch with community measures. Spatial Demography, 2(1). 55-65.

Nieto, S. (1999). The light in their eyes. New York: Teachers College Press.

Nieto, S. (2004). Affirming Diversity: The Sociopolitical Context of Multicultural Education (4th ed.). New York: Allyn \& Bacon Publishers.

Nieto, S. \& Bode, P. (2012). Affirming diversity: The sociopolitical context of multicultural education (6th ed.). Boston: Pearson Education, Inc. 
Ogbu, J. U. (2003). Black American students in an affluent suburb: A study of academic disengagement. Mahwah, NJ: Lawrence Earlbaum Associates.

Patrick, H. \& Ryan, A. M. (2005). Identifying adaptive classrooms: Dimensions of the classroom social environment. In K. A. Moore \& L. H. Lippman (Eds.), What do children need to flourish? Conceptualizing and measuring indicators of positive development (pp. 271-287). New York: Springer.

Patrick, H., Kaplan, A., \& Ryan, A. M. (2011). Positive classroom motivational environments: Convergence between mastery goal structure and classroom social climate. Journal of Educational Psychology, 103(2), 367-382. doi: http://dx.doi.org/10.1037/a0023311

Patrick, H., Ryan, A. M. \& Kaplan, A. (2007). Early adolescents' perceptions of the classroom social environment, motivational beliefs, and engagement. Journal of Educational Psychology, 99(1), 83-98.

Gorski, P.C. (2009). What we're teaching teachers: An analysis of multicultural teacher education coursework syllabi. Teaching and Teacher Education, 25(2), 309-318.

Ponterotto, J., Baluch, S., Greig, T., \& Rivera, L. (1998). Development and initial score validation of the Teacher Multicultural Attitude Survey. Educational \& Psychology Measurement, 58(6), 1002-1016.

Ponterotto, J. G., Burkard, A. W., Reiger, B., D’Onofrio, A. A., DuBuisson, A., \& Heenehan, M. (1995). Development and initial validation of the Quick Discrimination Index (QDI). Educational and Psychological Measurement, 55(6), 1016-1031.

Ponterotto, J. G. \& Ruckdeschel, D. E. (2007). An overview of the coefficient alpha and a reliability matrix for estimating adequacy of internal consistency coefficients with psychological research measures. Perceptual and Motor Skills, 105(3), 9971014.

Raudenbush, S. W. \& Bryk, A. S. (2002). Hierarchical linear models: Applications and data analysis methods (2nd ed.). Thousand Oaks, CA: Sage Publications.

Reddy, R., Rhodes, J., \& Mulhall, P (2003). The influence of teacher support on student adjustment in the middle school years: A latent growth curve study. Development and Psychopathology, 15(1), 119-138. doi:10.1017.S0954579403000075.

Reyes, M. R., Brackett, M. A., Rivers, S. E., White, M., \& Salovey, P. (2012). Classroom emotional climate, student engagement, and academic achievement. Journal of Educational Psychology, 104(3), 700-712. doi: http://dx.doi.org/10.1037/a0027268 
Robinson, E. N. (2012). The relationship between teacher cultural competency and student engagement (Doctoral Dissertation). Retrieved from ProQuest Dissertations and Theses. (1023814947)

Roland, E. \& Galloway, D. (2002). Classroom influences on bullying. Educational Research, 44 (3), 299-312. Retrieved from http://ejournals.ebsco.com/direct.asp?ArticleID=TM8RH26KE68QNG6KCBG2

Rosenberg, A.L., Greenfield, M.V.H., \& Dimick, J.B. (2006). Secondary data analysis: Using existing data to answer clinical questions. In D.F. Penson, J.T. Wei \& L.J. Greenfield (Eds.), Clinical Research Methods for the Surgeons (pp. 175-201). Totowa, NJ: Humana Press.

Ryan, A. M. \& Patrick, H. (2001).The classroom social environment and changes in adolescents' motivation and engagement during middle school. American Educational Research Journal, 3(2), 437-460. doi: 10.3102/00028312038002437

Sims, R. A. (2011). Cultural intelligence as a predictor of job satisfaction and intent to renew contract among expatriate international school teachers in Latin America (Doctoral Dissertation). Retrieved from ProQuest Dissertations and Theses. (877715915)

Sinclair, B., \& Fraser, B. (2002). Changing classroom environments in urban middle schools. Learning Environments Research, 5(3), 301-328.

Smith, R., Neisworth, J., \& Greer, J. (1978).Evaluating educational environments. Columbus, $\mathrm{OH}$ : Bell and Howell.

Southern Regional Education Board. (2008). Making middle grades work: An enhanced design to prepare all middle grades students for success in high school. Retrieved from

http://publications.sreb.org/2006/06V15-R08_MMGW_Brochure.pdf

Straffon, D. A. (2001). Assessing intercultural sensitivity levels of high school students in an international school (Doctoral Dissertation). Retrieved from ProQuest Dissertations and Theses. (252111373)

Stronge, J.H. (2002). Qualities of effective teachers. Alexandria, VA: Association for Supervision and Curriculum Development.

Sue, S., Zane, N., Nagayama-Hall, G. C., \& Berger, L. K. (2009). The case for cultural competency in psychotherapeutic interventions. Annual Review of Psychology, 60(1), 525-548. Retrieved from http://www.ncbi.nlm.nih.gov/pmc/articles/PMC2793275/doi:10.1146/annurev.psy ch.60.110707.163651 
Talbert-Johnson, C. (2004). Structural inequalities and the achievement gap in urban schools. Education and Urban Society, 37(1), 22-36.

Tapola, A. \& Niemivirta, M. (2008). The role of achievement goal orientations in students' perceptions of and preferences for classroom environment. British Journal of Educational Psychology, 78(2), 291-312.

Templeton, N. (2011). Understanding social justice: Improving the academic achievement of African American students. International Journal of Educational Leadership Preparation, 6(2), 39-47.

The Center for Mental Health in Schools at UCLA. (n.d.), About school and classroom climate. Retrieved from http://smhp.psych.ucla.edu/pdfdocs/schoolclassroomclimate.pdf

Thomas, R. M. (2003). Blending qualitative and quantitative research methods in theses and dissertations. Thousand Oaks, CA: Corwin Press.

Trickett, E. J. \& Moos, R. H. (1973). Social environment of junior high and high school classrooms. Journal of Educational Psychology, 65(1), 93-102.

Uebersax J. S. (2006). Likert scales: Dispelling the confusion. Retrieved from http://john-uebersax.com/stat/likert.htm

Vieno, A., Perkins, D. D., Smith, T. M., \& Santinello, M. (2005). Democratic school climate and sense of community in school: A multilevel analysis. American Journal of Community Psychology, 36(3-4), 327-341.

Waits, M., Campbell, H.E., Gau, R., Jacobs, E., Rex, T., \& Hess, R. K. (2006). Why some schools with Latino children beat the odds and others don't. Retrieved from http://www.beattheoddsinstitute.org/pdf/FAZ502_LatinEd_final.pdf

Walberg, H. J. \& Anderson, G. J. (1968). Classroom climate and individual learning. Journal of Educational Psychology, 59(6), 414-419.

Wang, M. (2009). School climate support for behavioral and psychological adjustment: Testing the mediating effect of social competence. School Psychology Quarterly, 24(4), 240-251. doi: http://dx.doi.org/10.1037/a0017999

Wang, M., Brinkworth, M., \& Eccles, J. (2013). Moderating effects of teacher-student relationship in adolescent trajectories of emotional and behavioral adjustment. Developmental Psychology, 49(4), 690-705. doi:http://dx.doi.org/10.1037/a0027916 
Wang, M. \& Dishion, T. J. (2012). The trajectories of adolescents' perceptions of school climate, deviant peer affiliation, and behavioral problems during the middle school years. Journal of Research on Adolescence, 22(1), 40-53. doi:10.1111/j.1532-7795.2011.00763.x

Wang, M. \& Holcombe, R. (2010). Adolescents' perceptions of school environment, engagement, and academic achievement in middle school. American Educational Research Journal, 47(3), 633-662. doi: 10.3102/0002831209361209

Wang, M. \& Peck, S. C. (2013). Adolescent educational success and mental health vary across school engagement profiles. Developmental Psychology, 49(7), 1266-1276. doi:http://dx.doi.org/10.1037/a0030028

Weinstein, C., Curran, M., \& Tomlinson-Clarke, S. (2003). Culturally responsive classroom management: Awareness into action. Theory into Practice, 42(4), 26976.

Weinstein, C., Curran, M., \& Tomlinson-Clarke, S. (2004). Toward a conception of culturally responsive classroom management. Journal of Teacher Education, 55 (1), 25-38. doi: 10.1177/0022487103259812

Wells-Rivers, D. (2011). The effect of teachers' cultural proficiency training on sixthgrade students' reading achievement (Doctoral dissertation). Retrieved from ProQuest Dissertations and Theses. (864030817).

Wentzel, K. R. (1997). Student motivation in middle school: The role of perceived pedagogical caring. Journal of Educational Psychology, 89(3), 411-419.

Westrick, J. M., \& Yuen, C. Y. M. (2007). The intercultural sensitivity of secondary teachers in Hong Kong: A comparative study with implications for professional development. Intercultural Education, 18(2), 129-145.

Wilen, W., Bosse, M.I., Hutchinson, J., \& Kindsvatter, R. (2004). Dynamics of Effective Secondary Teaching (5th ed.). Boston: Pearson, Inc.

Williams, C. C. (2006). The epistemology of cultural competence. Families in Society: The Journal of Contemporary Social Services, 87(2), 209-220.

Woltman, H., Feldstain, A., MacKay, C.J. \& Rocchi, M. (2012). An introduction to hierarchical linear modeling. Tutorials in Quantitative Methods for Psychology, $8(1), 52-69$.

Wyngaard, M. V. (2007). Culturally responsive pedagogies: African American high school students' perspectives. In J. L. Kincheloe and K. Hayes (Eds.), Teaching city kids: Understanding and appreciating them (pp. 121-129). New York: Peter Lang. 
Ziazi, Z. R. (2004). Adolescents' bonding to school: The impact of perceived school climate pathways on middle school students' bonding to school (Doctoral dissertation). Retrieved from ProQuest Dissertations and Theses. (305156059) 
VITA

Olivia L. R. Spence

spenceo@andrews.edu

\section{EDUCATION}

2016 Doctor of Philosophy: Curriculum \& Instruction

Andrews University, Berrien Springs, Michigan

Dissertation Title: Teachers' Cultural Competence and its Impact on Students' Perception of the Social Classroom Climate.

2011 Master of Arts: Education

Andrews University, Berrien Springs, Michigan

2009 Bachelor of Arts: History summa cum laude

University of the Southern Caribbean, St. Joseph, Trinidad

\section{PROFESSIONAL EXPERIENCE}

Instructional Facilitator 2014-present

School of Distance Education

Andrews University, Berrien Springs, Michigan

Adjunct Instructor (2013)

Department of Teaching, Learning, and Curriculum, School of Education

Andrews University, Berrien Springs, Michigan

Production Manager (2000-2005)

James Chin Ching and Associates, Port-of-Spain, Trinidad

Accounts Clerk (1998-2000)

Owen Taylor Chartered Accountants Limited, Port-of-Spain, Trinidad

\section{PUBLICATIONS \& PRESENTATIONS}

Spence, O. (2013). Book review: Metaphors we teach by: How metaphors shape what we do in the classroom. Journal of Research on Christian Education. 22(2), 221224.

Levy, M., Overstreet, T \& Spence, O. (2013, October). Why do they choose to become teachers and why does it matter? Poster presented at the 20th annual meeting of the American Association for Teaching and Learning (AATC) Conference, Chicago, Illinois. 